\title{
The Chesapeake Bay program modeling system: Overview and recommendations for future development
}

\author{
Raleigh R. Hood ${ }^{1, *}$, Gary W. Shenk ${ }^{2}$, Rachel L. Dixon ${ }^{3}$, Sean M.C. Smith ${ }^{4}$, William P. Ball ${ }^{3, \#,}$ \\ Jesse O. Bash ${ }^{5}$, Rich Batiuk ${ }^{6, \#}$, Kathy Boomer ${ }^{7}$, Damian C. Brady ${ }^{8}$, Carl Cerco ${ }^{9, \#}$, \\ Peter Claggett $^{2}$, Kim de Mutsert ${ }^{10}$, Zachary M. Easton ${ }^{11}$, Andrew J. Elmore ${ }^{12}$, Marjorie A. \\ M. Friedrichs ${ }^{13}$, Lora A. Harris ${ }^{14}$, Thomas F. Ihde ${ }^{15}$, Lara Lacher ${ }^{16}$, Li Li $^{17}$, Lewis C. Linker ${ }^{6}$, \\ Andrew Miller ${ }^{18}$, Julia Moriarty ${ }^{19}$, Gregory B. Noe ${ }^{20}$, George E. Onyullo ${ }^{21}$, Kenneth Rose ${ }^{1}$, \\ Katie Skalak ${ }^{22}$, Richard Tian ${ }^{2}$, Tamie L. Veith ${ }^{23}$, Lisa Wainger ${ }^{14}$, Donald Weller ${ }^{24}$, \\ Yinglong Joseph Zhang ${ }^{13}$
}

\footnotetext{
${ }^{1}$ Horn Point Laboratory, University of Maryland Center for Environmental Science, P.O. Box 775, Cambridge, MD 21613, USA

${ }^{2}$ U.S. Geological Survey Chesapeake Bay Program Office, 410 Severn Avenue, Suite 109, Annapolis, MD, 21403, USA

${ }^{3}$ Chesapeake Research Consortium, 645 Contees Wharf Road, Edgewater, MD 21037, USA

${ }^{4}$ University of Maine, School of Earth and Climate Sciences, Bryand Global Science Center, Orono, ME 04469, USA

${ }^{5}$ U.S. Environmental Protection Agency, Center for Environmental Measurement and Modeling, 109 T.W. Alexander Drive, Durham, NC 27709, USA

${ }^{6}$ U.S. Environmental Protection Agency, Chesapeake Bay Program Office, 410 Severn Avenue, Suite 109, Annapolis, MD, 21403, USA

${ }^{7}$ The Nature Conservancy, 114 South Washington Street, Easton, MD 21601, USA

${ }^{8}$ Darling Marine Center, University of Maine, 193 Clarks Cove Rd, Walpole, ME 04573, USA

${ }^{9}$ US Army Corps of Engineers Waterways Experiment Station, P.O. Box 631, Vicksburg, MS 39180, USA

${ }^{10}$ University of Southern Mississippi, Gulf Coast Research Laboratory, 703 East Beach Drive, Ocean Springs, MS 39564, USA

11 Virginia Tech, 155 Ag Quad Lane, Blacksburg, VA 24061, USA

${ }^{12}$ Appalachian Laboratory, University of Maryland Center for Environmental Science, 301 Braddock Rd, Frostburg, MD 21532, USA

${ }^{13}$ Virginia Institute of Marine Science, William \& Mary, 1375 Greate Rd, Gloucester Point, VA 23062, USA

${ }^{14}$ Chesapeake Biological Laboratory, University of Maryland Center for Environmental Science, P.O. Box 38, Solomons, MD 20688, USA

${ }^{15}$ Patuxent Environmental \& Aquatic Research Laboratory, Morgan State University, 10545 Mackall Road, St. Leonard, MD 20685, USA

${ }^{16}$ Smithsonian Conservation Biology Institute, 1500 Remount Rd, Front Royal, VA 22630 USA

${ }^{17}$ Department of Civil and Environmental Engineering, Penn State University, University Park, PA 16802, USA

${ }^{18}$ Department of Geography and Environmental Systems, University of Maryland Baltimore County, 1000 Hilltop Circle, Baltimore, MD 21250, USA

${ }^{19}$ Institute for Arctic and Alpine Research, Department of Atmospheric and Oceanic Sciences, University of Colorado, Boulder CO 80309, USA

${ }^{20}$ U.S. Geological Survey, Florence Bascom Geoscience Center, 12201 Sunrise Valley Drive, MS926A, Reston, VA 20192, USA

${ }^{21}$ District of Columbia Department of Energy and Environment, 1200 First Street NE, Washington DC 20002, USA

${ }^{22}$ U.S. Geological Survey, 12201, Sunrise Valley Drive, Reston, VA 20192, USA

${ }^{23}$ U.S. Department of Agriculture Agricultural Research Service, Pasture Systems and Watershed Management Research Unit, Building 3702, Curtin Road, University Park, PA 16802, USA

${ }^{24}$ Smithsonian Environmental Research Center, 647 Contees Wharf Road, Edgewater, MD 21037, USA
}

\section{A R T I C L E I N F O}

\section{Keywords:}

Chesapeake bay program

NOAA Chesapeake Bay office

Environmental protection agency

Modeling

Airshed modeling

Watershed modeling

Estuarine modeling

Hydrodynamic modeling

\begin{abstract}
A B S T R A C T
The Chesapeake Bay is the largest, most productive, and most biologically diverse estuary in the continental United States providing crucial habitat and natural resources for culturally and economically important species. Pressures from human population growth and associated development and agricultural intensification have led to excessive nutrient and sediment inputs entering the Bay, negatively affecting the health of the Bay ecosystem and the economic services it provides. The Chesapeake Bay Program (CBP) is a unique program formally created in 1983 as a multi-stakeholder partnership to guide and foster restoration of the Chesapeake Bay and its watershed. Since its inception, the CBP Partnership has been developing, updating, and applying a complex linked modeling system of watershed, airshed, and estuary models as a planning tool to inform strategic
\end{abstract}

\footnotetext{
* Corresponding author at: Horn Point Laboratory, University of Maryland Center for Environmental Science, P.O. Box 775, Cambridge, MD 21613, USA.

E-mail address: rhood@umces.edu (R.R. Hood).

\# Retired
} 
Biogeochemical Modeling Living Resource Modeling Chesapeake Assessment Scenario Tool Total Maximum Daily Load Chesapeake Bay Agreement management decisions and Bay restoration efforts. This paper provides a description of the 2017 CBP Modeling System and the higher trophic level models developed by the NOAA Chesapeake Bay Office, along with specific recommendations that emerged from a 2018 workshop designed to inform future model development. Recommendations highlight the need for simulation of watershed inputs, conditions, processes, and practices at higher resolution to provide improved information to guide local nutrient and sediment management plans. More explicit and extensive modeling of connectivity between watershed landforms and estuary sub-areas, estuarine hydrodynamics, watershed and estuarine water quality, the estuarine-watershed socioecological system, and living resources will be important to broaden and improve characterization of responses to targeted nutrient and sediment load reductions. Finally, the value and importance of maintaining effective collaborations among jurisdictional managers, scientists, modelers, support staff, and stakeholder communities is emphasized. An open collaborative and transparent process has been a key element of successes to date and is vitally important as the CBP Partnership moves forward with modeling system improvements that help stakeholders evolve new knowledge, improve management strategies, and better communicate outcomes.

\section{Introduction}

\subsection{The Chesapeake Bay program and its modeling system}

The Chesapeake Bay (hereafter, "the Bay") is the largest, most productive, and most biologically diverse estuary in the continental United States, providing crucial habitat for native plant and animal species, many of which are migratory (Boesch et al., 2001; Kemp et al., 2005). Natural economic benefits derived from the Bay have been valued at more than $\$ 100$ billion annually (CBF, 2014). The Bay supports economically important fisheries, with blue crabs, striped bass, and oysters generating the largest revenue (Dewar et al., 2009) and shellfish aquaculture activities growing rapidly (Hudson et al., 2016). The Bay waters also enhance coastal property values and support a vital tourist economy, including nature-based recreation industries (Klemick et al., 2018). However, increases in agricultural activity, urbanization, suburban sprawl, stream alterations, and air pollution since colonial times, and intensification since the mid-20th century, have led to excessive nutrient and sediment inputs entering the Bay (Brush, 2009), adversely affecting the health of the Bay ecosystem and the economic services it provides (CBF, 2014).

Since the mid 1900s increases in nutrient and sediment inputs to the Bay have led to a reduction in water clarity, expansion of hypoxia (DO < $2 \mathrm{mg} \mathrm{O} L^{-1}$ ) (Hagy et al., 2004; Williams et al., 2010; Bever et al., 2013), and increase in the occurrence of noxious biotic events like harmful algal blooms (HABs). Hypoxia reduces the catch per unit effort of fish that feed in deep waters of the Bay and can lead to fish kills (Buchheister et al., 2013). HABs can adversely affect the ecosystem by degrading water quality and can impact human health by contaminating shellfish they consume (e.g., via neurotoxic, amnesic, or diarrhetic shellfish poisoning; Glibert et al., 2005, Landsberg et al., 2006, Brookfield et al., 2021). HABs also adversely impact local seafood-related businesses through effects on shellfish populations and aquaculture (Gallegos and Bergstrom 2005; Tango et al., 2005; Marshall et al., 2008; Glibert and Burford 2017; Van Dolah et al., 2016). Recreational fisheries in the Bay are also sensitive to water clarity because visual predation is necessary for fishing lures to attract economically important game fish (MacDonald et al., 2009) and degraded water clarity is aesthetically apparent to coastal residents and tourists (Klemick et al., 2018).

The Chesapeake Bay Program (CBP) is a partnership formally created in 1983 to guide and foster restoration of the Chesapeake Bay and its watershed. This partnership includes all six states within the Bay watershed (Virginia, Maryland, Pennsylvania, West Virginia, Delaware, and New York) and the District of Columbia (D.C.), plus hundreds of federal, state, and local government agencies, academic institutions, and nonprofit interest groups. The CBP Partnership formed out of concerns regarding the loss of submerged aquatic vegetation (SAV) and extensive low oxygen (hypoxic and anoxic) waters in the Bay, referred to as "dead zones”, documented locally as early as the 1930's (Kemp et al., 2005).

Since its inception, the CBP Partnership has relied on a complex coupled modeling system to predict the watershed loads of total nitrogen, phosphorus, and sediment that the Chesapeake Bay can receive while still maintaining acceptable water quality in terms of dissolved oxygen concentrations, water clarity, and chlorophyll $a$ concentration. The 2010 version of this coupled modeling system (Cerco et al., 2010; Linker et al., 2013a, b; Shenk and Linker, 2013) specifically estimated the total maximum daily loads (TMDLs) of nitrogen, phosphorus, and sediment that could be allowed to reach Bay waters such that the tidal water quality standards were still met, as mandated by the Clean Water Act.

The 2014 Chesapeake Bay Watershed Agreement marked a substantial advancement in the restoration effort for the Bay, with all seven major watershed jurisdictions signing onto an expanded vision of Bay management (CBP 2014). The 2014 Agreement outlines five themes related to Abundant Life, Clean Water, Climate Change, Conserved Lands, and Engaged Communities, and provides specific goals and measurable outcomes associated with targeted timelines and ecological endpoints to evaluate success within each theme. The 2014 Agreement also brought an important motivational shift in efforts to restore the Chesapeake Bay. The 2014 Agreement and its creative framework of themes, goals, and outcomes incentivizes the changes necessary to achieve the TMDL levels by clearly identifying and leveraging diverse outcomes of societal benefit and value to stakeholder communities in the watershed. However, the current CBP modeling system retains its historical focus primarily on the strict regulatory interpretation of the TMDLs and associated water quality outcomes.

Modeling outcomes inform the management plans of individual jurisdictions and the overall strategy of the CBP Partnership, specifically efforts to reduce point and nonpoint pollution sources including regulations designed to restrict pollutant transport into the Chesapeake Bay and U.S. coastal waters. Over the past four decades, the CBP modeling system has significantly evolved as understanding of processes operating in the Bay and its watershed have advanced and management questions progressed. The CBP modeling system released in 2017 has multiple components (airshed, land use, watershed, estuarine hydrodynamic and water quality models). These sub-models determine Chesapeake Bay TMDLs in that they are used to force, either directly or indirectly, the biogeochemistry model that predicts changes in oxygen concentration, water clarity, and chlorophyll $a$ concentration that result from changes in nutrient and sediment loads. The CBP Partnership has also promoted the development of living resource models to advance habitat restoration for targeted estuarine species of concern. These include models of submerged aquatic vegetation (SAV) and benthic filter feeders directly linked to the estuarine hydrodynamic and water quality models, as well as stand-alone ecosystem models that simulate interactions of numerous higher trophic level species (e.g., fish, crabs) by using various outputs of the coupled modeling system as inputs.

\subsection{History of the Chesapeake Bay program modeling system}

The component models of the CBP modeling system and their coupling have been continually updated in response to emerging science 
and changing water quality and ecological management priorities since the 1980s (Linker et al., 2002; 2013a). Models have been periodically fixed at milestone states-of-development and then used to evaluate performance of investments implemented to meet TMDL targets for nitrogen, phosphorus and sediment, and to assess the sufficiency of strategies to raise dissolved oxygen concentrations in the Bay to levels determined necessary to support estuarine ecosystem services. It is important to emphasize that the Chesapeake Bay TMDLs are specifically designed to meet water quality standards to support living resources. For example, the limits on deep-water dissolved oxygen concentrations have been established to protect juvenile and adult fish as well as shellfish (See Table 2 in Irby and Friedrichs, 2019 and Tango and Batiuk, 2013).

Modeling results have also been used to evaluate water quality standards related to the proliferation of SAV, as well as necessary thresholds for water clarity and chlorophyll $a$ concentrations (USEPA 2010). The TMDL targets were first legally formalized by the CBP Partnership in 2010 (USEPA, 2010), and they were updated most recently with the 2017 "Midpoint Assessment" (USEPA, 2018) using the 2017 version of the CBP modeling system to evaluate the contemporary state of the restoration.

Developments in the CBP modeling system from its inception in 1982 to the 2017 milestone (i.e., 2017 Midpoint Assessment) include substantial increases in spatial and temporal resolution in the component airshed, watershed, and estuarine models, and deeper integration with other modeling activities outside of the component models. An example of the deeper integration is the recent incorporation of the SPAtially Referenced Regressions On Watershed attributes (SPARROW; Ator et al., 2011) model with the most recent (2017/"Phase 6") version of the watershed model. Web-based distribution of open source, public domain model source codes, executable models, data, results, documentation, tools to assess the effects of management actions on nutrient and sediment loads to the Bay, and general support of multiple models (Irby et al., 2016) have contributed to the development of the CBP modeling system. All of the sub-models are now open source and available for use and further development by the research and management communities, either directly through the internet or via request. These efforts have increased the transparency and accessibility of the CBP modeling system, provided opportunities for intermodel comparisons, increased stakeholder engagement, and fostered trust in the models and their predictions.

The general acceptance of the CBP modeling system for informing management decisions involved a deliberate and extensive process of review and engagement. Appendix C of the 2010 TMDL (USEPA 2010) lists 433 meetings where the TMDL and/or models used in the TMDL were the principal topics of the meeting (2005-2010) and 297 additional meetings where the TMDL and/or models were on the agenda (2008-2010). The meetings occurred both within the committee and workgroup structure of the CBP, at federal, state, and nongovernmental partner organizations and through scheduled public forums and webinars. Generally, stakeholder working groups, primarily the CBP's Water Quality Goal Implementation Team and its workgroups, determine how the models will be used to assist decision-making. These groups are also charged with determining appropriate model inputs related to land use, agricultural systems, and management actions according to the best available data. Technical working groups, primarily the Modeling Workgroup, determine the structure and parameterization of the models and inputs such as atmosphere and ocean forcing functions. The CBP's Scientific and Technical Advisory Committee (STAC) also plays two key roles in model development. STAC supports broadly attended workshops that encourage cross-fertilization of ideas and result in scientific recommendations to the CBP that drive the development of models. The foundation of this paper is one such workshop. STAC also forms committees that perform independent scientific peer reviews of the models (e.g., Easton et al., 2017). The overall review process and the roles of different groups within and outside of the CBP are discussed in Section 1 of the Chesapeake Assessment Scenario Tool (CAST) documentation
(CBP, 2020a).

The participatory development process has expanded in scope over time, with earlier models primarily receiving scientific review and later models increasingly receiving review and input from the stakeholder community. The process resulted in a steady evolution of the models so they were up-to-date but also grounded with empirical information. This multi-decade process of development and feedback has led to a linked modeling system with sufficient transparency and accrued trust so the results are accepted by a wide range of managers and stakeholders, as well as by the scientific community. The multi-decadal process is ongoing with leadership provided for many years by a small group of people at the CBP (including coauthors R. Batiuk, L. Linker and G. Shenk). This experience with the CBP modeling system provides a template for how complicated models can be developed and directly used to inform large-scale management decisions.

As part of the 2017 Midpoint Assessment, the CBP Partnership concluded there were no "fatal flaws" in the milestone 2017 modeling system (i.e., an absence of flaws substantial enough to invalidate its use for decision-making by the CBP Partnership). The 2017 modeling system provided improvements over previous versions (CBP, 2020a) and incorporated feedback from the scientific community and key stakeholders. Three key groups reviewed the 2017 CBP modeling system: (1) the Scientific and Technical Advisory Committee (STAC), composed primarily of scientists that advise the CBP; (2) the Water Quality Goal Implementation Team and its workgroups, whose membership includes managers, stakeholders, non-governmental organizations, and scientists, and (3) technical managers and scientists in the Modeling Workgroup (CBP, 2020a, section 13). Starting in 2019, federal, state, and local jurisdictions have been applying the 2017 modeling system to aid in the development of the Phase III Watershed Implementation Plans. These are plans of local management actions, designed for their jurisdictional waters to meet the TMDLs, that will guide water quality management in the Chesapeake Bay region until the scheduled Bay-wide assessment in 2025. The science- and modeling-based approaches to coproduce knowledge, formulate solutions to problems and adaptively guide restoration activities is fundamental to the environmental management approach of the CBP Partnership and will continue into the foreseeable future, particularly as plans are now being made for a next generation modeling system to incorporate new science and monitoring, expand the capability of the models, and to assess the challenge of 2035 climate change to achieving Chesapeake water quality standards.

\subsection{Management perspectives}

The CBP modeling system was developed specifically to inform management. Formulations and testing of the models are therefore driven by regulatory management needs. The linked models are regulatory models, distinct from parallel computational platforms for exploratory, research-oriented modeling activities that are also ongoing in the Bay region (e.g., Xu and Hood, 2006; Xu et al., 2011; Feng et al., 2015; Wiggert et al., 2017; Zhang et al., 2015; 2016; Irby et al., 2016; Irby and Friedrichs, 2019; St-Laurent et al., 2020; Ator and Garcia, 2016; Ator et al., 2019; Testa et al., 2017). As a tool for management with specific deadlines and milestones, the CBP modeling system must also be available and ready to be used for the next set of questions and decisions on a schedule that meets management deadlines. Examples of major court and management policy mandated deadlines are the assessments for the 2010 TMDL, 2017 Midpoint Assessment, and upcoming 2025 assessment.

Environmental managers from watershed jurisdictions use results from the coupled modeling system to guide water quality management decisions within their local subregions. A major use of the modeling system is to develop equitable nutrient and sediment loading targets across state and local jurisdictions and inform efficient implementation of best management practices (BMPs). Managers use the modeling system to: 1) set nutrient and sediment reduction targets; 2) configure 
nutrient and sediment reduction plans to meet the targets; and 3) quantify progress towards the implementation of reduction plans and local and Bay-wide restoration goals. The expansion of the restoration goals in the 2014 Agreement inspired further consideration of whether and how the coupled modeling system can be used beyond the past focus on prescriptive water quality issues. Under the 2014 Agreement, managers need information to assess progress related to living resources in the Bay and its watershed and consider the effects of climate change, and would benefit from models that can populate a decision-support system to analyze trade-offs and co-benefits, and to further encourage stakeholder engagement.

Chesapeake Bay restoration accomplishments, including development of the linked modeling system, are cultivated through collaborations among government and nongovernment researchers (primarily academics), creating opportunities for engagement among groups of managers and scientists who monitor, measure, test, and model processes relevant to the entire socioecological system comprising the Chesapeake Bay and its watershed. These collaborations open novel opportunities for model-based experiments to test hypotheses and validate CBP model findings. This is where the regulatory CBP modeling system and research-oriented models intersect, inform, and influence each other. Model comparisons can reveal consistencies and contradictions between CBP model findings and other models or observations (e. g., Irby and Friedrichs, 2019; St-Laurent et al., 2019), resulting in an enhanced understanding of underlying assumptions and processes that ultimately improve the CBP modeling system.

The CBP modeling system informs Bay policy and funding decisions that involve billions of dollars in public and private environmental investments (see, for example https://www.epa.gov/sites/productio n/files/2016-03/documents/2015-06.pdf). Therefore, the CBP modeling system has to be scientifically defensible, transparent, timely, useful to manage current environmental issues, and representative of the needs of stakeholders in multiple jurisdictions. Field research and monitoring data are crucial components used to develop and evaluate models whose outputs are used to guide management efforts. Targeted research informed by modeling is essential to efficiently advance resource management (Nichols and Williams 2006). These tools must also assist managers to quantify benefits, costs, uncertainties, and risks. Models that contribute to satisfying these requirements create a consistent documented foundation on which to base legislation, regulations, and investments.

\subsection{Successes and emerging challenges}

The CBP modeling system has played a crucial role in recent management successes. These include the achievement of the 2025 goals for nitrogen and phosphorus pollutant load reductions collectively from hundreds of Chesapeake Bay watershed municipal and industrial wastewater treatment facilities a decade early (Dance, 2016). In addition, trends in recent years suggest that the summertime anoxic volume (i.e., dead zone) is decreasing (Fig. 1, and see Ni et al., 2020) and SAV has shown signs of recovering (Lefcheck et al., 2018; see also CBP 2020c).

However, the CBP modeling system will need to evolve and advance

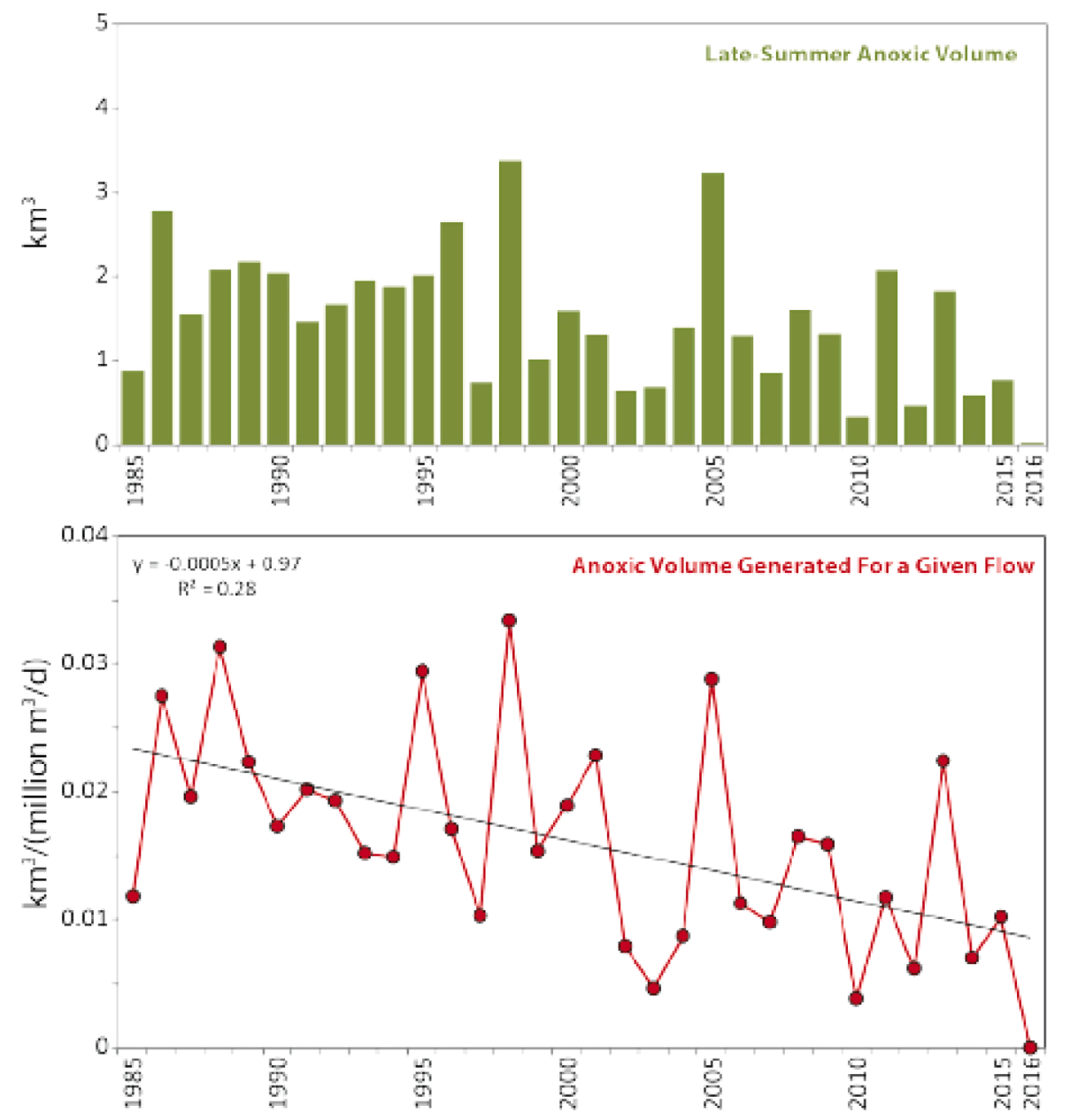

Fig. 1. Late summer anoxic volume (top panel) and late summer anoxic volume normalized to flow (bottom panel), the latter showing a pronounced decline from 1985 to 2016. 
to address new challenges to provide managers with relevant information. The most daunting future challenge is ensuring the modeling system can inform management decisions under a changing natural and human environment. Globally influenced changes in regional weather patterns and sea level rise are affecting temperature, watershed dynamics, estuarine hydrodynamics, biogeochemistry, and ecology (e.g., Irby et al., 2018, Lefcheck et al., 2017, St-Laurent et al., 2020, Testa et al., 2018, Ni et al., 2020). In addition, increasing human population in the watershed will continue to influence stressors that will interact with the effects of climate change and sea level rise. The human population in the Chesapeake Bay watershed is projected to increase by about 12 percent from 2010 to 2025 (17.3 million to 19.4 million) (CBP, 2020b). The 2014 Agreement explicitly addresses climate change with goals and outcomes related to climate resiliency, monitoring, assessment, and adaptation. These considerations challenge the CBP modeling system to ensure that the modeling results can inform these goals.

In addition to its recognition of climate change relevance, another notable aspect of the 2014 Agreement is its identification of goals and targets that go beyond water quality-based metrics. For example, the 2014 Agreement highlights consideration of the effects that water quality has on tidal and nontidal living resources which, beyond SAV and benthic filter feeders, have not been a prior focus. The modeling system would need to expand its capabilities to other species in order to support multiple-objective decision-making that could better encompass the associated broader set of goals, such as the simultaneous impacts to habitat quality and quantity, a variety of aquatic organisms, and fisheries harvests in response to restoration. Relating management-induced water quality responses to living resources is a formidable task considering the diverse species and habitats involved and that multiple factors beyond Bay water quality and habitat (e.g., ocean conditions and societally driven global and local harvests) can also affect most living resources.

Another class of challenges centers on the scale of the predictions from the CBP modeling system. High-resolution simulations to guide the design, implementation, and performance evaluation of optimal water quality management practices at local scales are in high demand. For example, the current watershed model in the CBP modeling system averages many conditions for a given land use within a county, potentially obscuring the importance of implementing best management practices where they can best reduce and prevent nutrient and sediment runoff (Easton et al., 2020). Local and state governments responsible for implementing management actions related to the TMDLs have expressed interest in maximizing co-benefits of their investments on nutrient and sediment controls. Co-benefits are ecosystem services that achieve nutrient and sediment reduction objectives while also addressing 2014 Agreement outcomes related to flood control, open space amenities, recreational uses, terrestrial species habitat, and healthy fisheries. Some CBP managers need tools that predict localized responses of interest (e. g., nontidal stream health) while others need tools suitable for integration across jurisdictions to achieve regional and Bay-wide goals.

\section{The CBP modeling system and recommendations for future development}

This paper summarizes the results of a 2018 workshop designed to identify needed modifications and advancements to the CBP modeling system to address the emerging management questions and challenges spurred by the 2014 Agreement and scheduled to be assessed in 2025. The workshop (Hood et al., 2019) involved academic and government scientists and managers active in the CBP Partnership who were specifically tasked to review the status of the modeling system (as of 2017), reflect upon the history of CBP modeling efforts, and offer guidance on future research needs and priorities. The development of the CBP modeling system offers lessons learned that are relevant to other large watershed-estuarine systems facing similar water quality impairments and management challenges.
Recommendations were developed during workshop breakout sessions that began the afternoon of the first day and continued through the morning of the third and final day of the workshop. Breakout groups were formed for land change modeling, watershed hydrology, watershed nitrogen, watershed phosphorus, watershed sediment, estuarine hydrodynamics, estuarine biogeochemistry, and estuarine living resources. Breakout groups leaders were charged with delivering a short, bulleted list of high-priority recommendations to be reported in plenary in the final workshop session. Leaders sought to develop consensus within the breakout sessions around the priority recommendations during the workshop. Leaders, with the assistance of interested workshop participants, wrote related sections of the workshop report (Hood et al., 2019) that emphasized the priority recommendations, but also more fully addressed the workshop questions.

As mentioned above, the CBP Modeling System (Fig. 2) comprises airshed, land use, watershed, and estuarine models. The airshed model predicts changes in atmospheric deposition of inorganic nitrogen and other selected species on the watershed and tidal Bay due to changes in emissions. The land use model predicts changes in land use, sewage, and septic systems in response to shifts in population, expected housing and commercial property demand, and land use policies. The watershed model combines the output of these models with other data sources, such as implemented BMPs and the US Census of Agriculture, to predict the point source and non-point source (distributed) loads of nitrogen, phosphorus, and sediment entering the Bay, for the nine major tributary rivers and along shorelines of the Bay and its many estuarine tributaries. The estuarine hydrodynamic and biogeochemistry models predict variations in Bay circulation and water quality due to changes in input loads provided by the watershed model, changes in atmospheric forcing, and regional effects of climate change (i.e., sea level rise and changes in precipitation and temperature). In addition, the biogeochemistry model can simulate the impacts of changes in water quality on SAV and benthic filter feeders. Finally, there are currently two living resource models developed by the NOAA Chesapeake Bay Office (NCBO) that are not part of the CBP Modeling System but can use output from the estuarine hydrodynamic and biogeochemistry models to assess how changes in water quality due to management actions might impact higher trophic levels.

The components of the CBP modeling system, including the NCBO living resource models, are all "loosely coupled" in that data are transferred manually from one sub-model to another (i.e., the output data of one model are transferred to a "downstream" model). This loose coupling has the advantage of facilitating work flow because the CBP sub-models are often used for separate tasks and at separate times. For example, the estuarine biogeochemistry model determines the allowable nutrient and sediment loads that will meet water quality standards and is run infrequently for goal setting. The watershed model typically has thousands of scenarios run each year on how to achieve the allowable loads. The airshed model provides a limited range of national emission reduction scenarios from the Clean Air Act that can be considered by CBP decision makers. Loose coupling also improves scenario analysis efficiency, that is, it is easier to work on a single model for the numerous sensitivity runs and tests that are required for each launch/application of the CBP models. Note, however, that some of the CBP sub-models are fully coupled, i.e., where the feedback loops are too critical to do otherwise. For example, the SAV and benthic filter feeder models, mentioned above and described in Section 2.4.1, are directly coupled to the estuarine biogeochemistry model so that they can provide continuous dynamic feedback to one another.

\subsection{Airshed model}

\subsubsection{Overview of the 2017 airshed model}

The airshed model in the coupled system is the open-source Community Multiscale Air Quality (CMAQ; Fig. 3; Foley et al., 2010). CMAQ itself consists of a series of coupled models (meteorological, emission, and photochemical air quality) that work in concert to estimate the 


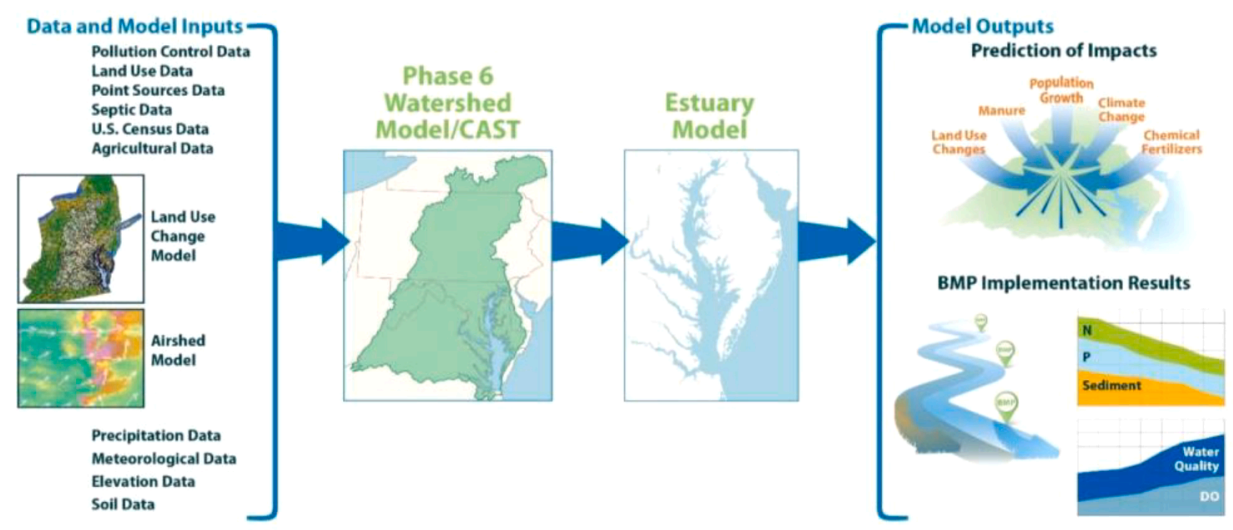

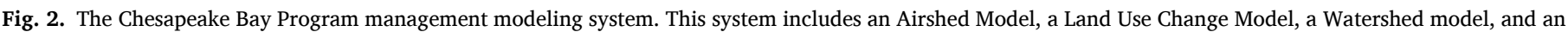

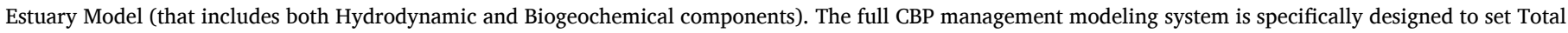
Maximum Daily Loads, inform the development of Watershed Implementation Plans and track progress toward achieving restoration goals in Chesapeake Bay.

emissions and fates of atmospheric gaseous and particulate pollutants (acid, nutrient, or toxic) and their precursors (Foley et al., 2010). CMAQ predicts the fate of these pollutants as they transport through the airshed and deposit back to Earth's surface or react to form secondary pollutants.

CMAQ is maintained by the U.S. Environmental Protection Agency (EPA) Center for Environmental Measurements and Modeling, and since its initial release in 1998, CMAQ has been widely used to evaluate potential national, regional, and state-specific air quality policy management decisions. CMAQ can be used to explore different meteorological and atmospheric pollutant emission scenarios (Campbell et al., 2019). For example, CMAQ is often used to test the impact of future emission regulations on deposition and determine which individual emission sources are the largest contributors to air pollution at a site (Zhang et al., 2012). CMAQ's generalized and flexible formulation has enabled incorporation of alternate process algorithms and numerical solutions to include new science in the model to address increasingly complex air pollution issues.

CMAQ requires two primary types of inputs: meteorological information and emission rates from sources that affect air quality. The CMAQ version 5.0.2 model used with the 2017 CBP modeling system has a 3-dimensional domain that covers the North American continent at a $12 \times 12 \mathrm{~km}$ grid scale (Fig. 4) that includes the Chesapeake Bay watershed and Bay tidal waters. The model uses year-specific meteorological inputs from the Weather Research and Forecasting (WRF; Skamarock and Klemp, 2008) model, and combines hourly emissions data from the U.S. EPA's National Emissions Inventory with the open-source Sparse Matrix Operator Kernel Emissions (SMOKE) model to estimate the magnitude and location of pollution sources. CMAQ then calculates atmospheric transport, transformation, and deposition of a suite of anthropogenic pollutants including ozone, particulate matter, toxics, acid deposition, and several forms of oxidized (e.g., NOx), and reduced (e.g., $\mathrm{NH}_{3}$ ) nitrogen. The 2002 to $2012 \mathrm{CMAQ}$ simulations used the bidirectional $\mathrm{NH}_{3}$ exchange option where the surface ammonia flux is modeled as a gradient based process that can result in emissions from land use with enriched ammonium concentrations in the soil or vegetation (e.g., agriculture) or deposition to land to better capture the observed variability in $\mathrm{NH}_{3}$ dry deposition (Bash et al., 2013).

CMAQ is continuously evaluated against network, satellite, and field sampled atmospheric chemistry and air quality observations. CMAQ effectively describes seasonal variability and trends (2002-2012) in oxidized and reduced nitrogen wet deposition and in ambient oxidized nitrogen concentrations over its broad domain, which gives confidence that wet and dry deposition of nitrogen to the Chesapeake Bay watershed are also simulated well (Bash et al., 2013; Qiang Zhang et al., 2019a).

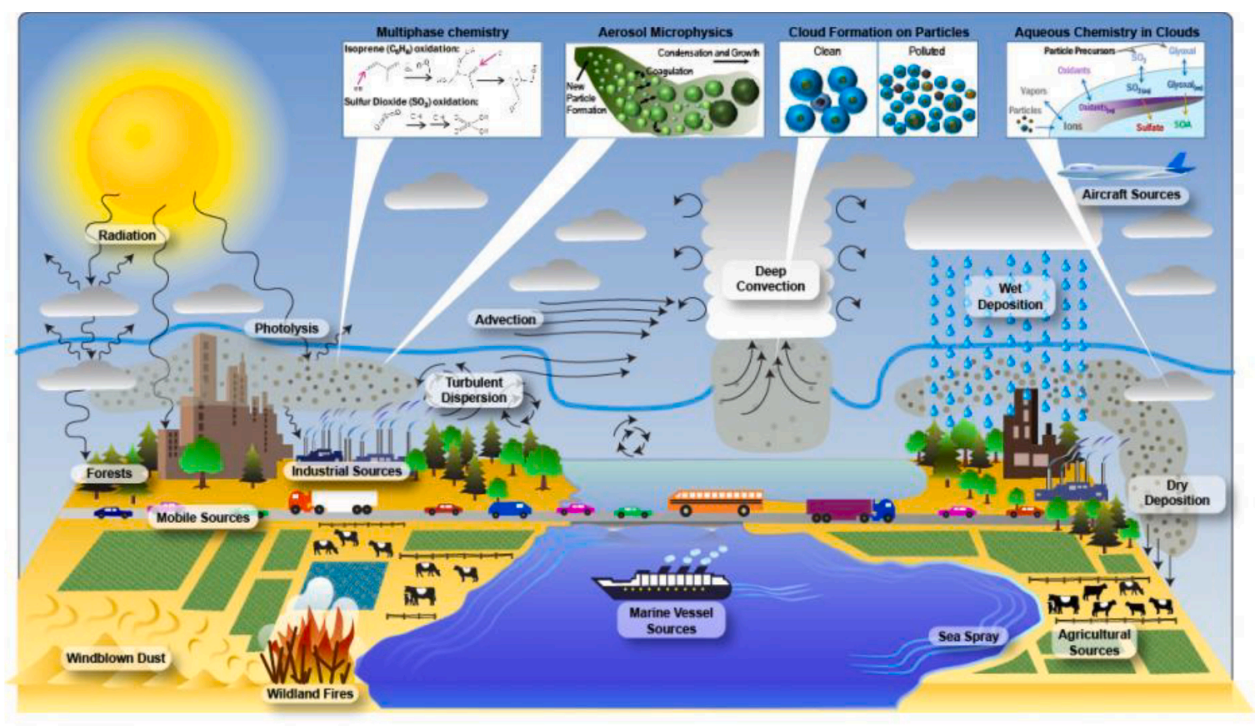

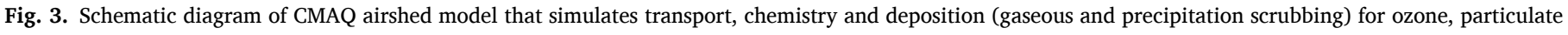
matter, toxics, acids, trace gasses, etc., simultaneously (from https://www.epa.gov/cmaq/overview-science-porcesses-cmaq). 


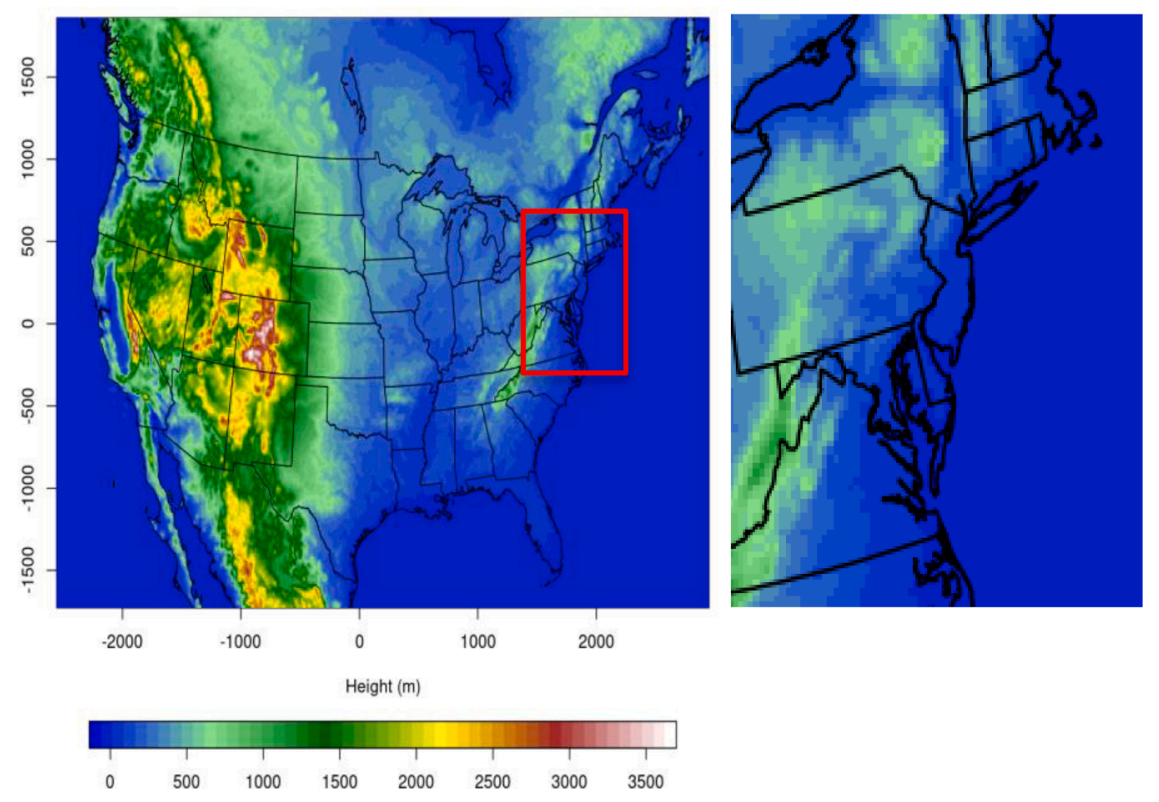

Fig. 4. CMAQ model $12 \times 12 \mathrm{~km}$ grid / topography over North America (left map) and the Chesapeake Bay region (right map). The pixilation in the topography reveals the $12 \times 12$ resolution.

\subsubsection{Airshed model advantages and limitations}

The CMAQ model is based on first principles and is not calibrated to specific monitoring stations. However, CMAQ is routinely evaluated against network observations to assess its performance in capturing the magnitude and trends in ambient concentrations and wet deposition at monitoring sites (Appel et al., 2021; Zhang et al., 2019a; Kelly et al., 2019). Starting with CMAQ v5.3, there is an option for land-use-specific dry deposition (Appel et al., 2021). This option allows better integration of flux estimates from the model grid cells (with a grid spacing on the order of $10 \mathrm{~s}$ of $\mathrm{km}$ ) with critical loads assessments and dry deposition impacts on water quality where finer-scale details are necessary due to differences in the retention and sensitivity of different land uses to pollutant/nitrogen deposition.

In the Chesapeake Bay watershed, however, where dry deposition accounts for approximately half of the atmospheric nitrogen loading, modeling of this deposition cannot be sufficiently evaluated due to the lack of a routine dry deposition monitoring network. To mitigate this uncertainty, model algorithms were developed from field-scale observations (e.g., Bash et al., 2013) but this results in uncertainty for land use types where these detailed measurements are absent. Additionally, ambient atmospheric measurements of nitric acid and ammonia, primary components of nitrogen dry deposition, are uncommon making even a qualitative evaluation difficult (Wang et al., 2021). Improvements in satellite air-quality measurements, specifically $\mathrm{NH}_{3}$ (Wang et al., 2021), are filling in many of these measurement gaps but do not yet have a sufficient history of observations to assess trends in ambient concentrations.

\subsubsection{Airshed model summary recommendations}

In the short-term, research should focus on the influence of climate change on the atmospheric deposition of nitrogen as wet, dry, and organic nitrogen deposition. The CMAQ model should include the full characterization of organic nitrogen deposition, including pollen and other particulate forms, to better constrain mass balances of nitrogen deposition to surface waters in watersheds and coastal systems. Organic nitrogen deposition can be an important atmospheric nitrogen source in many areas, and is currently underestimated by CMAQ 5.0.2 and earlier versions in most areas.

A second area of short-term focus is better quantification of the biases in predicted oxidized nitrogen concentrations in CMAQ to improve the accuracy of model predictions for the Chesapeake Bay watershed portion of the grid. Land-use-specific deposition estimates should be adopted that have been validated against field measurements. The process of validating the deposition estimates will help guide efforts to reduce parameter uncertainty and provide loading estimates that are more relevant to watershed transport processes and mitigation (e.g., riparian buffers).

In the long-term, CMAQ should be run at a higher spatial resolution with a nonuniform horizontal grid and apply methods to enable more complete quantification of the effects of parameter uncertainty on model predictions. A more resolved model grid could improve prediction for the Chesapeake Bay subregion because the current $12 \times 12 \mathrm{~km}$ resolution fails to fully resolve the observed spatial variability in atmospheric deposition, especially with deposition related to sea breezes, along major transportation corridors, and for other processes dependent on local scales. An unstructured grid would allow for higher resolution where it is needed, while also keeping computational demands reasonable. Output from CMAQ is used as inputs to other models and sensitivity analyses would provide the basis for propagating uncertainty through the coupled modeling system.

Other long-term priorities are developing the ability to make more direct connections to the watershed model and estuarine hydrodynamic and biogeochemistry models, and evaluation of parameterization throughout the entire model domain. More direct connections to other CBP models that receive deposition predictions (e.g., providing CMAQ with specific information about land use from the watershed model and/ or specific information about temperature and heat exchange from the hydrodynamic model) would enable the model to better capture feedbacks.

\subsection{Land use change model}

\subsubsection{Overview of the 2017 land use change model}

The U.S. Geological Survey began developing the Chesapeake Bay Land Change Model (CBLCM) in 2012 (Fig. 5) to inform how land use planning and land conservation decisions would impact water quality and wildlife habitats. The CBLCM was developed in response to two STAC-sponsored independent scientific peer reviews of earlier modeling efforts at forecasting land change effects. The reviews emphasized, among other issues, the need to simulate multiple future scenarios and 
to explicitly quantify and communicate model uncertainties (Pyke et al., 2008 and Pyke et al., 2010). Results from the CBLCM are used to inform the locality-specific Phase III Watershed Implementation Plans developed by Maryland, Pennsylvania, West Virginia, and several counties in Virginia (WIP, 2019a,b,c,d).

The CBLCM is a pseudo-cellular automata urban growth model that stochastically simulates the future footprint of residential and commercial development associated with growth in population and employment (Fig. 6; see also output posted on the Phase 6 viewer at: https://chesapeake.usgs.gov/phase6/map/). The 2017 version of the model incorporates data from 2013 onward to forecast annual development to 2025 at a 30-meter cell resolution, and associated conversions of forest and farmland and changes in the populations served by sewer or septic systems. The model's forecasts are based on: (1) state-sanctioned projections of population and employment; (2) population and housing data and trends reported by U.S. Census Bureau; (3) land-cover trends derived from the National Land Cover Database (Homer et al., 2015); (4) mapped protected lands and sewer service areas; and (5) county-level zoning data (for the baseline scenario).

The CBLCM simulates residential and commercial growth within individual counties by first assessing the amount of future county-level housing and employment that will occur as infill or redevelopment within Census urbanized areas. Remaining future housing and employment represent demands for greenfield residential and commercial development, respectively. Greenfield residential development is simulated by stochastically allocating seed cells of residential growth onto a residential probability surface. The residential probability surface is derived through logistic regression, comparing randomly-sampled observations of growth within residential areas (e.g., change in National Land Cover Database developed area, classes 21-24, within Census
Block Groups with a housing to jobs ratio greater than one) with randomly sampled explanatory variables estimated for all areas suitable for growth (i.e., unprotected, gently sloped, and undeveloped lands). A residential seed will sprout and grow into a patch of residential development if the value of the probability surface at the seed-cell location exceeds a random value assigned to the seed. The patch growth routine is the pseudo-cellular automata part of the model. Seed cells grow over a "resistance" surface weighted by proximity to the seed and proximity to the nearest road. Residential patch size potentials for each seed are randomly selected from the observed patch size distribution of residential development occurring between 2001 and 2011. As a patch is grown, households are accumulated within the patch from an underlying housing density surface. Patches stop growing when, either the maximum patch size is reached, the county-level demand for housing is met, or localized obstructions to growth (e.g., roads, steep slopes, open water, protected lands) prevent the patch from achieving its assigned size. This entire process is repeated for greenfield commercial growth using the greenfield demand for jobs and raster surfaces representing employment probability, job density, and commercial areas.

For any given future scenario, the CBLCM simulates 101 independent Monte Carlo iterations, the results of which are then averaged by watershed model land-river segment (described in Section 2.3). These stochastic iterations enable the assessment of model uncertainty associated with the growth allocation process. For every land-river segment, the relative standard deviation of future development is calculated to model uncertainty. In addition, the results of the logistic regressions are saved for every scenario and can be inspected to understand the explanatory power of the residential and commercial probability surfaces.

In addition to the baseline "current zoning" scenario, the CBLCM is

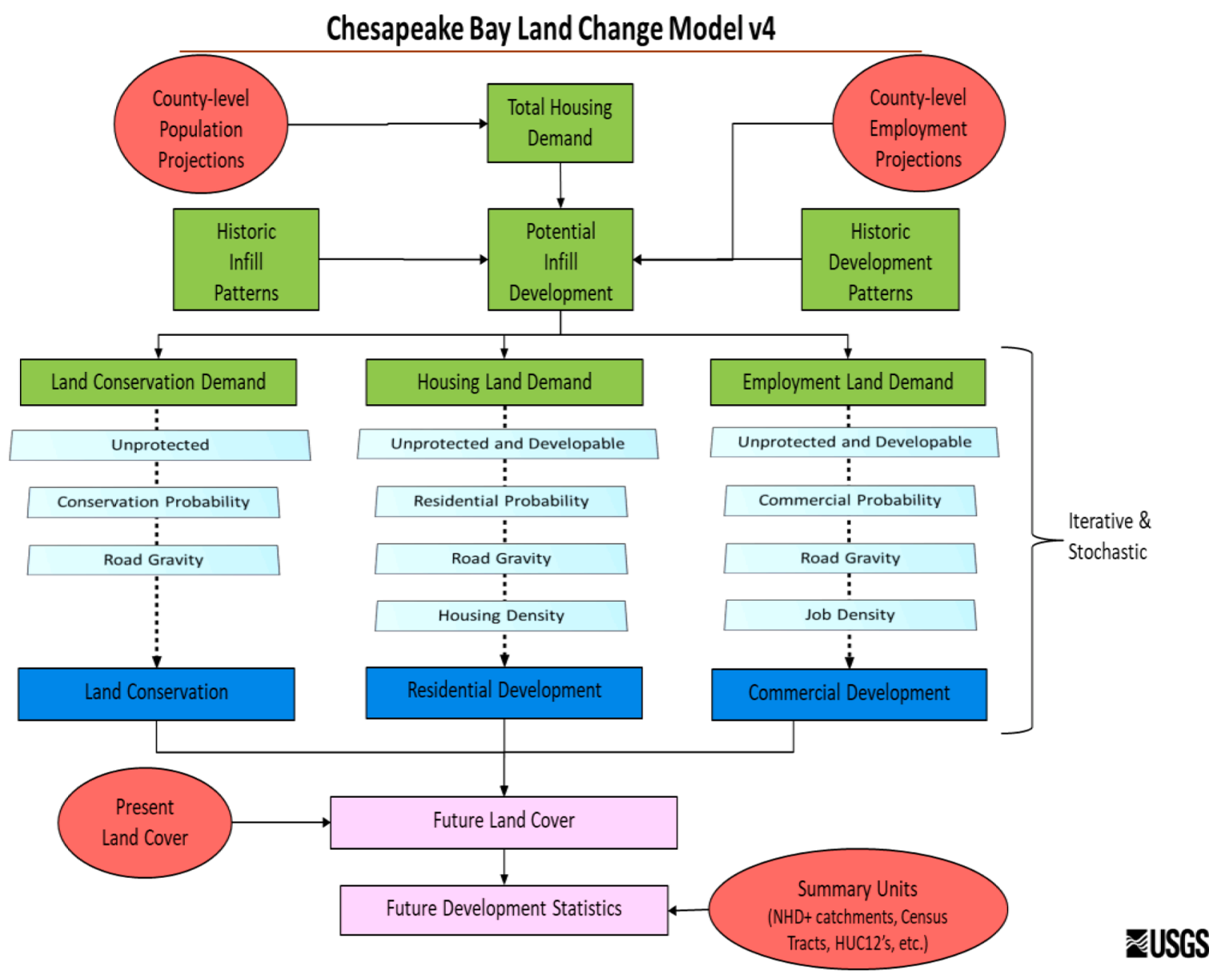

Fig. 5. Diagram of the Chesapeake Bay Land Change Model. 

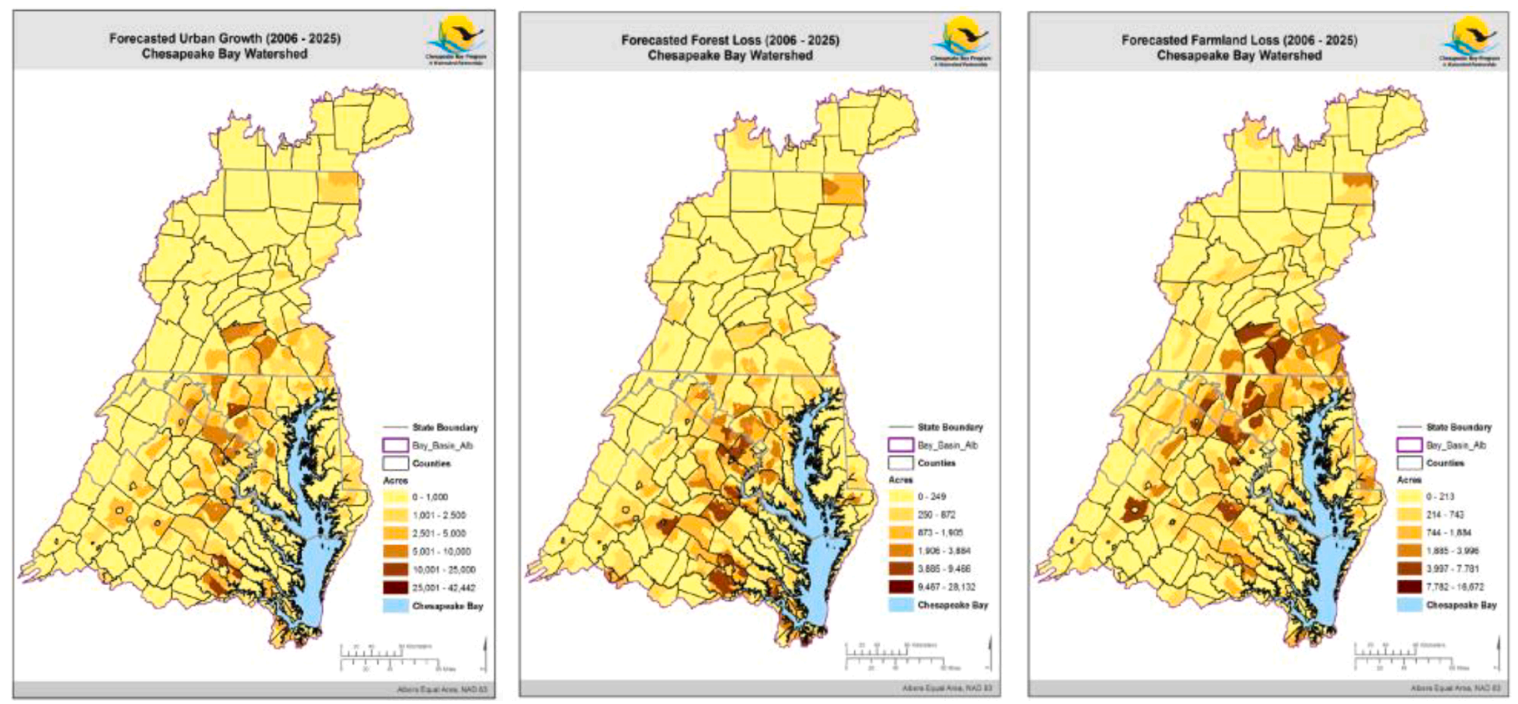

Fig. 6. CBCLM projected (2006-2025) future urban growth (left panel), forest loss (middle panel) and farmland loss (right panel).

capable of simulating alternative future scenarios of residential and commercial development through adjustments to the county-level population and employment projections, proportion of infill-togreenfield development, and proportion of urban-to-rural development. Areas suitable for development, housing and employment densities, and the extent of sewer service areas can also be adjusted uniquely for any given scenario (e.g., Fig. 7). To support development of the Phase III Watershed Implementation Plans, 13 alternative future scenarios representing 2025 land use conditions were created by the CBP Partnership and run through the CBLCM and watershed model. These scenarios include: "Historic Trends", "Current Zoning", "Forest Conservation", "Agricultural Conservation", "Growth Management", and eight custom jurisdictional scenarios known as "Land Policy BMPs" for the jurisdictions of D.C., Delaware, Maryland (3 scenarios), Pennsylvania, Virginia, and West Virginia. Descriptions of these scenarios can be found in the scenario section of the user documentation for the Chesapeake Assessment Scenario Tool (CBP, 2020b).
The CBLCM is designed to simulate plausible, long-term average levels of residential and commercial land use change. Unlike land cover change, which can be consistently observed by satellites over time, land use change is challenging to validate because few areas have been consistently mapped for land use over multiple time periods. Fortunately, Maryland maintains statewide tax parcel data attributed to landuse and year-built fields which can be used to validate county-level rates of residential and commercial land consumption simulated by the CBLCM. Rates were estimated as acres of consumption per year, per housing unit, and per job. Modeled residential land consumption rates were compared from 2013 to 2025 against observed residential rates for 2001 - 2011 and 2011 - 2019. For most counties, the CBLCM simulated plausible but higher residential land consumption rates compared to observations over the more recent 2011-2019 period and lower residential land consumption rates compared to observations over the earlier period, 2001-2011. The nationwide housing boom occurred during the former period as did high levels of suburban sprawl

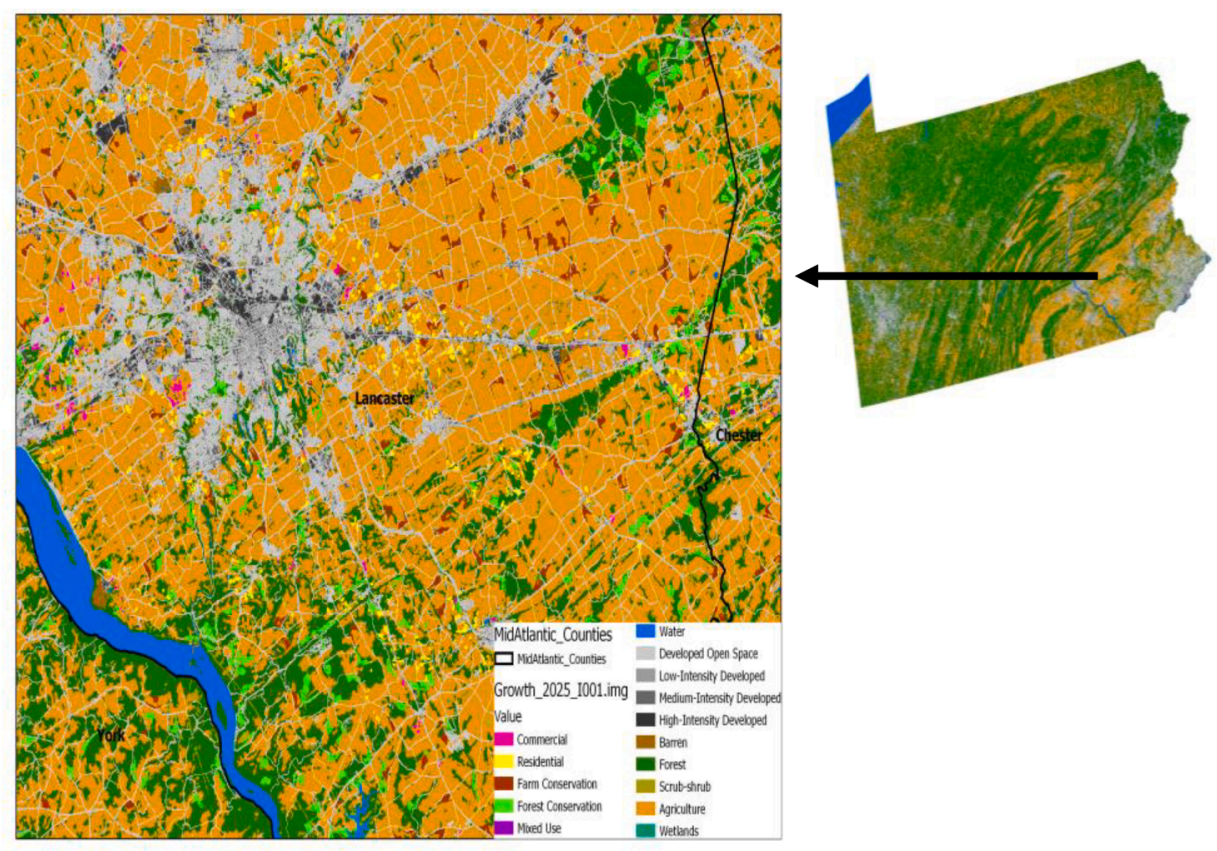

Fig. 7. Simulated year 2025 residential, commercial, and mixed-use development and farm and forest land conservation in southeastern Pennsylvania, USA. 
development. In contrast, during the latter period, the nation was recovering from an economic recession. For commercial growth, the CBLCM simulated plausible but higher rates of land consumption over the single observation period, 2006-2016. This is largely due to an under-estimation of job densities (jobs/acre), particularly in rural counties.

\subsubsection{Land use change model advantages and limitations}

For input to watershed and water quality models, accurately simulating land use is more important than accurately simulating land cover because it is more relevant to nutrient and sediment loading rates. For example, the land uses of turf grass and cropland have the same cover type, "herbaceous", yet very different nutrient inputs and yields. As another example, a land use model will simulate the entire footprint of large lot residential development, and not just the impervious portions.

As a regional land use model, some specific advantages of the CBLCM are that it simulates urban infill/redevelopment, residential, and commercial greenfield development and distinguishes between growth on sewer versus septic systems. The CBLCM can also simulate multiple stochastic iterations of growth per scenario enabling the quantification of spatial uncertainty. Moreover, the CBLCM estimates residential and commercial densities, which are necessary for deriving impervious cover from land use and are essential for land use planning.

The central limitation of the CBLCM is that it is challenging to validate because no states except Maryland have data for consistently mapping land use over multiple time periods. Accurately simulating urban land use change requires estimation and prediction of the demand for land, density of development, and the portion of growth attributable to infill and redevelopment. The CBLCM attempts to estimate and predict all three of these components, but validation to date has been very limited.

\subsubsection{Land use change model summary recommendations}

Areas of focus for improving CBLCM in the long-term include further specification of possible futures and improved code design. The functionality and transparency of CBLCM could be improved by leveraging results from regional transportation models (e.g., Motor Vehicle Emission Simulator, MOVES; Koupal et al., 2013; Kall et al., 2014; Liu, 2015) and household microsimulation models (e.g., Simple Integrated Land Use Orchestrator, SILO; Moeckel, 2017) and enhanced representation of population cohorts (i.e., by age and income) and employment sectors (e. g., services, administrative/financial, warehousing).

In addition, efforts should be undertaken to incorporate temporally dynamic feedbacks between development capacity, density, growth probability, and spillover, as well as spatial allocation of infill development and redevelopment within urban areas with limits based on wastewater treatment capacity. The high-resolution land use data for the Chesapeake Bay watershed could be used to exclude already developed lands from future greenfield development more effectively. The CBLCM should also be modified to allow simulation of future: 1) changes in cropping systems, pasture, and farm animals; 2) changes in forests including changes in composition, phenology, seral stage, and disturbance; and 3) conditions consistent with a range of Representative Concentration Pathways (RCPs) and sea-level rise scenarios and their associated population and employment projections. Finally, a modular design should be adopted using open-source code and leveraging cloud computing and storage resources.

\subsection{Watershed model}

\subsubsection{Overview of the 2017 ("Phase 6") watershed model}

The watershed model estimates freshwater, sediment, nitrogen, and phosphorus loads to the Chesapeake Bay from multiple sources in the watershed and determines how different management actions would affect these loadings. There are two versions of the 2017 model which are constrained to produce identical output over the long term: (1) a time-averaged (average annual loads) version widely used by the CBP Partnership for scenario assessments and Watershed Implementation Plan development; and (2) a dynamic version used in calibration and to drive the estuarine models. For full documentation of both versions and the relationship between them, see CBP 2020a.

2.3.1.1. Time-Averaged watershed model. The CBP uses the timeaveraged version of the 2017 watershed model in the Chesapeake TMDL to set planning targets, design implementation plans, and track the progress in implementation of nutrient reduction efforts relative to their goals (Chesapeake Assessment Scenario Tool, CAST; CBP, 2020a). CAST provides estimates of average annual loads that would be expected given ten years of typical weather conditions. Typical weather conditions were defined by the CBP during the TMDL process as the period 1991-2000. Importantly, this model is intended to calculate the nitrogen, phosphorus, and sediment load annually delivered to the tidal Bay from each land use within each segment, given a set of management options. Scenarios of management options may include land use estimates from the CBLCM, atmospheric deposition from CMAQ, specification of point source and septic system discharges, and implementation of urban best management practices and agricultural conservation practices, collectively referred to as BMPs.

The structure of the time-averaged 2017 watershed model for nitrogen and phosphorus load predictions is organized by nine primary components (Fig. 8). The approach for estimating nutrient loads involves several sequential computations. The top line in Fig. 8 (Average Loads, $\Delta$ Inputs, and Sensitivities) represents the calculation of water quality loads exported from a land use to a stream in a watershed segment, taking into account local applications of nutrients, but not local watershed conditions (e.g., watershed location, geology). The average load represents the Chesapeake Bay watershed-wide average annual load per acre for a given land use type, $\Delta$ Inputs represents the local deviation from the Chesapeake Bay watershed-wide mean input rate in pounds per acre for inputs such as fertilizer, manure, and atmospheric deposition. Sensitivity is the change in load to a stream from a unit change in an input. Sensitivity factors are specific to land use and input types.

After nutrient loads to a stream are derived from the initial step described above, the loads are then multiplied by the acres of the land use in the watershed segment (Land Use Acres) and modified by the effect of implemented local BMPs. Land-to-Water factors are then applied to account for spatial differences in loads due to physical watershed characteristics. Land-to-Water factors do not add to or subtract from the loads over the entire Chesapeake Bay watershed. Instead, they represent the spatial variability of nutrient delivery. The application of the four components results in an estimate of nutrient loads delivered to a stream or water body in a land-river segment.

After nutrient loads delivered to a stream are estimated in the previous step, Stream-Delivery factors are then applied to account for processes influencing nutrient concentrations in stream flows with a mean annual discharge less than 100 cubic feet per second. Conceptually, these are attenuation factors that act to decrease nutrient delivery in small streams, as the loads move downstream to the boundary of the larger river reaches. River-Delivery factors account for nutrient attenuation processes in the larger rivers. Finally, Direct Loads are nutrient loads that do not come from the land surface or subsurface and include point sources, stream bank erosion, and direct deposition of livestock manure in streams. Fig. 9 shows the major nitrogen and phosphorus inputs to the time-averaged model from 1985 to 2019 , and Fig. 10 shows annual mean total nitrogen and phosphorus loads in the Chesapeake Bay watershed for the year 2017 simulated by the time-averaged model.

Each component in Fig. 8 is represented by simple coefficients; however, the technical methods of deriving the coefficients through a collaborative process can be quite complex. The CBP Partnership has used multiple models and multiple lines of evidence from scientific 

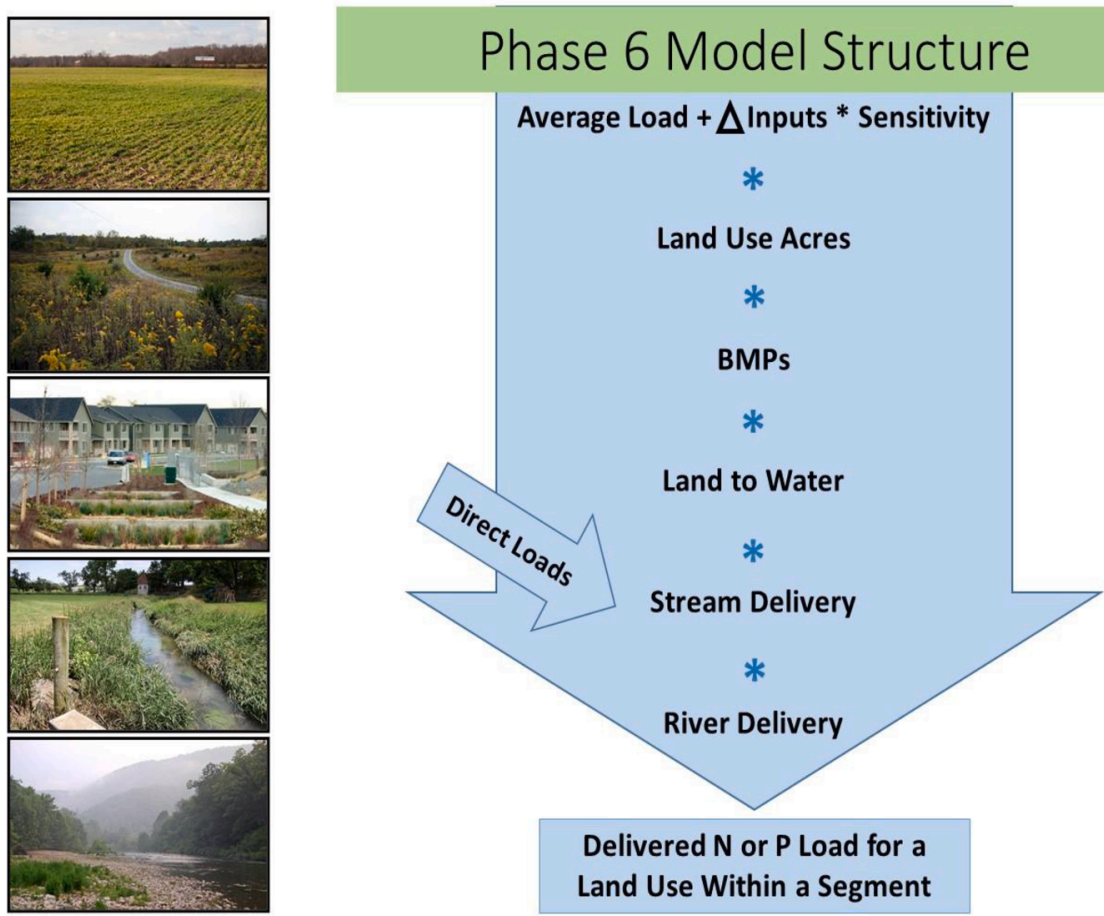

Fig. 8. The Phase 6 Watershed Model Structure.

observations wherever possible to estimate the coefficients. For example, average loads are calculated using the average of several fullycalibrated models (Table 1). Other coefficients are borrowed directly from companion models. Land-to-water and stream-to-river factors are taken directly from USGS SPARROW simulations of the Chesapeake Bay watershed (Ator et al., 2011), while land use acres are from the CBLCM and atmospheric deposition is from CMAQ. BMP reduction factors are estimated by a collaborative expert literature review process (e.g., Berg et al., 2013). River-to-bay factors are calculated from the calibrated dynamic model. Full description of the sources of information and the CBP partnership decisions are available (CBP 2020a)

The time-averaged structure for sediment load prediction is similar to the nine components described above for nutrients, but with some important differences in source and delivery estimation. The top line of Fig. 8, rather than representing edge-of-stream nutrients, now pertains to field-mobilized sediments. These sediment loads are estimated using a spatial application of RUSLE (Revised Universal Soil Loss Equation) predictions (USDA, 2013). Land-to-water factors are now conceptualized as "delivery ratios" for mobilized sediment and are implemented based on observations of yield reductions across a range of increasing watershed drainage area sizes (Cavalli et al., 2013; Roehl, 1962). Direct load sources are similar to those for nutrients with stream erosion playing a greater role. Net average annual reductions in sediment loads within streams are assumed to be low relative to other terms in the model based on SPARROW results (Brakebill et al., 2010) and sediment budgets (Noe et al., 2020), therefore stream-to-river factors are set such that they counteract erosion sources. Reductions to sediment loads due to reservoir sedimentation are estimated using approaches designed for the SPARROW model load estimation approach (Brakebill et al., 2010).

2.3.1.2. Dynamic watershed model. The CBP Partnership also maintains
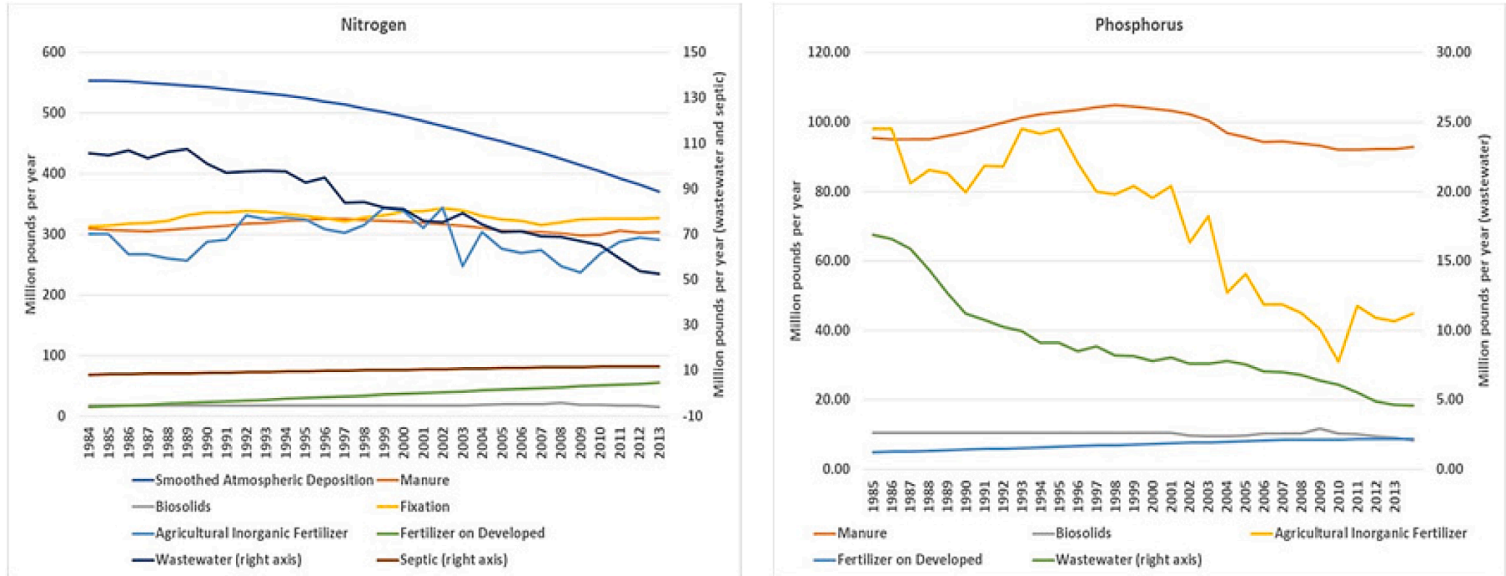

Fig. 9. Major nitrogen (left panel) and phosphorus (right panel) inputs to the Phase 6 Model. Note that wastewater and septic are plotted on the right-hand axes, which is enlarged by a factor of four reflecting the approximate difference of the delivery of nutrients deposited on land and discharged directly to waterways. The atmospheric deposition is the expected deposition over the 10-year period of hydrology 1991-2000 given emissions in the indicated year. 

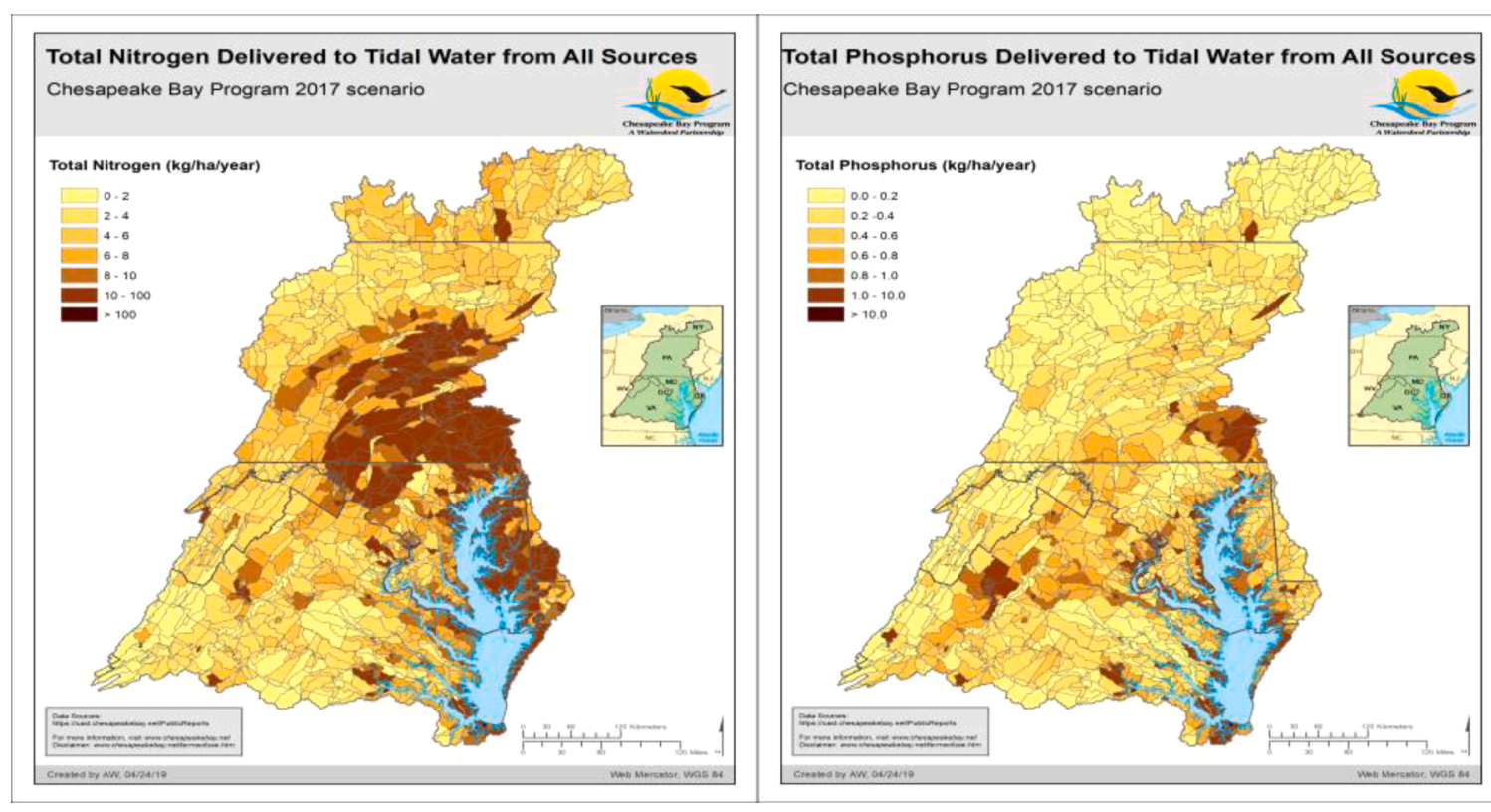

Fig. 10. Spatial sources of total nitrogen (left panel) and total phosphorus (right panel) loads simulated by the time-averaged Chesapeake Assessment Scenario Tool (CAST). These maps represent annual means for 2017.

Table 1

Models incorporated into the 2017 time-averaged watershed model (CAST).

\begin{tabular}{lll}
\hline Model & Use in Phase 6 Model & Reference \\
\hline CBP Phase 5.3.2 Watershed & Average loads & Shenk and Linker, \\
$\quad$ Model & Nitrogen sensitivity & 2013 \\
USGS SPARROW regression & Average loads & Ator et al., 2011 \\
model & Nitrogen sensitivity & \\
& Land-to-water & \\
& Stream delivery & \\
USDA CEAP/APEX Chesapeake & Average loads & USDA-NRCS, 2011 \\
model & Nitrogen sensitivity & \\
APLE & Phosphorus sensitivity & Vadas, 2014 \\
RUSLE & Sediment edge-of-field & USDA-NRCS, 2007 \\
& loads & \\
rSAS & Lag time & Harman et al., 2016 \\
UNEC & Lag time & CBP 2020a, section \\
& & 10 \\
Modflow & Lag Time & Sanford et al., 2012 \\
\hline
\end{tabular}

a dynamic version of the watershed model to provide daily loads to the estuarine water quality model and to estimate some parameters such as river delivery factors and stormwater runoff for use in the time-averaged model. The relationship between the time-averaged and the dynamic models is depicted in Fig. 11. The dynamic model uses Hydrological Simulation Program-Fortran (HSPF, see Borah and Bera, 2004) to simulate hydrology, sediment transport, and nutrient transport in streams. HSPF simulates time-dependent hydrologic and water quality processes on land surfaces, in the subsurface, in streams, and within well-mixed impoundments. Nutrient export from the land surface and subsurface is temporally downscaled from the long-term predictions of the time-averaged model using an algorithm dependent on nutrient application timing and HSPF simulations of hydrology and sediment. The structure is documented in CBP 2020a, section 10. The simulations run for the Chesapeake Bay implementation are forced with hourly values of rainfall, snowfall, temperature, evapotranspiration, wind, solar radiation, dewpoint, and cloud cover. Input data include land use acreage from the CBLCM and atmospheric deposition from CMAQ, as well as BMPs, fertilizer and manure applications, and point source and septic loads to calculate daily flow and associated nutrient and sediment loads.

\subsubsection{Time-Averaged and dynamic watershed model advantages and limitations}

The adaptable multi-model structure of the watershed model allows the ongoing leveraging of other models and analyses of monitoring data for its improvement. The flexible construction is conducive to effective adaptive management which guides better decision making, thereby improving environmental results (Easton et al., 2017). The reduced complexity of CAST, the time-averaged version, is more understandable to the stakeholder community and has allowed for greater participation in model development. Moreover, the relatively fast run times and web interface for CAST allow users to generate their own scenarios or custom reports of previously run scenarios. Additionally, because the CAST structure is compiled from multiple sources, its use facilitates an uncertainty quantification. Finally, because of the simplified CAST structure, it is able to take advantage of spatially and temporally dense data sets for water quality measurements and daily load calculations at critical points in the watershed, including near the head of tide for major Bay tributaries.

But opportunities for improvement in simulation capacity remain. The details of calculation for individual model components can be quite complex and not all of the parameters can be estimated using companion modeling approaches. As a result, no comprehensive assessment of load prediction uncertainty has been completed, particularly with respect to model quantification of load alterations due to anthropogenic changes over time (Easton et al., 2017). Demand has increased for better targeting of management practices to improve the effectiveness and lower costs of restoration, and with this, a need to develop better estimates of nutrient and sediment transport potential at a fine scale (Easton et al., 2020). A related issue is the need to improve targeting of practices that reduce those species of nutrients and sources of sediment with greater efficacy towards water quality load reductions (Shenk et al., 2020; Craig et al., 2008; Filoso et al., 2015). Model upgrades will be needed to appropriately assess the effect of landscape, land use, and land management on fine-scale delivery and speciation. This is particularly true of the sediment simulation approach that requires support from measurements from small headwater streams to large rivers and delivery functions customized to varied landscape settings (Easton et al., 2017; Smith et al., 2011; Noe et al., 2020). 


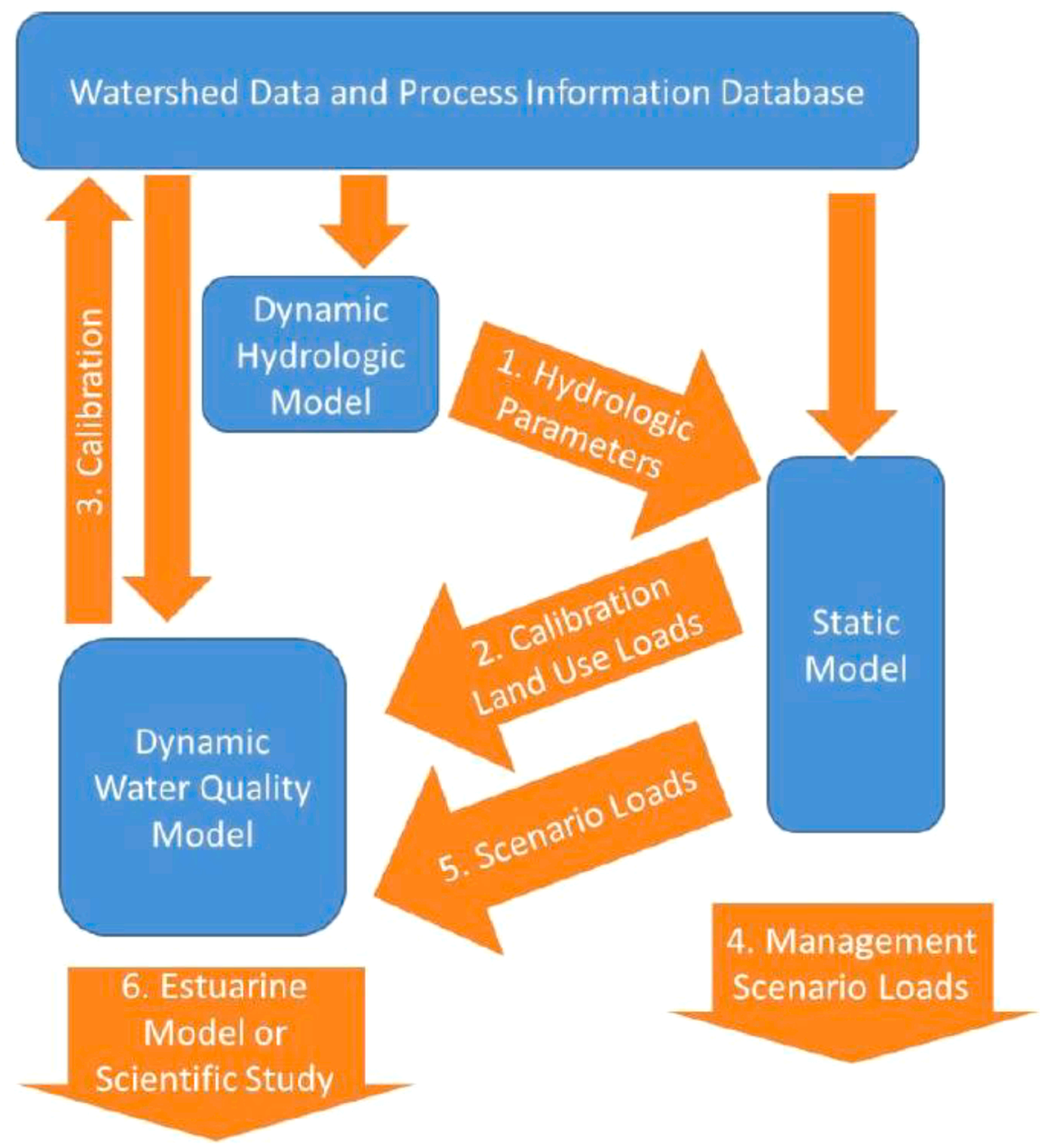

Fig. 11. Relationship between the time-averaged and dynamic watershed models.

\subsubsection{Watershed model summary recommendations}

2.3.3.1. General recommendations. Development of the watershed model components of the CBP modeling system should focus on accurately predicting delivery of nutrients and sediment consistently across spatial scales and properly account for lag times in movement from watershed sources to the Bay. Special attention to scaling issues is necessary to identify water quality problems and management solutions at a site or stream segment scale, as well as cumulative impacts on the scale of a river and watershed.

The watershed models should strive to adopt agile, modular designs to facilitate investigation of varied processes and alternative algorithms, and to increase transparency for scientists working on diverse aspects of watershed hydrology as well as sediment, nitrogen, and phosphorus transport and transformation. This should include formalisation of rules and procedures for linking modules across spatial and temporal scales. Modularization will provide greater flexibility and facilitate examination and testing of alternative approaches for quantification and simulation of biophysical processes at lower and higher resolutions and with different levels of mechanistic detail (Leavesley et al., 2002). Additionally, modular design will facilitate functional expansion of the models to simulate future issues, such as the transport and fate of contaminants of emerging concern. All data, code, output, and documentation should be made openly available online to enable a community modeling approach to future model development.

2.3.3.2. Watershed hydrology recommendations. Improved simulations of Chesapeake Bay hydrology within the dynamic watershed model would improve predictions of the effects of management actions on nutrient and sediment delivery. One area in need of improvement is representation of the hydrologic processes at sub-basin scales to better depict the spatial distribution of nutrient and sediment source problems, and to generate more finely resolved predictions of pollutant transport within the Bay watershed. Such information would identify areas that, if managed sustainably, would be most effective to help achieve management and restoration goals (Veith et al., 2003, 2004; Easton et al., 2008, 2017; Tomer, 2018).

Another area for improvement is the development of a version of the model based on a standard watershed layer appropriate for the scale that management actions are implemented, such as the National Hydrography Dataset (NHD) or Hydrologic Unit Code (HUC). Closer matching between model and management spatial scales would allow for easier conversion and communication of model results to managers.

Over the long term, a complementary approach to the basin-wide management-scale model would be to perform high-resolution subbasin scale dynamic simulations in a few select locations that can be used to inform the larger-scale management model. Models operating at scales commensurate with processes occurring on hillslopes and in small headwater streams and capable of resolving fine-scale locations of BMP implementation would more accurately quantify headwater inputs into higher order rivers and estuarine tributaries. These smaller-scale watershed models and the related data assembly can be developed based on regular or irregular mesh grids, or can use Hydrologic Response Unit (HRU)-based hillslope, physiographic district, or tributary scale resolution (Reger and Cleaves, 2008; Cleaves, 2003; Smith et al., 2011; Smith and Wilcock, 2015; Amin et al., 2017, 2018; Liu et al., 
2017; Veith et al., 2019; Williams et al., 2015; Collick et al., 2015). In particular, recent developments in watershed reactive transport modeling have advanced forward to couple watershed hydrological processes and land-surface interactions with multi-component reactions to capture the dynamics of water and biogeochemical interactions, including nutrients, carbon, and sediment transport (Bao et al., 2017; Li, 2019; Zhi et al., 2019).

A candidate dynamic watershed model that could address many of these limitations and recommendations is the Bio-Reactive Transport and Flux version of the Penn State Integrated Hydrologic Modeling System (BioRT-Flux-PIHM) (Zhi and Li, 2020). In BioRT-Flux-PIHM, water flow is dictated by watershed hydrology that is influenced by meteorological conditions and other watershed characteristics. Domain discretization is fundamental to the approach and an unstructured triangular irregular network (e.g., Delaunay triangles) is generated with geometric and parametric constraints (Bhatt et al., 2014). Fig. 12 shows an example of the domain decomposition of Mahantango Creek watershed into 2606 triangular mesh elements and 509 linear stream elements. BioRT-Flux-PIHM couples flow and transport calculations within a full biogeochemical, thermodynamic, and kinetic framework (Steefel et al., 2015), thereby enabling explicit tracing of spatial and temporal evolution of geochemical species in fluid and solid phases. In particular, this code has been applied to understanding fine-scale nutrient and carbon transformation and transport processes (Wen et al., 2020; Zhi and Li, 2020). These modeling efforts, coupled with insights from data, have propelled the Shallow and Deep Hypothesis, which underscores the essential role of nutrient concentration contrast in shallow soil water and deeper groundwater in shaping stream and river concentration and discharge relationships (and therefore loads) at different flow regimes (Zhi and Li, 2020). These insights, combined with river chemistry data, can be used to predict nutrient loads with simplified model structure with reduced computational cost, and to estimate nutrient removal in groundwater aquifers. The use of these reactive transport models however are not limited to nutrients and carbon. They can also be used to simulate other water quality parameters, including cations, salinity, and sediments.

2.3.3.3. Watershed sediment recommendations. Translating edge-of-field to edge-of-stream is difficult due to high variability across the spatial scales, watershed location, sub-regional setting, and localized land use, resulting in potentially high uncertainty in estimation (Smith and Wilcock, 2015). In addition, the balance of deposition and erosion in stream reaches is highly variable but critical to sediment budgets (Noe et al., 2020). These issues can be addressed with the creation of new empirical functions through documentation of sediment transport processes and rates for varied sediment grain size classes throughout watershed stream channel networks in varied land use settings. Better documentation is particularly important in the low-order headwater streams that traverse the steepest elevation gradients, penetrate the farthest into upland areas, and comprise over half of the total channel network length in the Bay watershed.
Time lags in sediment movement to the Bay highlight the importance of making sure that stakeholders understand that there can be temporal gaps between sediment source management investments and Bay water quality outcomes (Pizzuto, 2014). In the short-term, an updated CBP watershed model could better represent how runoff drainage networks affect sediment sources, sinks, transport, and fate. The addition of residence times of sediment located in temporary storage zones would improve predictions of sediment responses to management actions. An updated model for watershed sediment simulations would also carry over to improved simulation of constituents (e.g., nutrients) associated with sediments, and the use of sediment results as input to habitat quality and effects on living resources (e.g., SAV, oysters). Local and regional dynamics of erosion, followed by the transport, deposition, remobilization, and eventual delivery to the Bay, are often very important to local communities and stakeholders.

The spatiotemporal scales of existing empirical and rules-based models do not match process-based sediment models (Dietrich et al., 2003). In the longer-term, the formulations related to sediment transport within the watershed model should be refined to better represent the time scales of sediment delivery and thus allow for better assessment of management practices for both the sediments and associated nutrients (Pizzuto 2014; Filoso et al., 2015; Williams et al., 2017). New science and data are needed to fill gaps in our current knowledge of watershed sediment erosion and delivery rates in prominent physiographic settings and under different land use conditions (Smith and Wilcock, 2015; Noe et al., 2020).

A CBP-sponsored 2017 legacy sediments workshop identified knowledge gaps and how they could be addressed (Miller et al., 2019a). To build on this effort, the CBP Partnership would benefit from the establishment of a sediment modeling workgroup with expertise in geomorphology and with stakeholder representation to engage in both long-term and short-term knowledge co-generation and strategies to improve the representation of sediment dynamics in the CBP watershed model (Smith et al., 2011). It is anticipated that it could take a decade or more for full development (including new data collection) and implementation (i.e., calibration, validation) of a revised sediment transport formulation in the watershed model.

2.3.3.4. Watershed nutrient recommendations. The time-averaged version of the nutrient watershed model should be enhanced to become more spatially explicit and mass-conserving. An enhanced version of the time-averaged model could be fit to the fluxes estimated from monitoring data (as it is done with the SPARROW model, e.g., Ator and Garcia, 2016) and be informed by ensemble predictions of the model component coefficients in a similar manner to the 2017 time-averaged model. This new version would allow for investigation of the watershed effects of BMP performance, including localized effects and interactions with the effects of climate change (Craig et al., 2008; Filoso and Palmer, 2011). A spatially-explicit version would also allow for better quantification of nutrient sources and sinks that depend on the spatial arrangement of riparian and wetland areas (Weller and Baker,

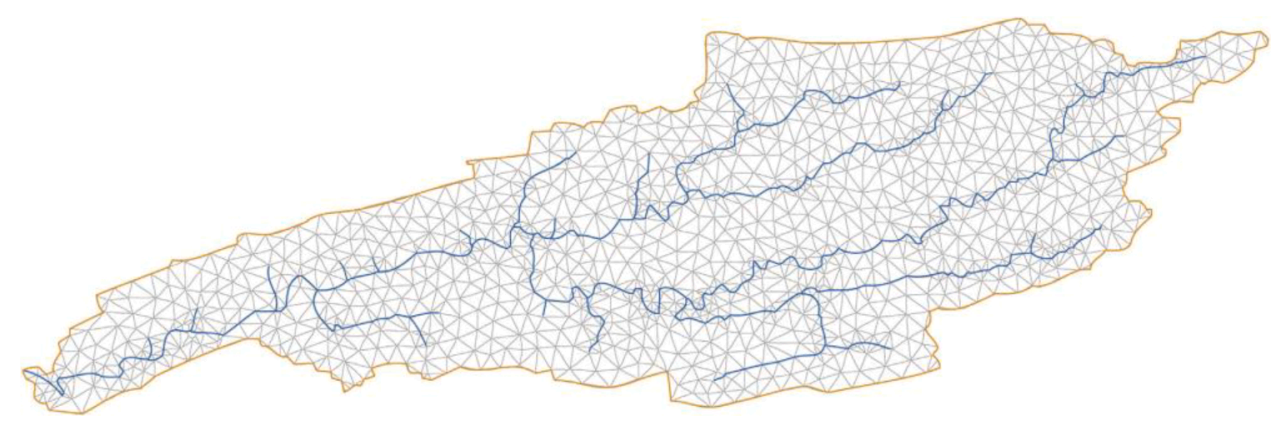

Fig. 12. Domain decomposition of Mahantango Creek watershed. Figure reproduced from Bhatt et al. (2014). 
2014), and improved representation of hydrologic connectivity to identify critical source areas that contribute disproportionately to loads that could then be targeted by management (Wallace et al., 2018). Finally, this new version would offer the opportunity to quantify nutrient legacy effects, revisit riverine biogeochemical processes especially in active channels and floodplains - and to incorporate new sources of high-resolution data on land use and geomorphology to better represent variability in nutrient retention in forest types and forest seral stages over time and under elevated atmospheric $\mathrm{CO}_{2}$ (Craine et al., 2018).

For both the time-averaged and dynamic watershed models, the nutrient forms and species simulated should be evaluated to ensure they can be easily matched to the forms in the estuarine biogeochemical model. For example, partitioning nutrients into particulate and dissolved phases in the watershed models would improve connectivity with the estuarine model (e.g., Dari et al., 2018). Reactivity might also be considered since effective targeting of management will require implementing practices that reduce the reactive constituents (e.g., Liu et al., 2018; Miller et al., 2019b). Lags related to nitrogen delivery require expanded considerations of groundwater flow pathways and new approaches to quantify travel times and removal rates within drainage networks (Sanford and Pope, 2013; Phillips and Lindsey, 2003). Specification of delivery processes under varied settings and conditions will be necessary, requiring expanded forms of measurement in each of the prominent physiographic settings in the Chesapeake Bay watershed. For example, an approach that relates nutrient delivery potential to a measurement such as a topographic wetness index or connectivity index could take advantage of recent increases in land use and elevation measurement scales. Temporally and spatially dense sensor arrays in low-order streams would allow for development and validation of such approaches (Easton et al., 2020). Addition of organic carbon to the watershed models is also warranted, both to force estuarine biogeochemical models and allow more accurate representation of watershed loads of oxygen-demanding material. In the present versions of the watershed models, carbon loads are derived from the simulated nutrient and sediment loads. Implementing these recommendations will improve the watershed models' ability to identify critical source areas, especially those in hydrologically active and connected zones, and allow for smooth coupling to other models.

Implementing these recommendations will require re-analyses of existing data and collection of additional data (e.g., Ator et al., 2020). Specifically, nitrogen speciation, sources, and sinks will need to be characterized, particularly in low-order streams. Leveraging existing data will involve extensive data gathering and the development of new data analysis strategies for using relatively short time series to determine spatial and temporal variability. New data in previously unmonitored areas, small streams, and directly discharging groundwater should be collected to fill important gaps. Field-scale nutrient flux data should be collected relative to field conditions and landscape position to better identify and manage critical source areas (Buda et al., 2009; Buda, 2013, 2013).

\subsection{Estuarine hydrodynamics and biogeochemistry models}

\subsubsection{Overview of the 2017 estuarine hydrodynamics and biogeochemistry models}

The estuarine model is composed of two independent models. A hydrodynamic model computes transport information, which is stored "offline" for repeated use by a biogeochemical model. The biogeochemical model is the decision model for projected attainment of tidal Bay dissolved oxygen, chlorophyll, and water clarity standards under TMDL scenarios.

2.4.1.1. Estuarine hydrodynamic model. The estuarine hydrodynamic model (Curvilinear Hydrodynamics in 3-dimensions or CH3D) is based on a model originally developed by Sheng (1986) that was modified extensively for application to the Chesapeake Bay (Johnson et al., 1991; Kim, 2013). The hydrodynamic model is forced by tides, wind, freshwater inflow, and heat exchange at the water surface. Tides are based on observations recorded near the mouth of the Bay (NOAA Tides and Currents; https://tidesandcurrents.noaa.gov/). Wind and heat exchange are obtained from local meteorological observations (NOAA National Center for Environmental Information https://www.ncdc.noaa. gov/cdo-web/datasets/GHCND/locations/CITY:US240002/detail).

Salinity and temperature fields are prescribed on the open boundary, outside the Bay mouth, based on observations (Chesapeake Bay Program Water Quality Database https://www.chesapeakebay.net/what/ downloads/cbp_water_quality_database_1984_present). Daily freshwater inflow from rivers, diffuse coastal plain surface flows, and groundwater flows are all prescribed using output from the dynamic 2017 watershed model. The CH3D model then calculates time-dependent variations in salinity, temperature, water-level elevation, velocity, and turbulent diffusivity in three dimensions with a 90-second time step.

There are up to 19 layers in the vertical dimension with a uniform layer thickness of $1.52 \mathrm{~m}$, except that the top layer thickness fluctuates with sea level. The surface layer is $2.14-\mathrm{m}$ thick at mean tide. Horizontally, the governing equations in the Cartesian coordinate system are recast in a boundary-fitted curvilinear coordinate system to cope with the irregular shoreline configuration and deep channel orientation. In the present Chesapeake Bay configuration, there are 11,064 surface cells and 56,920 total cells with an average grid cell dimension of $1025 \times$ 1025 m (Fig. 13).

2.4.1.2. Estuarine biogeochemical model. The velocity and diffusivity outputs from the CH3D hydrodynamic model, along with nutrient and sediment loads prescribed by the dynamic 2017 watershed model, are used to force a finite-volume biogeochemical model (Corps of Engineers Integrated Compartment Water Quality Model, abbreviated as CEQUAL-ICM or simply ICM; Cerco and Cole, 1993; Cerco and Noel, 2013). The ICM Model uses the same grid as CH3D and is forced with hourly transport from CH3D, daily loads from the watershed model, and monthly boundary concentrations of all state variables at the mouth of the Bay. The time step is determined dynamically based on computational stability requirements and is $15 \mathrm{~min}$ on average. ICM incorporates 24 state variables that include physical variables (salinity, temperature, fixed solids) three groups of phytoplankton, dissolved oxygen, and multiple forms of carbon, nitrogen, and phosphorus (Fig. 14).

Salinity is computed by solving the three-dimensional mass conservation equation for a conservative substance. Computation of temperature, however, includes atmospheric heat exchange at the water surface, evaluated following Edinger et al. (1974). Salinity and temperature are computed in the biogeochemical model to provide quality assurance of the linkage to the hydrodynamic model. When forced by the same boundary conditions and surface heat flux, salinity and temperature computed in the biogeochemical model should be identical to the hydrodynamic model (Dortch et al., 1992).

Organic carbon undergoes numerous transformations in the water column. The model carbon cycle (Fig. 14) is defined in this context around the process of eutrophication (Nixon 1995) and consists of the following elements: phytoplankton production and excretion; predation on phytoplankton; dissolution of particulate carbon; heterotrophic respiration; and settling (Cerco, 2000). Algal production is the primary autochthonous organic carbon source to the water column (Cerco and Noel, 2004), although carbon also enters the system through external loading (Brookfield et al., 2021). Predation on algae releases particulate and dissolved organic carbon to the water column. A fraction of the particulate organic carbon undergoes first-order dissolution to dissolved organic carbon. Dissolved organic carbon produced by excretion, predation, and dissolution is respired at a first-order rate to inorganic 


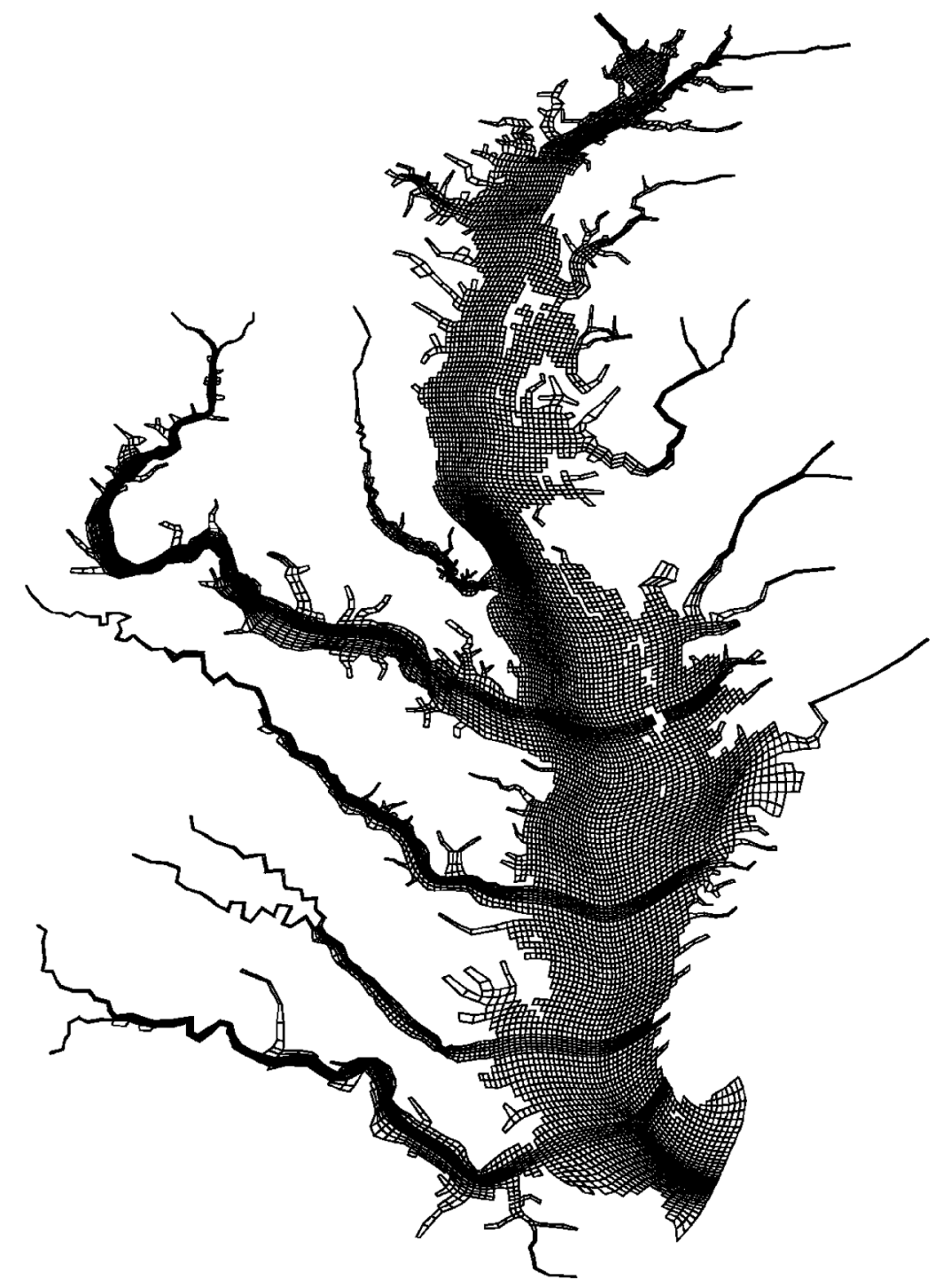

Fig. 13. CH3D hydrodynamic model horizontal grid.

carbon. Particulate organic carbon that does not undergo dissolution settles to the bottom sediments.

The model nitrogen cycle (Fig. 14) includes the following processes: algal uptake and metabolism; predation; hydrolysis of particulate organic nitrogen; mineralization of dissolved organic nitrogen; settling; and nitrification. External loads provide the ultimate source of nitrogen to the system. Available nitrogen is incorporated by algae during growth and released as ammonium and organic nitrogen through respiration and predation. A portion of the particulate organic nitrogen hydrolyzes to dissolved organic nitrogen. The balance settles to the sediments. Dissolved organic nitrogen is mineralized to ammonium. In an oxygenated water column, a fraction of the ammonium is subsequently oxidized to nitrate+nitrite through nitrification. Particulate nitrogen which settles to the sediments is mineralized and recycled to the water column, primarily as ammonium. Nitrate and nitrite move in both directions across the sediment-water interface, depending on relative concentrations in the water column and sediment porewater.

The model phosphorus cycle (Fig. 14) includes the following processes: algal uptake and metabolism; predation; hydrolysis of particulate organic phosphorus; mineralization of dissolved organic phosphorus; dissolution of particulate inorganic phosphorus; and settling and resuspension. External loads provide the ultimate source of phosphorus to the system. Dissolved phosphate is incorporated by algae during growth and released as phosphate and organic phosphorus through respiration and predation. Dissolved organic phosphorus is mineralized to phosphate. A portion of the particulate organic phosphorus hydrolyzes to dissolved organic phosphorus. The balance settles to the sediments. Dissolution of particulate inorganic phosphorus is also possible. Within the sediments, particulate organic phosphorus is mineralized and recycled to the water column as dissolved phosphate.

In the model carbon, nitrogen, and phosphorus cycles, three classes of particulate constituents are considered: labile, refractory, and slow refractory, corresponding to classes utilized in the benthic sediment diagenesis model. ICM includes a benthic diagenesis submodel for calculating sediment oxygen demand and sediment-water nutrient flux, and a sediment transport submodel for calculating sediment loading, deposition, erosion, and transport, which considers four solids size classes (Cerco et al., 2010; Cerco and Noel, 2013). Bottom shear stress, for computing erosion and deposition, is a combination of stress generated by currents and surface waves (Harris et al., 2013). A multi-level bed framework tracks the distribution of each size class in each layer and stores bulk properties including layer thickness, porosity, and mass (Warner et al., 2008b). An SAV model calculates the water clarity/SAV standard for the restoration of SAV and accounts for positive feedbacks that improve water clarity (Cerco and Moore, 2001). A model of benthic filter feeders (three filter feeder groups) accounts for the 

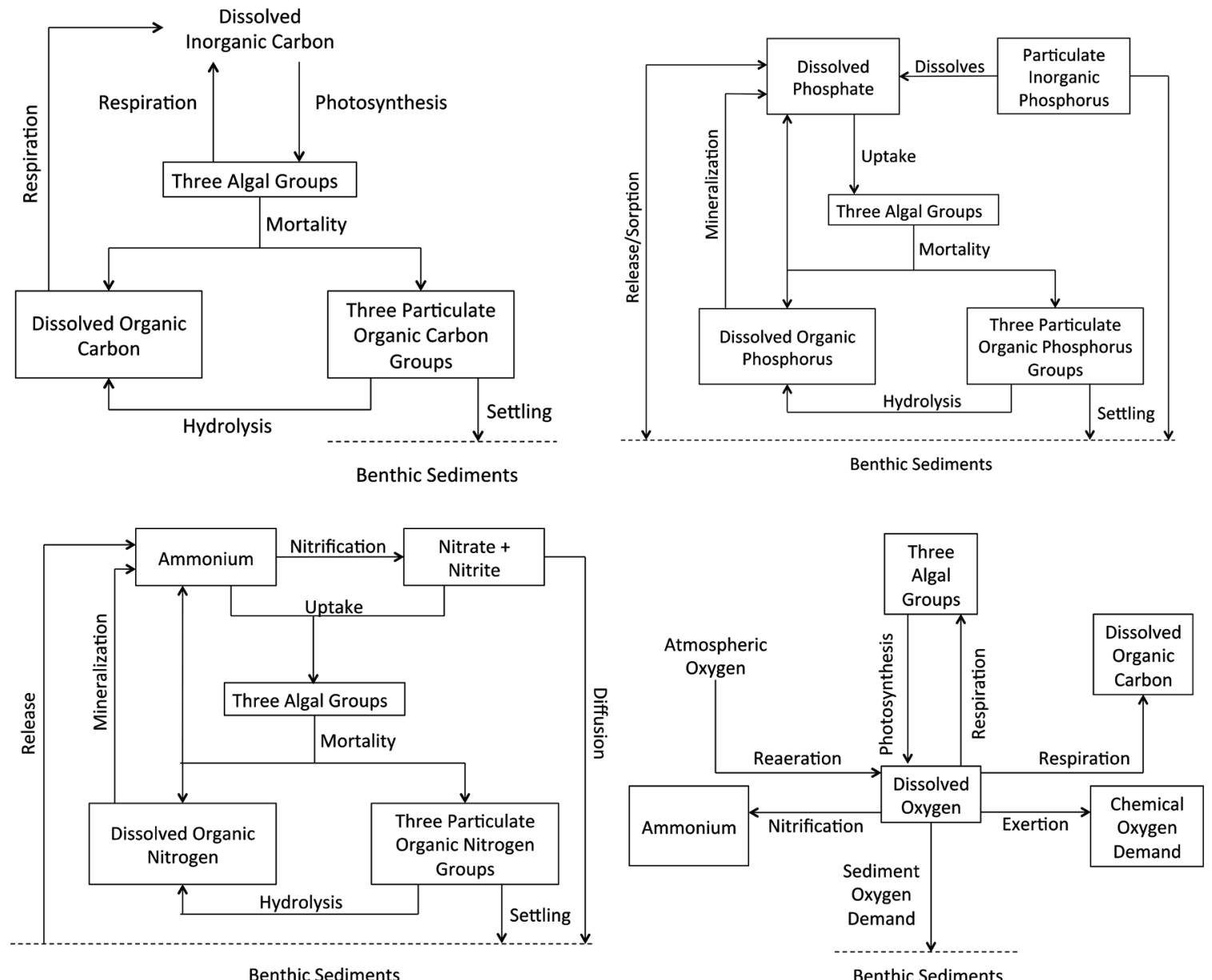

Benthic Sediments

Fig. 14. Schematic diagrams of the $\mathrm{C}, \mathrm{P}, \mathrm{N}$ and $\mathrm{O}_{2}$ cycles in CE-QUAL-ICM.

effects of filtration on water quality and clarity.

The sediment diagenesis submodel (Fig. 15), based on DiToro (2001) (see also Brady et al., 2013; and Clark et al., 2017), is coupled to ICM to account for the response of sediment-water nutrient and oxygen exchanges to management actions in the watershed. The spatial and computational time scales of the sediment diagenesis model are the same as the water quality model. The diagenesis model considers a $10-\mathrm{cm}$ thick active sediment layer that incorporates an aerobic surface layer with the remaining depth considered anaerobic. The thickness of the surface aerobic layer is time variable and is calculated based on

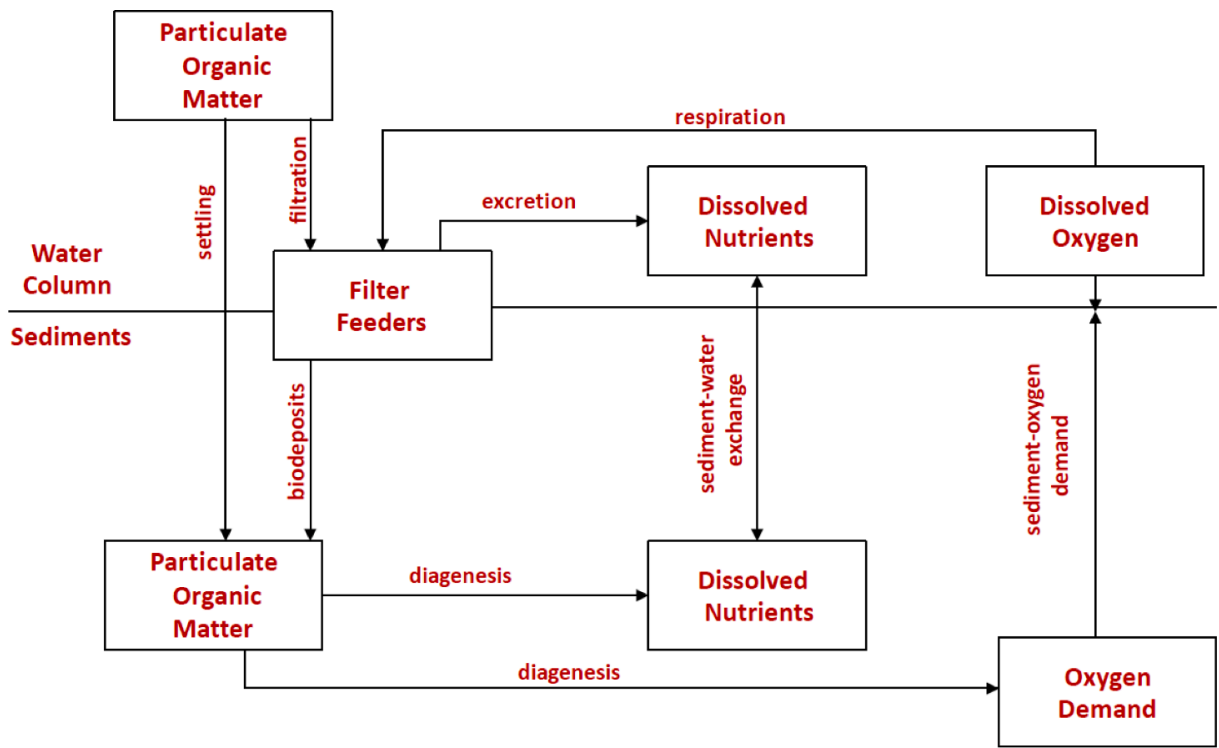

Fig. 15. Schematic diagram of the sediment diagenesis submodel. 
overlying water column oxygen concentration and model calculated sediment oxygen demand. The aerobic first layer is much thinner than the anoxic second layer $(1-2 \mathrm{~mm}$ vs. $10 \mathrm{~cm})$. In the anoxic layer, diagenesis of organic matter (nitrogen, phosphorus, and carbon) creates ammonium, phosphate, and oxygen demand, respectively. The fate of these substances (i.e., release to water column, release to atmosphere, burial) is determined by processes including nitrification, denitrification, sulfate reduction and methanogenesis. Ten years of model spin-up are required to equilibrate new scenario loads with burial and refractory diagenetic processes.

\subsubsection{Estuarine model advantages and limitations}

The CH3D/ICM combination provides computations of estuarine transport processes and water quality in three dimensions on spatial scales of meters (vertical) to kilometers (horizontal and lateral) and on an intra-tidal time scale. The grid is based on quadrilateral elements in the horizontal-lateral plane. CH3D is distinctive, however, in the use of "non-orthogonal curvilinear coordinates." The non-orthogonal representation implies that the grid elements are not required to meet at right angles as in models which employ orthogonal curvilinear coordinates. The non-orthogonal coordinate system allows improved representation of complicated channel geometry and irregular shorelines. The computational grid employs a Z-grid representation in the vertical axis. In the Z-grid, variations in depth are represented by varying the number of cells in the vertical direction. The cells are of constant thickness except for the surface cell which varies according to meteorological and tidal forcing. The Z-grid avoids the artificial vertical mixing which is associated with sigma coordinate systems (constant number of vertical cells, which vary in thickness, throughout). The artificial mixing associated with a sigma grid was noted early in the model application and was avoided to compute bottom-water anoxia in the Bay channel.

Perhaps the greatest advantage of the eutrophication component is the use of organic carbon throughout the model kinetics representations. Traditional water quality models were often based on alternate quantities such as biochemical oxygen demand (BOD) or "organic matter." Phytoplankton was quantified as chlorophyll rather than as carbon biomass as in the present model. The carbon-based kinetics maximize the use of current, rigorous observations in the model calibration and verification and avoid the need to define quantities such as BOD-tochlorophyll ratio. One rationale for the use of organic carbon is to make the water-column kinetics consistent with the carbon-based sediment diagenesis model. The model is also distinctive in that the "labile," "refractory," and "slow refractory" carbon, nitrogen, and phosphorus variables in the diagenesis model have direct corresponding state variables in the water column. The definition of direct corresponding state variables avoids the need to define empirical relationships between detailed representation in the sediments (i.e., three reaction classes) and less detailed representation in the water column (e.g., total organic carbon).

The phytoplankton kinetics in the model (Cerco and Noel, 2004) are distinctive in that they employ, to the greatest extent possible, quantities currently measured in field and laboratory investigations. Growth is related to maximum photosynthetic rate $\left(\mathrm{g} \mathrm{C} \mathrm{g}^{-1} \mathrm{chl} \mathrm{d}^{-1}\right)$ rather than a specified daily-average growth rate. Production is related to light via the Jassby and Platt (1976) relationship and is based on photosynthetically active radiation ( $\mu$ mole photons $\mathrm{m}^{-2} \mathrm{~s}^{-1}$ ) rather than thermal units such as langleys. The model has been rigorously calibrated to observed photosynthetic rates and primary production (Cerco and Noel, 2004).

However, as the modeling effort developed, and additional capabilities were added to the CH3D/ICM combination, some disadvantages of the grid configuration became apparent. The grid went through several refinements which improved resolution in the horizontal-lateral plane. Inevitably, the limitations of representing complicated shoreline configuration with quadrilaterals emerged. An unstructured grid that employs triangular elements could be a better approach.

The Z-grid represents changes in depth by varying the number of cells in the vertical. When changes in depth are steep, the variation in number of cells can become dramatic, resembling a "stairstep" or even a "wall." This can create problems. For example, computing the turbidity maximum at the head of the bay, using the sediment transport module, is impeded by the sharp variation in number of cells at the head of the Bay channel. Sediment moving upstream cannot climb the "stairs" at the head of the channel. A smoothly sloping bottom would improve computation of upstream sediment transport although care must be taken not to adversely affect the representation of stratification associated with a sigma grid. Another problem arises when using the model in the shallow upper-reaches of tributaries. In such regions the model may have only one or two depth levels and hence be unable to reproduce the estuarine circulation required to effectively model salinity in the shallows.

In addition, the outer boundary of the physical model is currently located at the Bay mouth, a region of sharp changes in topography and strong currents. This is not ideal. Moving the outer boundary offshore to the continental shelf, away from the mainstem Bay, would, among other things, improve simulations of future impacts of sea level rise on Chesapeake Bay. Finally, the lack of coastal wetting and drying in the current model does not allow for consideration of impacts from sea level rise inundation of the coastline and its wetlands.

The eutrophication component incorporates representation of several "living resource" components including submerged aquatic vegetation (SAV) and bivalve filter-feeding organisms. Living resources are included based on their value to management or their necessity to the model. For example, correct representation of the spatial distribution of phytoplankton is impossible without incorporating the effects of filter feeders. The living resource components are based on massbalance relationships. A disadvantage is that the complete, detailed, life cycles of the living resources are not represented. The simplification of the life cycles compromises the model's ability to represent the spatial and temporal distribution of the resources. For example, the distribution of SAV is largely based on light availability. While the influence of light on SAV distribution is well-established, the distribution of SAV is also influenced by recruitment and propagation, which are not considered in the model. The distribution of bivalves is also strongly influenced by recruitment. Since living resources are not the primary focus of the model, the additional calibration and computational resources required for more realistic representations may not be necessary. However, the limitations of the current representations must be recognized. Creation of specific, dedicated living resource models may be a superior alternative to adding complexities to the present models.

\subsubsection{Estuarine model summary recommendations}

Short-term and long-term efforts should continue the present trend of resolving finer spatial scales to make the estuarine models more directly applicable to assessing the performance of management actions at scales relevant to local communities and stakeholders. Prediction of locally relevant restoration outcomes may also prove a powerful incentive to motivate further investment and implementation. Application to smaller scales requires that the models have sufficient resolution to resolve tidal tributaries and relatively fast changes in biogeochemistry, such as dielcycling hypoxia (Tyler et al., 2009). However, refining spatial scale and increasing parameters have costs in computational time, development effort, data requirements, and parameter uncertainty. Some regions of the Chesapeake Bay may not benefit from further increases in spatial and temporal resolution and so careful consideration should be given to determining exactly where higher resolution is needed.

Multiple approaches for improving representation at local scales are available for consideration, including unstructured or nested horizontal grids (the term unstructured refers to grids composed of triangles, tetrahedra or irregularly shaped elements). An unstructured/hybrid grid (with hybrid referring to grids that combine multiple types of vertical and/or horizontal grid structures) would be a good candidate approach because it allows for inclusion of local-scale processes while maintaining 
efficient use of computational resources. SCHISM (Semi-implicit Crossscale Hydroscience Integrated System Model; Zhang et al., 2015; 2016; Ye et al., 2018) is an example of an unstructured model (Fig. 16) that provides advantages over the current CBP hydrodynamic model (CH3D). SCHISM is an open-source community-supported modeling system based on hybrid triangular-quadrangular unstructured grids, designed for seamless simulation of 3D baroclinic circulation across creek-lake-river-estuary-shelf-ocean scales. It uses a highly efficient and accurate semi-implicit, hybrid finite-element/finite-volume method with a Eulerian-Lagrangian algorithm to solve the Navier-Stokes equations (in hydrostatic form) to address a wide range of physical and biogeochemical processes. The number of vertical layers can also be varied spatially (Zhang et al., 2015), and thus a single SCHISM grid can seamlessly morph between 1D/2D/3D configurations ('model polymorphism'; Zhang et al., 2016). The use of "shaved" cells (i.e., cells that have a sloped bottom and avoid the staircase effects associated with $\mathrm{Z}$ coordinates) near the bottom not only captures the underlying bathymetry/topography, but also greatly improves model accuracy for bottom-controlled processes such as salt intrusion and gravity overflow (Ye et al., 2018).

In addition, two-way "online" coupling (rather than one-way "offline") between the hydrodynamic and biogeochemical models is critical for enabling investigation of how biogeochemical and biological processes affect physical processes. For example, increased particulates in the water column will impact estuarine bottom temperature via light attenuation (Kim et al., 2020), and SAV can impact water velocities. Such feedbacks of the biogeochemistry on the physical fields may be important in setting local TMDLs.

A second recommendation (also longer-term) is to implement a modular, experimental simulation framework that allows for testing of new and alternative biogeochemical formulations. This would allow investigation of additional processes and alternative formulations to increase certainty in the results provided to management based on the foundational version of the coupled modeling system. Such a framework or testbed approach would also expand the engagement of the CBP modeling system with academic and government research communities which would facilitate incorporation of latest scientific advancements. Such inter-model comparison approaches have been successfully performed that include the CBP estuarine model (Irby et al., 2016; Irby and Friedrichs 2019) and in a comparison of shallow water models in the Chester River of the Bay (Friedrichs et al., unpublished). These collaborative groups of modeling teams were more effective than individual efforts in advancing the models in large part because of the balance between the teams working separately while also meeting on a regular basis to share their findings and insights. A similar collaborative approach is recommended for the next generation model of the Chesapeake Bay estuary.

Finally, the 2014 Agreement has focused attention on the prediction of management actions on living resources and thus it will be important to put more formal effort into the identification of specific types of products from the hydrodynamic and biogeochemical models that can inform living resource models. The CBP Partnership will benefit from the enhancement of the working relationship between hydrodynamicbiogeochemical and living resource modeling groups because of the ecological, economic, and societal relevance of linking the Chesapeake Bay TMDL to living resources.

\subsection{Estuarine living resource models}

\subsubsection{Overview of the 2017 estuarine living resource models}

As discussed above, the CBP modeling system includes simple submodels for SAV and benthic filter feeders that are coupled to the estuarine hydrodynamics and biogeochemistry models, designed with water quality effects in mind. Two additional living resource models, Chesapeake Bay Fisheries Ecosystem management Model (CBFEM) and Chesapeake Bay Atlantis Model (CAM), have been developed by the $\mathrm{NCBO}$ to support Chesapeake Bay restoration, but these are not official components of the CBP coupled modeling system.

The CBFEM is an implementation of Ecopath with Ecosim (Christensen et al., 2009). It uses the biomass estimations of 45 trophic groups representing fisheries species of interest to the Bay, and their prey and predators (Table 2) to create a mass-balanced snapshot of the trophic linkages in the Bay as it may have been in 1950 (Townsend, 2014). The 45 trophic groups include species of commercial and ecological importance, represented by either single stocks, sub-stocks, or species groups that occupy similar foraging niches. As is typical for Ecopath with Ecosim applications, the Ecopath snapshot provides the base model for time-dependent Ecosim simulations. The CBFEM Ecosim model simulates the annual mean biomass values of the aforementioned species and groups for 53-years (1950-2002) to provide an assessment of the recent decadal dynamics of the Bay's fish species (Townsend, 2014).

The CBFEM Ecosim simulations have been loosely coupled to the

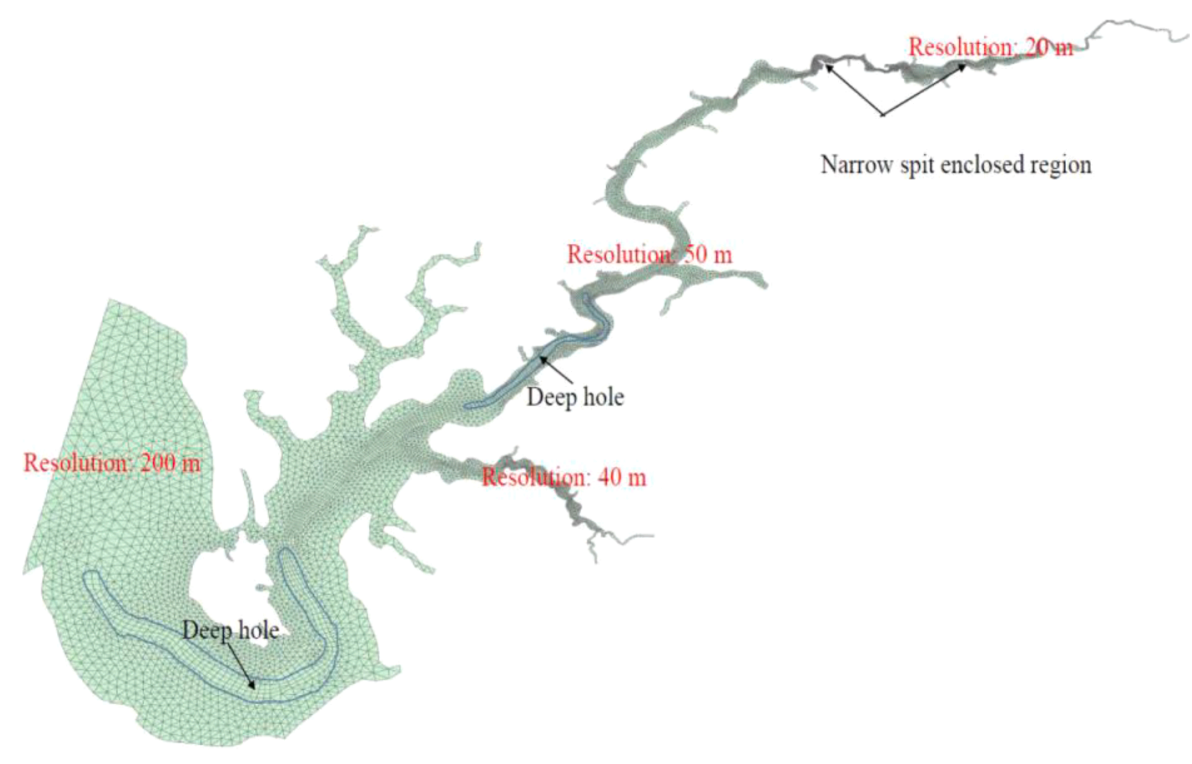

Fig. 16. Example of a estuarine hydrodynamic model with an unstructured grid: Semi-implicit Cross-scale Hydroscience Integrated System Model (SCHISM) implemented in Chester River in Chesapeake Bay. Figure reproduced from Ye et al. (2018). 
Table 2

Basic parameters for the Chesapeake Bay Fisheries Ecosystem management Model (CBFEM). Table adapted from Townsend (2014).

\begin{tabular}{|c|c|c|c|c|c|c|c|}
\hline EwE group \# & Group name & Trophic level & Biomass (t/ km²) & Prod./biomass $\left(\mathrm{yr}^{\wedge}-1\right)$ & Cons./biomass $\left(\mathrm{yr}^{\wedge}-1\right)$ & Ecotrophic efficiency & Prod./cons. \\
\hline 1 & Striped bass YOY & 3.56 & 0.0125 & 1.8 & 23.266 & 0.401 & 0.077 \\
\hline 2 & Strped bass resident & 3.52 & 2.1 & 0.4 & 4.441 & 0.554 & 0.09 \\
\hline 3 & Striped bass migratory & 3.36 & 2.946 & 0.3 & 2.3 & 0.483 & 0.13 \\
\hline 4 & Bluefish YOY & 4.17 & 0.0161 & 5.65 & 18.111 & 0.014 & 0.312 \\
\hline 5 & Bluefish adult & 4.05 & 0.24 & 0.589 & 3.3 & 0.63 & 0.178 \\
\hline 6 & Weakfish YOY & 4.26 & 0.0257 & 4 & 13.525 & 0.304 & 0.296 \\
\hline 7 & Weakfish adult & 4.15 & 0.489 & 0.685 & 3.1 & 0.906 & 0.221 \\
\hline 8 & Atlantic croacker & 3.25 & 1.67 & 0.916 & 5.4 & 0.801 & 0.17 \\
\hline 9 & Black drum & 3.03 & 1.263 & 0.19 & 2.1 & 0.1 & 0.09 \\
\hline 10 & Summer flounder & 3.66 & 0.454 & 0.52 & 2.9 & 0.95 & 0.179 \\
\hline 11 & Menhanden YOY & 2.99 & 18.089 & 1.5 & 15.86 & 0.686 & 0.095 \\
\hline 12 & Menhanden adult & 2.13 & 33 & 0.8 & 7.8 & 0.941 & 0.103 \\
\hline 13 & Alewife and herring & 3.13 & 5.986 & 0.75 & 9.4 & 0.95 & 0.08 \\
\hline 14 & American eel & 3.38 & 3.22 & 0.25 & 2.5 & 0.5 & 0.1 \\
\hline 15 & Catfish & 3.09 & 1.155 & 0.28 & 2.5 & 0.95 & 0.112 \\
\hline 16 & White perch YOY & 3.55 & 0.00305 & 2 & 19.921 & 0.576 & 0.1 \\
\hline 17 & White perch adult & 3.55 & 0.3 & 0.5 & 4.2 & 0.886 & 0.119 \\
\hline 18 & Spot & 2.86 & 1.674 & 1 & 5.8 & 0.9 & 0.172 \\
\hline 19 & American shad & 3.04 & 0.4 & 0.7 & 3.5 & 0.725 & 0.2 \\
\hline 20 & Bay anchovy & 3.41 & 3.4 & 3 & 10.9 & 0.494 & 0.275 \\
\hline 21 & Other flatfish & 2.99 & 0.169 & 0.46 & 4.9 & 0.95 & 0.094 \\
\hline 22 & Gizzard shad & 2.43 & 2.086 & 0.53 & 14.5 & 0.95 & 0.037 \\
\hline 23 & Reef-associated fish & 3.4 & 0.232 & 0.51 & 3.1 & 0.9 & 0.165 \\
\hline 24 & Non-reef-associated fish & 3.05 & 1.228 & 1 & 5 & 0.9 & 0.2 \\
\hline 25 & Littoral forage fish & 2.85 & 5.21 & 0.8 & 4 & 0.95 & 0.2 \\
\hline 26 & Sandbar shark & 4.05 & 0.024 & 0.23 & 1.4 & 0.217 & 0.164 \\
\hline 27 & Other elasmobranchs & 3.33 & 0.5 & 0.15 & 0.938 & 0.112 & 0.16 \\
\hline 28 & Piscivorous birds & 3.98 & 0.3 & 0.163 & 120 & 0 & 0.001 \\
\hline 29 & Non-piscivorous birds & 2.73 & 0.121 & 0.511 & 120 & 0 & 0.004 \\
\hline 30 & Blue crab YOY & 2.8 & 1.58 & 5 & 12.057 & 0.879 & 0.415 \\
\hline 31 & Blue crab adult & 3.09 & 4 & 1 & 4 & 0.881 & 0.25 \\
\hline 32 & Oyster YOY & 2 & 3.28 & 6 & 8.965 & 0.096 & 0.669 \\
\hline 33 & Oyster $1+$ & 2.09 & 20.4 & 0.15 & 2 & 0.414 & 0.075 \\
\hline 34 & Soft clam & 2.09 & 6.932 & 0.45 & 2.25 & 0.95 & 0.2 \\
\hline 35 & Hard clam & 2 & 2.626 & 1.02 & 5.1 & 0.95 & 0.2 \\
\hline 36 & Ctenophores & 3.48 & 3.4 & 8.8 & 35.2 & 0.205 & 0.25 \\
\hline 37 & Sea nettles & 4.13 & 0.583 & 5 & 20 & 0 & 0.25 \\
\hline 38 & Microzooplankton & 2 & 6.239 & 140 & 350 & 0.95 & 0.4 \\
\hline 39 & Mesozooplankton & 2.72 & 10.3 & 25 & 83.333 & 0.956 & 0.3 \\
\hline 40 & Other suspension-feeders & 2 & 6 & 2 & 8 & 0.823 & 0.25 \\
\hline 41 & Other infauna/epifauna & 2.1 & 66.675 & 1 & 5 & 0.9 & 0.2 \\
\hline 42 & Benthic algae & 1 & 1.717 & 80 & & 0.9 & \\
\hline 43 & SAV & 1 & 419 & 5.11 & & 0.084 & \\
\hline 44 & Phytoplankton & 1 & 27 & 160 & & 0.684 & \\
\hline \multirow[t]{2}{*}{45} & Detritus & 1 & 1 & & & 0.031 & \\
\hline & YOY $=$ young-of-the-year & & & & & & \\
\hline
\end{tabular}

CBP water quality model (ICM) by forcing it with time-dependent chlorophyll $a$ (Townsend 2014) and SAV (Ma et al., 2010) output to assess how water quality management strategies affect living resources. For the chlorophyll $a$ application, the model was used to simulate the impacts of a $40 \%$ reduction of nutrient inputs on upper-trophic-level species (e.g., the biomass of striped bass and blue crabs) and other commercially-important fished species (e.g., Atlantic menhaden, and Eastern oysters; Townsend, 2014). These simulations allow connections to be made between water quality and commercially and recreationally important species, and they can be used to assess trade-offs between water quality management goals and fisheries management goals.

The Chesapeake Bay Atlantis Model (CAM) is, in contrast to CBFEM, a spatially explicit (three-dimensional), full system (biogeochemical, physical and trophic) simulation model (Ihde et al., 2016; Ihde and Townsend, 2017). The CAM domain is composed of 97 irregular polygons and includes the brackish waters and sediments of the mainstem Chesapeake Bay and eight of its largest tributaries (Fig. 17). Water movement in CAM is driven by the Navy Coastal Ocean Model (NCOM) Relocatable Model. Nutrient and sediment loads to the model are derived from the CBP dynamic watershed Phase 5.3.2 model (Shenk and Linker, 2013).

CAM includes 26 invertebrate functional groups, including primary producers and multiple bacterial groups, and 29 vertebrate groups. Most invertebrates are modeled as single state variables $\left(\mathrm{mg} \mathrm{N} \mathrm{m}^{-3}\right)$, but two invertebrate groups, blue crab and brief squid, are modeled as linked juvenile and adult state variables. All vertebrate groups are divided into 10 age classes, each tracked by abundance and weight-at-age. CAM uses nitrogen as the currency for all state variables. Metabolic waste and decaying organisms form multiple forms of detritus that are cycled through bacteria to provide nutrients for both planktonic and benthic floral growth. Habitat types in CAM include both static physical factors such as mud, sand, rock, and woody debris, and dynamic biogenic functional groups such as marsh, SAV, and oyster reef, that provide refuge for prey from predator groups. Fish and other animal groups are assigned a "dependence" to one or more of the seven habitat types, and at least one such habitat must be available in a box for biomass of a group to move into that box.

CAM has been used to estimate the higher trophic level impacts of fully achieving the goals of the U.S. EPA TMDL requirements under present day climate conditions and warmer water temperatures, habitat loss, and water quality restoration (TMDL) under assumed future climate conditions (Fig. 18; Ihde et al., 2016; Ihde and Townsend 2017). These simulations used nutrient and sediment loads derived from the CBP's Phase 5.3.2 Watershed Model (Fig. 19; Ihde et al., 2016). The 


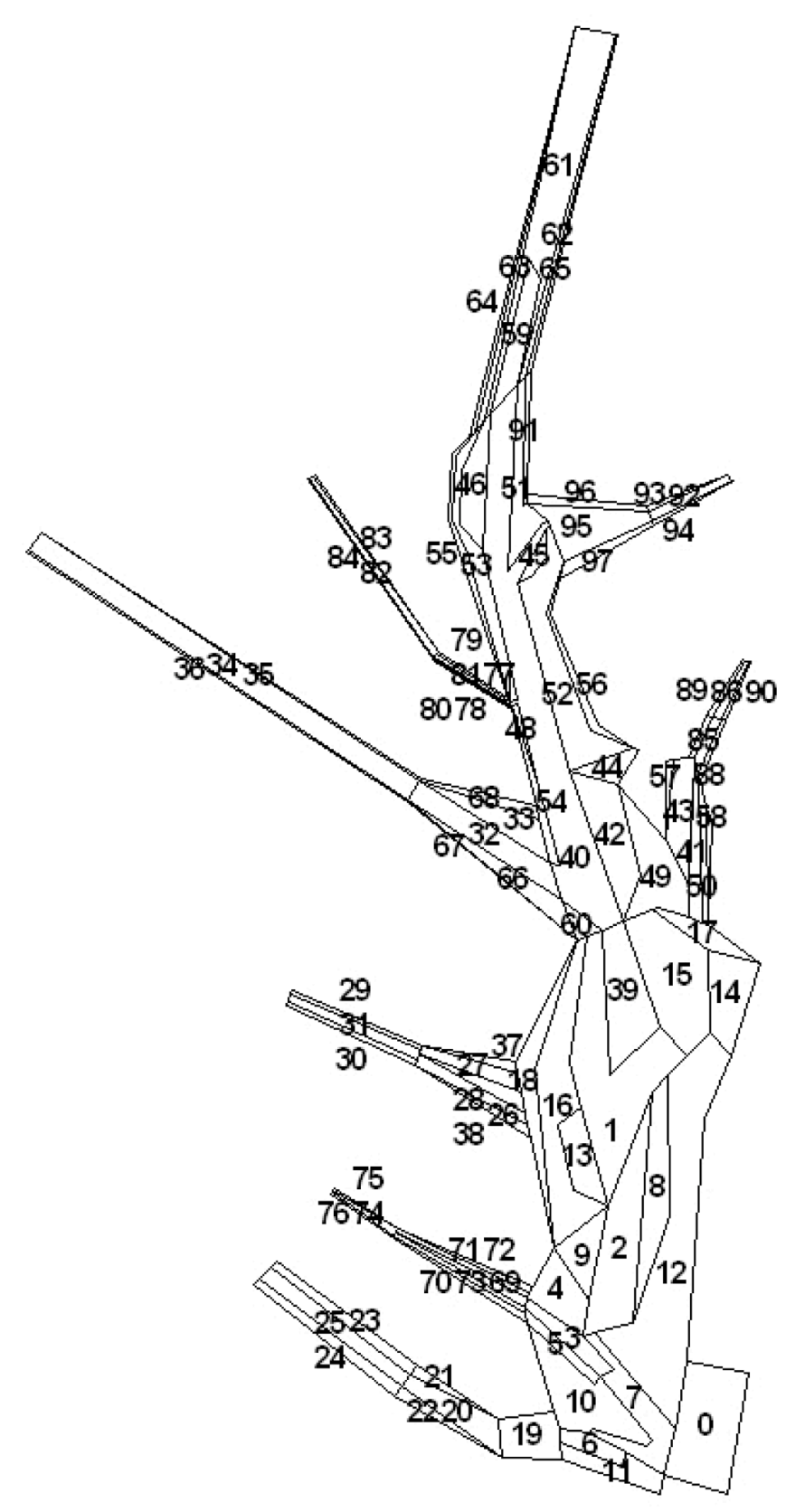

Fig. 17. Spatial structure of the Chesapeake Bay Atlantis Model (CAM). The model consists of 97 irregular polygons determined by salinity, depth, bottom type (mainstem only) and management boundaries. Figure reproduced from Ihde et al. (2016).

CAM and the CBFEM have not been directly coupled to the CBP estuarine hydrodynamic and biogeochemical models. Indeed, the CAM overlaps the functionality of the ICM because Atlantis is built on its own biogeochemical model (Murray and Parslow, 1999).

\subsubsection{Estuarine living resource models advantages and limitations}

Estuarine living resource models are needed to estimate ecosystem status and predict the impacts of anthropogenically induced changes to forcing conditions on higher trophic level species, most notably the TMDL mandated nutrient loads and altered climate. Unlike more targeted living resource models that simulate individual species or just a few species, these ecosystem models put the population dynamics of modeled groups in the context of the entire ecosystem with predators, prey, and competitors, providing a mechanism for achieving the larger goal of ecosystem-based management.

Simpler approaches, like CBFEM, mainly focus on trophic factors, whereas more complex approaches, like CAM, also include the dominant physical and biogeochemical forcings. The CBFEM produces a massbalanced state of the ecosystem, which is then used to simulate the system over time in response management actions. In contrast, CAM is designed to estimate cumulative effects of multiple factors acting simultaneously on the system. The structure of CAM is spatially explicit, and it is much more complex than CBFEM. As a result, the CAM model is computationally expensive and simulations can take days. In comparison, Ecopath with Ecosim produces model estimates in seconds to minutes.

Because the CBFEM and CAM models integrate a variety of different data from an array of sources, model estimates carry the burden of uncertainty inherent in each of those sources. As a result, the uncertainty of the model outputs is very large. Thus, the CBFEM and CAM models are not, at present, applied to tactical tasks like setting fishery harvest limits. Instead, they could be used to supplement tactical models, providing contextual information such as potential ecosystem impacts and tradeoffs for a range of different management options to refine decision making.

Finally, it should be noted that the CBFEM and CAM model simulations are constrained to reflect the characteristics of the observed system. Yet, ultimately, these models may be needed to predict the future on timescales of multiple decades or more, in response to future forcing conditions that have not been observed in the past, thus adding even more uncertainty to the model predictions.

\subsubsection{Estuarine living resource models summary recommendations}

Efforts to further incorporate living resources into the CBP modeling system predictions could start with the development of additional models, like CBFEM and CAM, that use CBP model output to drive higher trophic level models. In the short term, outputs can be used to estimate responses to habitat changes of key species in response to management actions. The current SAV model in ICM responds to water clarity; however, other factors also influence SAV growth such as propagation processes and the physical characteristics of the bottom substrate. These additional influences could be added to the ICM model to more realistically simulate SAV growth and bed expansion in response to restoration efforts and improved water clarity in the Bay. Similar expansions to the existing formulation can be implemented for benthic filter feeders within the ICM (Newell et al., 2002; Harding and Mann 2001; North et al., 2010) to increase their realism and include more feedbacks. This approach has been used for fish population dynamics in Chesapeake Bay for both menhaden (Dalyander and Cerco 2010) and bay anchovy (Adamack et al., 2017). Both efforts used an agent-based (Lagrangian) approach to simulate population dynamics, but Eulerian-based approaches could also be implemented.

Another short-term approach is to process the output of the estuarine models to assess habitat suitability of key species, for example, the effect of temperature and oxygen on striped bass (Fig. 20). Habitat suitability is widely used to inform management on how altered environmental conditions will affect habitat quantity and quality (e.g., Secor et al., 2009; Brown et al., 2013). A new generation of these habitat models, such as species distribution models, niche modeling, and bioclimatic models, are now being widely applied (Guisan and Thuiller, 2005; Ehrlén, and Morris 2015; Crear et al., 2020a,b). Models of higher trophic level habitat that use estuarine model output could be modular so that they can be easily interchangeable and allow for direct comparisons of responses across species.

Further adapting and integrating one or both of the existing food web models with the estuarine models is another relatively short-term approach. The feasibility of trying to extract the higher trophic level formulations from CAM and loosely or tightly couple them to CH3D and ICM is an open question. One role that may be important for CAM is to function as a companion model to ICM to address many of the goals and 


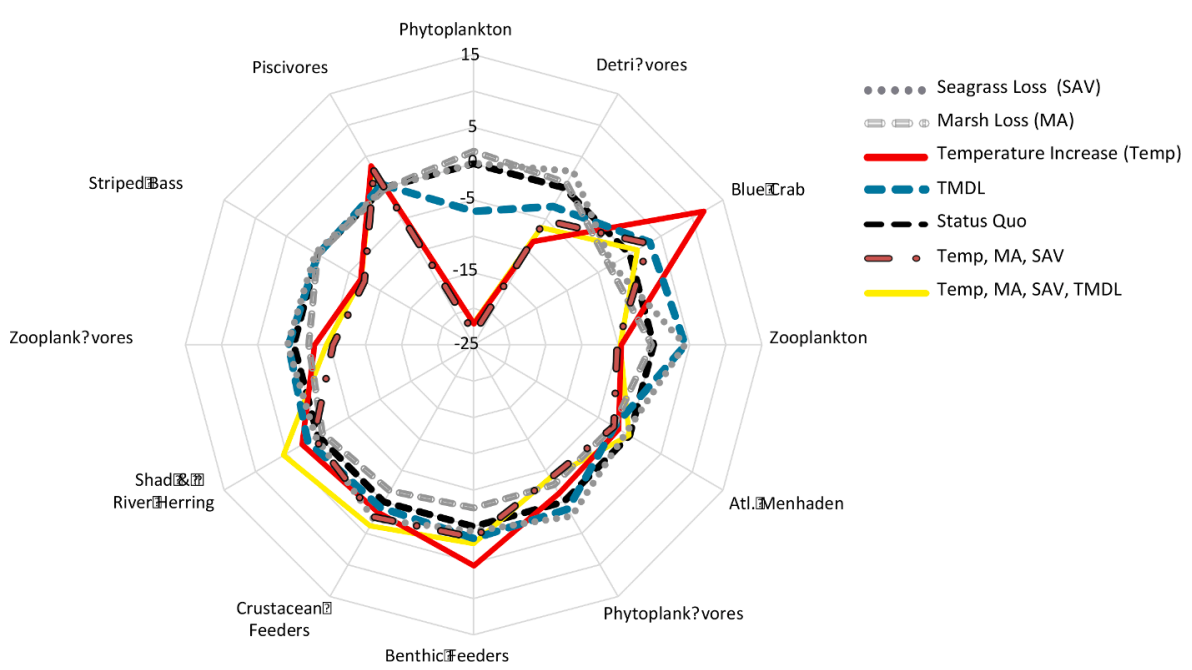

Fig. 18. Effect (percent change from Status Quo scenario) of individual stressors (Submerged Aquatic Vegetation [SAV] loss [50\%]; Marsh grass [MA] loss [50\%]; Temperature increase [Temp; $+1.5{ }^{\circ} \mathrm{C}$; nutrient and sediment management, or "Total Maximum Daily Load" [TMDL] requirements), and combinations of those stressors, on selected CAM groups (axes) of ecological and management interest. Each scenario simulation was run for 50 years. Details of each scenario can be found in Ihde and Townsend (2017). Figure and caption modified from Ihde and Townsend (2017).

Effects of changing conditions On our living resources

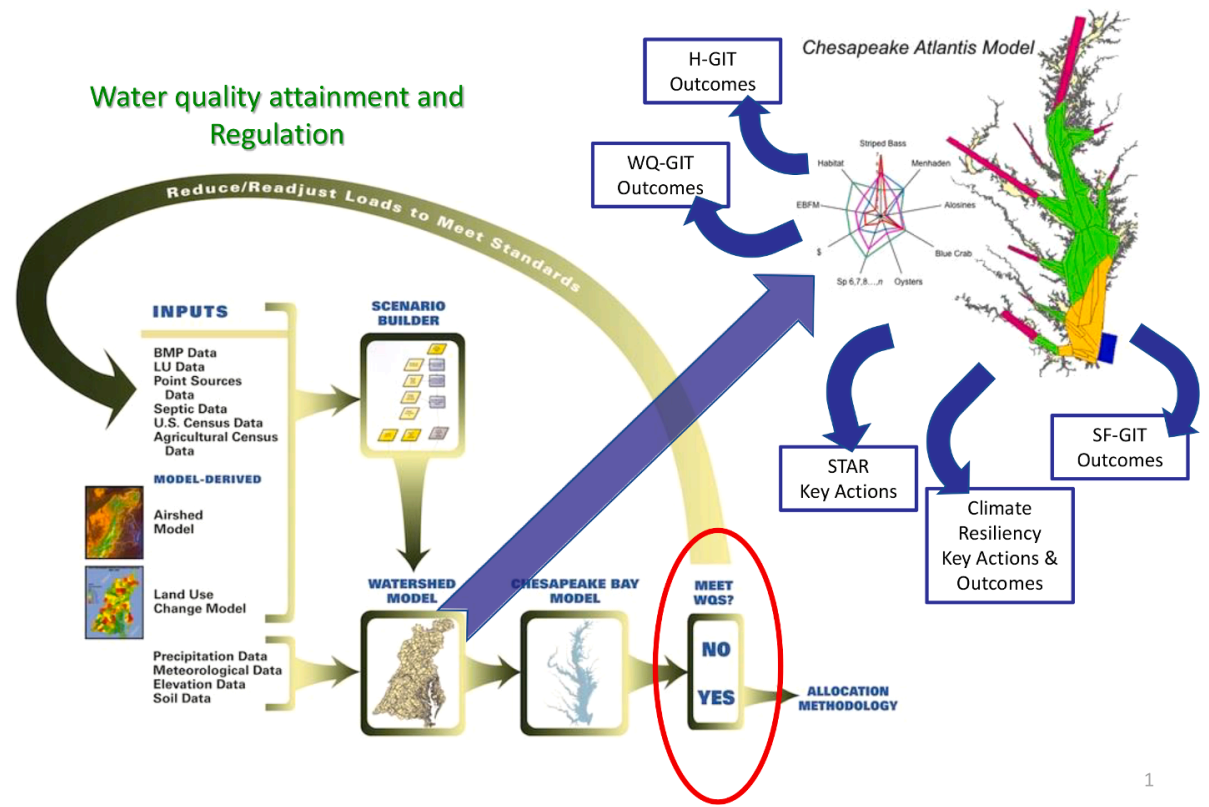

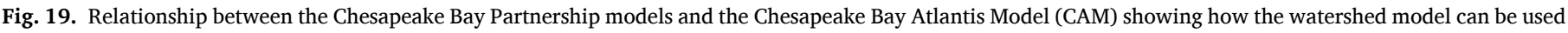
to force CAM to examine effects of restoratioin and changing conditions on living resources.

outcomes of the 2014 Agreement that relate to higher trophic level species that are not simulated by ICM. In addition, or alternatively, the CBFEM could be developed further into a spatially-explicit Ecospace model, which would allow for loose coupling to CH3D-ICM, as Ecospace does not contain its own physical or biogeochemical model. Making use of the habitat capacity model within Ecospace (Christensen et al., 2014) would allow for using CH3D and ICM output as environmental drivers affecting the biomass and spatial distribution of estuarine living resources. Comparing an Ecospace version of CBFEM with CAM would then provide a multiple model approach for higher trophic levels (Lewis et al., 2021). Issues related to commercial and recreational fish abundances, food web energetics (e.g., pelagic versus benthic pathways), system resilience, and human interactions could be quantified to allow for comprehensive assessment of the costs, benefits, and tradeoffs of different management strategies (e.g., Wainger et al., 2013).

A technical challenge to the incorporation of living resources within the CBP modeling system is how to couple the models to the watershed and estuarine models (Ganju et al., 2016). The living resources models have different temporal and spatial scales compared to the CBP watershed and estuarine models. An investment in protocols and software for coupling models (Warner et al., 2008a; Koralewski et al., 2019) will ensure consistency in the results across the living resource models that will aid in interpretation and comparisons across species and food webs. Creating these protocols in the co-production framework of the CBP will also serve to build the same transparency and trust that is already in place for the airshed, watershed, land use, hydrodynamic, and estuarine models.

The CBP Partnership would benefit from the establishment an Ecosystem Modeling Subcommittee responsible for both tidal and nontidal aquatic systems. The collection of examples and food web models, along with other living resource models developed outside of the $\mathrm{CBP}$ and fisheries management models, can serve as prototypes for a more comprehensive analysis of water quality effects on Chesapeake Bay living resources. The Subcommittee should adopt a portfolio of 


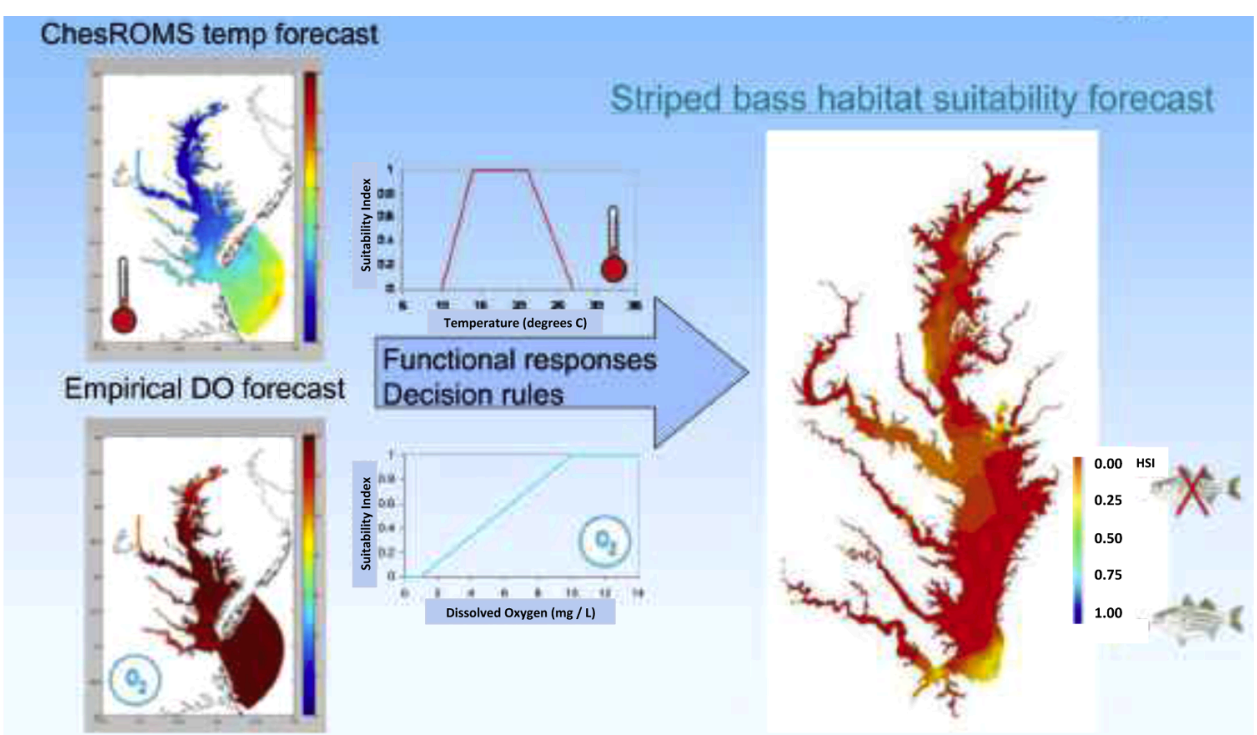

HSI = Habitat Suitability Index

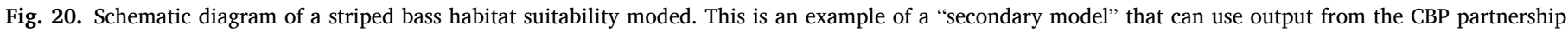
models (e.g., water quality parameters) to define habitat quality and /or impacts on higher trophic level organisms.

modeling approaches for living resources that includes agreed-upon protocols for: (1) analyzing output from the CBP Modeling System from a habitat/organism perspective; (2) translating CBP Modeling System output to develop habitat or growth suitability indices; (3) using CBP Modeling System output as input for living resource and higher trophic level models; and (4) integrating organisms into the ICM water quality model as has been done, for example, with benthic filter feeders and SAV.

An explicit strategy for further incorporating living resources into the modeling system would encourage effective and efficient progress. As a starting point, the Subcommittee could consider nonlinear responses of living resources to nutrients and sediment, new approaches and purposes for modeling primary producers that include botanical processes, and re-integrating consumers into the ICM biogeochemical model to facilitate coupling to higher trophic levels (e.g., zooplankton, which is not explicitly included in the ICM model). The Subcommittee could also articulate mechanisms for communication and stakeholder involvement, emphasizing that modeling living resource responses allows communication of co-benefits of restoration to stakeholders.

\section{Lessons learned}

The CBP modeling system has contributed to several management successes that are due, in large part, to broad acceptance of the models by the scientific, management and stakeholder communities. This acceptance is the result of several factors. First, the members and participants of the Modeling Workgroup adhere to a set of core values that have promoted: 1) integration of the most recent airshed, watershed, and estuarine research and knowledge to support modeling for restoration decision making; 2) innovating, embracing creativity, and encouraging improvement in the development and support of transparent and robust modeling tools; 3 ) independence in making modeling decisions on the basis of best available evidence and using the most appropriate methods to produce, run, and interpret models, independent of policy considerations; and 4) inclusiveness with a strong commitment to an open and transparent process and the engagement of relevant partners, that results in strengthening the CBP's decision making tools. Adherence to these values for more than three decades has resulted in a buildup of trust among scientific, management and stakeholder communities.

In addition, the CBP models have always been developed in phases.
For example, Phase 6 of the watershed model development was completed in 2017 and the CBP is now working on the next generation of models for the 2025 assessment - now designated as Phase 7 . The use of phases has several advantages. It provides a subtle reminder to scientists and managers that the CBP models are continually evolving. It also reminds scientists and managers of their approval of the previous modeling phase, which facilitates approval of new models that are refined and improved versions of the previous model phase. In addition, the CBP partners and collaborators understand that whatever the current model phase, it too will be further refined and the known current model limitations will be addressed going forward in the ongoing evolution of the CBP models.

The formal procedures for model partnership development and approval are supported by CBP's longstanding commitment to being deeply collaborative, with a transparent approach to open-source model development and application. Another approach used by the CBP scientific community to increase CBP model transparency and access is convening technical transfer workshops on the models and tools to increase understanding and promote wide use. The CBP has also used its web sites and on-line documentation to create an extensive public record of what has been agreed to in CBP model development, including specifics of all major decisions and public access to the supporting technical material.

\section{Summary and going forward}

The CBP Partnership has used its linked modeling system as a planning tool to inform strategic management decisions toward Bay restoration since the 1980s. Over the last decade the modeling system has been used to formulate the 2010 Chesapeake Bay TMDL, evaluate progress and make midcourse adjustment in 2017, and inform the states' and DC's development of three phases of Watershed Implementation Plans that detail actions to be taken to reduce nutrients and sediment. Although model development has been driven by regulatory management needs, the development process is built on a foundation of monitoring, research, and collaborative engagement that cultivates the understanding necessary to manage water quality and habitat conditions in the Chesapeake Bay and its watershed. Given past successes in the CBP modeling system, there is ample evidence that new modeling tools will continue to be developed and incorporated into the modeling system to assist managers in setting, communicating, and achieving 
Table 3

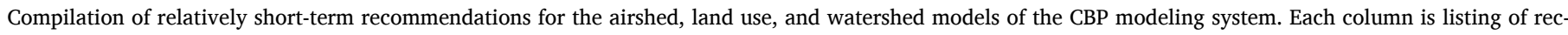
ommendations in the order they appear in the text.

\begin{tabular}{|c|c|c|c|c|}
\hline \multirow[t]{2}{*}{ Airshed } & \multirow[t]{2}{*}{ Land Use } & \multicolumn{3}{|c|}{ Watershed } \\
\hline & & General & Hydrology & Nutrients/Sediments \\
\hline $\begin{array}{l}\text { Assess climate change } \\
\text { effects on deposition } \\
\text { of nitrogen }\end{array}$ & $\begin{array}{l}\text { Update land cover data every } 5 \\
\text { years; hotspots of land-use } \\
\text { changes every } 2 \text { years }\end{array}$ & $\begin{array}{l}\text { Increase spatial resolution } \\
\text { and include explicit time lags }\end{array}$ & $\begin{array}{l}\text { Consider representing more sub- } \\
\text { basin scale processes }\end{array}$ & $\begin{array}{l}\text { Incorporate runoff drainage effects on sediment } \\
\text { sources and transport }\end{array}$ \\
\hline $\begin{array}{l}\text { Fully characterize } \\
\text { deposition of organic } \\
\mathrm{N}\end{array}$ & $\begin{array}{l}\text { Map animal operations and } \\
\text { forest age }\end{array}$ & $\begin{array}{l}\text { Switch to a modular design to } \\
\text { allow for comparison of } \\
\text { alternative formulations }\end{array}$ & $\begin{array}{l}\text { Use a standard watershed layer } \\
\text { system that matches with the } \\
\text { spatial scale of management }\end{array}$ & $\begin{array}{l}\text { Revisit sediment erosion and delivery rates from } \\
\text { different physiographic settings and land use } \\
\text { conditions. }\end{array}$ \\
\hline $\begin{array}{l}\text { Quantify biases in } \\
\text { predicted oxidized N }\end{array}$ & $\begin{array}{l}\text { Characterize cropland and } \\
\text { pasture based on use of BMPs }\end{array}$ & & & $\begin{array}{l}\text { Enhance time-averaged nutrient version to be } \\
\text { spatially-resolved }\end{array}$ \\
\hline \multirow[t]{2}{*}{$\begin{array}{l}\text { Use validated land use- } \\
\text { specific deposition } \\
\text { estimates }\end{array}$} & & & & $\begin{array}{l}\text { Evaluate the species and form of nutrients } \\
\text { represented in the model; consider adding } \\
\text { organic carbon }\end{array}$ \\
\hline & & & & $\begin{array}{l}R e \text {-analyze data and collect new data on nutrient } \\
\text { species and forms and previously unmonitored } \\
\text { sources (e.g., groundwater, low-order streams). }\end{array}$ \\
\hline
\end{tabular}

Table 4

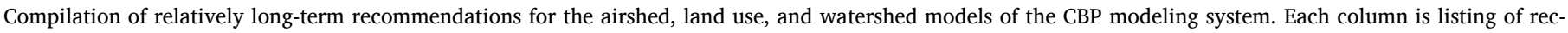
ommendations in the order they appear in the text.

\begin{tabular}{|c|c|c|c|}
\hline \multirow[t]{2}{*}{ Airshed } & \multirow[t]{2}{*}{ Land Use } & \multicolumn{2}{|r|}{ Watershed } \\
\hline & & General & Hydrology/Sediments/Nutrients \\
\hline $\begin{array}{l}\text { Move to higher spatial resolution with } \\
\text { non-uniform grid to resolve } \\
\text { Chesapeake Bay watershed }\end{array}$ & Link to transportation models & $\begin{array}{l}\text { Use open source with the ability to } \\
\text { run on-line }\end{array}$ & $\begin{array}{l}\text { Implement highly-resolved sub-basin models } \\
\text { and simulations; BioRT-Flux-PHIM is a good } \\
\text { candidate for hydrology }\end{array}$ \\
\hline $\begin{array}{l}\text { Analyze of parameter uncertainty over } \\
\text { full range of variation }\end{array}$ & $\begin{array}{l}\text { Better represent population (e.g., age, income) } \\
\text { and employment sectors }\end{array}$ & $\begin{array}{l}\text { Switch to a modular design with } \\
\text { formal protocols for coupling }\end{array}$ & $\begin{array}{l}\text { Reformulate sediment dynamics from statistical } \\
\text { relationships to process-based }\end{array}$ \\
\hline $\begin{array}{l}\text { Better link to watershed and estuarine } \\
\text { models }\end{array}$ & $\begin{array}{l}\text { Incorporate feedbacks between development } \\
\text { capacity, density, growth, and spillover }\end{array}$ & $\begin{array}{l}\text { Consider issues such as transport } \\
\text { and fate of contaminants of } \\
\text { emerging concern }\end{array}$ & $\begin{array}{l}\text { Increasingly localize predictions to enable } \\
\text { better evaluation of performance of actions and } \\
\text { to relate actions to stakeholders. }\end{array}$ \\
\hline \multirow[t]{2}{*}{$\begin{array}{l}\text { Rectify the parameterization across the } \\
\text { grid }\end{array}$} & $\begin{array}{l}\text { Better represent spatial allocation of infill } \\
\text { development within urban areas based on } \\
\text { wastewater treatment capacity }\end{array}$ & & Form a sediment modeling workgroup \\
\hline & $\begin{array}{l}\text { Add capability to simulate future conditions } \\
\text { related to agriculture, forest changes, and } \\
\text { climate change }\end{array}$ & & \\
\hline
\end{tabular}

future TMDLs under uncertain future conditions influenced by varied scenarios of BMP implementation, land use, and climate change.

Envisioning the future of the CBP modeling system is timely. There have been recent advances in physical and biogeochemical process understanding, computer science, and environmental systems modeling approaches and techniques. The upcoming 2025 assessment offers an opportunity to continue this process through the use of improved models. This paper provides an overview of the 2017 CBP management modeling system and presents recommendations on potential improvements for 2025 and beyond. These improved models would better support and inform watershed management of nutrients and sediment for water quality goals and be an important step toward explicitly assessing management actions on living resources.

The recommendations are summarized for the various component models in Tables 3, 4, and 5. Tables 3 and 4 represent the Airshed, Land Use, and Watershed models by short-term (Table 3) and long-term (Table 4). The recommendations for the remaining Estuarine and Living Resources models are summarized in Table 5, without separation by time frame, but still with the order proceeding as presented in the paper, which roughly places shorter-term recommendations first.
Four major themes in the recommendations that apply to all the models are the need for: (1) finer spatial resolution; (2) improved connectivity and coupling of the component models; and (3) estimation of uncertainty. Modeling at higher and/or variable resolution would improve input to local watershed TMDLs and Watershed Implementation Plans, including fine-scale atmosphere, land use and watershed modeling capability. This starts with the need for better representation of watershed delivery mechanisms for surface water, nutrients, and sediment, as well as the changes to delivery patterns due to BMP implementation.

While the models within the modeling system are linked, more explicit representation of the connectivity and coupling among the models would enhance their usability and interpretability. This includes how information is transferred among models and the adoption of modular approaches. There is an equally imperative demand for better simulations of the many linkages between water quality and living resources in the Bay to predict the effects of attainment of nutrient reduction goals on living resources and to create opportunities to understand and leverage co-benefits associated with restoration. Models that more fully represent higher trophic levels and ecosystem dynamics 
Table 5

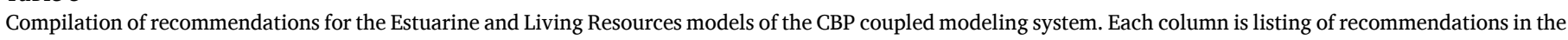
order they appear in the text.

\begin{tabular}{|c|c|}
\hline Estuarine & Living Resources \\
\hline $\begin{array}{l}\text { Move to an unstructured/hybrid grid with adjustable vertical and horizontal resolution, } \\
\text { wetting/drying, such as SCHISM }\end{array}$ & Use outputs to quantify habitat suitability for key species and life stages \\
\hline $\begin{array}{l}\text { Implement a modular framework to allow for testing of alternative formulations and } \\
\text { processes }\end{array}$ & Expand representation of existing SAV and benthic filter feeders (oysters) within ICM \\
\hline Develop details for simulating tributaries and shallow habitats & $\begin{array}{l}R e \text {-formulate existing population models and develop new models that are imbedded } \\
\text { within ICM grid }\end{array}$ \\
\hline \multirow[t]{5}{*}{ Ensure linkages to living resources, such zooplankton and benthos } & Extract aspects of the two food web models (CAM, CBFEM) and add or couple them to ICM \\
\hline & CAM can function as a modular replacement or alternative model to ICM \\
\hline & $\begin{array}{l}\text { Comparing an Ecospace version of CBFEM with CAM would provide a multiple model } \\
\text { approach for higher trophic levels }\end{array}$ \\
\hline & $\begin{array}{l}\text { Develop coupler protocols and software to ensure consistent exchange of information } \\
\text { among models }\end{array}$ \\
\hline & Form an Ecosystem Modeling committee \\
\hline
\end{tabular}

and feedbacks could provide a more complete picture of whether the conditions that support desirable living resource outcomes are being achieved.

Many of the recommendations involve adding resolution or expanding aspects of the models and, therefore, have costs in computational time, development effort, data requirements, and parameter uncertainty. Some regions of the model domains may not benefit from further increases in resolution and so careful consideration should be given to determining where higher resolution will result in substantial management benefits. These models must be flexible and computationally efficient to enable scenario analysis with multiple runs (ensembles) to create probabilities of outcomes under different conditions.

Efforts aimed at characterizing the uncertainty in the CBP Partnership model projections (e.g., Irby and Friedrichs, 2019) should continue, in addition to independent verification and sensitivity testing to understand model skill. Many recommendations involved attempts to increase the confidence in model predictions, often by increasing resolution and by implementing more complicated process representations. Formal uncertainty analysis of large, coupled modeling systems is a challenge (Allen et al., 2007; Pianosi et al., 2016; Razavi and Gupta, 2015). A useful exercise is to also look for opportunities to simplify processes and formulations within the models, and to consider computational aspects to ensure simulations can be performed on the schedule needed by management decision-making.

Another direction to move forward is to integrate data-driven and process-based models (Karpatne et al., 2017; Reichstein et al., 2019; Shen, 2018), taking advantage of the strength of both models. As outlined in this paper, process-based models can offer process-based scientific insights and cause-consequence relationships. Machine learning techniques, on the other hand, can learn from data to facilitate the parameterization of process-based models and reduce model uncertainty. In particular, in recent years, deep learning approaches have gained momentum in hydrological forecasting (Fang et al., 2019; Rahmani et al., 2021; Shen, 2018). A recent study has also shown the promise of training a deep learning model (Long Short Term Memory, LSTM) at the continental scale using largely available hydrometeorology data to forecast dissolved oxygen (DO), an important water quality measure (Zhi et al., 2021). The model learned the theory of DO dependence on water temperature; it also indicated the critical needs of data collection under conditions that lead to DO peaks and troughs. Further data-driven model development can potentially lead to insights of temporal trends and spatial patterns that can advance hydro-biogeochemical theories and forecasting capabilities for water quality response to changing climate and human perturbations.

The development of the coupled modeling system and its use to inform management was, and will continue to be, a long-term process and investment. The CBP Partnership will benefit from continuing its efforts to increase stakeholder engagement to create a shared vision of effective restoration strategies and to help guide model development and application. Linkages to the scientific community are also important to maintain the "pressure" of peer review so the models are up to date. The trust accumulated to date must be maintained into the future as recommendations are considered and implemented.

\section{Declaration of Competing Interest}

None.

\section{Acknowledgements}

The views expressed in this manuscript are those of the authors alone and do not necessarily reflect the views and policies of the U.S. Environmental Protection Agency. This article has been peer reviewed and approved for publication consistent with USGS Fundamental Science Practices (https://pubs.usgs.gov/circ/1367/). This review paper is based on information that was provided by 70 scientists and managers who participated in a workshop that was convened on January 17-19, 2018 at the National Conservation Training Center in Shepherdstown, West Virginia, USA. This workshop was funded by the Chesapeake Bay Scientific and Technical Advisory Committee (STAC) via the Chesapeake Research Consortium. The lead author would like to thank all of the workshop participants for their contributions to that workshop and this paper. In addition, special thanks go to STAC support personnel (specifically, coauthor Rachel Dixon and staff member Elaine Hinrichs) who handled all of the logistics involved in planning and running the workshop. The development of this paper was supported by NSF grant no. 1556661, NASA grant no. 80NSSC17K0258 49A37A and NOAA grant no. NA15NMF4570252 NCRS-17 to R. Hood. Additional support to coauthors was provided by multiple US Federal and State Agencies, and US Universities (see author affiliations above). This is UMCES contribution no. CN 6018. Any use of trade, firm, or product names is for descriptive purposes only and does not imply endorsement by the U.S. Government.

\section{References}

Adamack, A.T., Rose, K.A., Cerco, C.F., 2017. Simulating the Effects of Nutrient Loading Rates and Hypoxia On Bay Anchovy in Chesapeake Bay Using Coupled hydrodynamic, Water quality, and Individual-Based Fish Models. Modeling coastal hypoxia (Springer).

Allen, J.I., Somerfield, P.J., Gilbert, F.J., 2007. Quantifying uncertainty in highresolution coupled hydrodynamic-ecosystem models. J. Mar. Syst. 64, 3-14. 
Amin, M.G.M., Karsten, H.D., Veith, T.L., Beegle, D.B., Kleinman, P.J., 2018. Conservation dairy farming impact on water quality in a karst watershed in northeastern US. Agric. Syst. 165, 187-196.

Amin, M.G.M., Veith, T.L., Collick, A.S., Karsten, H.D., Buda, A.R., 2017. Simulating hydrological and nonpoint source pollution processes in a karst watershed: a variable source area hydrology model evaluation. Agric. Water Manage. 180, 212-223.

Appel, K.W., Bash, J.O., Fahey, K.M., Foley, K.M., Gilliam, R.C., Hogrefe, C., Hutzell, W. T., Kang, D., Mathur, R., Murphy, B.N., Napelenok, S.L., Nolte, C.G., Pleim, J.E., Pouliot, G.A., Pye, H.O.T., Ran, L., Roselle, S.J., Sarwar, G., Schwede, D.B., Sidi, F.I., Spero, T.L., Wong, D.C., 2021. The Community Multiscale Air Quality (CMAQ) model versions 5.3 and 5.3.1: system updates and evaluation. Geosci. Model Dev. 14, 2867-2897. https://doi.org/10.5194/gmd-14-2867-2021.

Ator, S.W., Garcia, A.M., 2016. Application of SPARROW modeling to understanding contaminant fate and transport from uplands to streams. J. Am. Water Resour. Assoc. 52 (3), 685-704. https://doi-org.proxy-um.researchport.umd.edu/10.1111/1752-1 688.12419.

Ator, S.W., Brakebill, J.W., Blomquist, J.D., 2011. Sources, fate, and transport of nitrogen and phosphorus in the Chesapeake Bay watershed-An empirical model. U.S. Geological Survey Scientific Investigations Report 2011-5167. http://pubs.usgs. gov/sir/2011/5167/.

Ator, S.W., Blomquist, J.D., Webber, J.S., Chanat, J.G., 2020. Factors driving nutrient trends in streams of the Chesapeake Bay watershed. J. Environ. Qual. 49, 812-834.

Ator, S.W., García, A.M., Schwarz, G.E., Blomquist, J.D., Sekellick, A.J., 2019. Toward explaining nitrogen and phosphorus trends in Chesapeake Bay Tributaries, 1992-2012'. JAWRA J. Am. Water Resour. Assoc. 55, 1149-1168.

Bao, C., Li, L., Shi, Y., Duffy, C., 2017. Understanding hydrogeochemical processes at the watershed scale: 1. Development of RT-Flux-PIHM. Water Resour. Res. 53 (3), 2328-2345. https://doi.org/10.1002/2016WR018934.

Bash, J.O., Cooter, E.J., Dennis, R.L., Walker, J.T., Pleim, J.E., 2013. Evaluation of an regional airquality model with bidirectional NH3 exchange coupled to an agroecosystem model. Biogeosciences 10, 1635-1645.

Berg, J., Burch, J., Cappuccitti, D., Filoso, S., Fraley-McNeal, L., Goerman, D., Hardman, N., Kaushal, S., Median, D., Meyers, M., Kerr, B., Stewart, S., Sullivan, B. Walter, R., Winters, J., 2013. Recommendations of the Expert Panel to Define Removal Rates for Individual Stream Restoration Projects. Prepared by T. Schueler, Chesapeake Stormwater Network,and B. Stack, Center for Watershed Protection. Test-drive revisions approved by the WQGIT September 8, 2014. https://www.che sapeakebay.net/documents/Stream_Panel_Report_Final_08282014_Appendices_A_G. pdf.

Bever, A.J., Friedrichs, M.A.M., Friedrichs, C.T., Scully, M.E., Lanerolle, L.W.J, 2013. Combining observations and numerical model results to improve estimates of hypoxic volume within the Chesapeake Bay, USA'. J. Geophys. Res.: Oceans 118, 4924-4944.

Bhatt, G., Kumar, M., Duffy, C.J., 2014. A tightly coupled GIS and distributed hydrologic modeling framework. Environ. Model. Software 62, 70-84.

Boesch, D.F., Brinsfield, R.B., Magnien, R.E., 2001. Chesapeake Bay eutrophication: scientific understanding, ecosystem restoration, and challenges for agriculture. J. Environ. Qual. 30, 303-320.

Borah, D.K., Bera, M., 2004. Wathershed-scale hydrologic and nonpoint-source pollution models: review of applications. Trans. ASAE 47, 789-803.

Brady, D.C., Testa, J.M., DiToro, D.M., Boyton, W.R., Kemp, M.W., 2013. Sediment flux modeling: calibration and application for coastal systems. Estuar Coast Shelf Sci 117, 107-124.

Brakebill, J.W., Ator, S.W., Schwarz, G.E., 2010. Sources of Suspended-Sediment Flux in Streams of the Chesapeake Bay Watershed: a Regional Application of the SPARROW Model 1. JAWRA J. Am. Water Resour. Assoc. 46, 757-776.

Brookfield, A.E., Hansen, A.T., Sullivan, P.L., Czuba, J.A., Kirk, M.F., Li, L., Newcomer, M.E., Wilkinson, G., 2021. Predicting algal blooms: are we overlooking groundwater? Sci. Total Environ., 144442

Brown, C.W., Hood, R.R., Long, W., Jacobs, J., Ramers, D.L., Wazniak, C., Wiggert, J.D., Wood, R., Xu, J., 2013. Ecological forecasting in Chesapeake Bay: using a mechanistic-empirical modeling approach. J. Marine Syst. 125, 113-125.

Brush, G.S., 2009. Historical land use, nitrogen, and coastal eutrophication: a paleoecological perspective. Estuaries Coasts 32, 18-28.

Buchheister, A., Bonzek, C.F., Gartland, J., Latour, R.J., 2013. Patterns and drivers of the demersal fish community of Chesapeake Bay. Mar. Ecol. Prog. Ser. 481, 161-180.

Buda, A., 2013. Surface-runoff generation and forms of overland flow. Treatise On Geomorphology. Elsevier.

Buda, A.R., Kleinman, P.J., Srinivasan, M.S., Bryant, R.B., Feyereisen, G.W., 2009. Factors influencing surface runoff generation from two agricultural hillslopes in central Pennsylvania. Hyrdol. Process. 23, 1295-1312.

Buda, A.R., Kleinman, P.J.A., Bryant, R.B., Feyereisen, G.W., Miller, D.A., Knight, P.G., Drohan, P.J., 2013. Forecasting runoff from Pennsylvania landscapes. J. Soil Water Conserv. 68, 185-198.

Campbell, P.C., Bash, J.O., Spero, T.L., 2019. Updates to the Noah land surface model in WRF-CMAQ to improve simulated meteorology, air quality, and deposition. J. Adv. Model. Earth Syst. 11, 231-256.

Cavalli, M., Trevisani, S., Comiti, F., Marchi, L., 2013. Geomorphometric assessment of spatial sediment connectivity in small Alpine catchments. Geomorphology 188, $31-41$.

CBF, 2014. The Economic Benefits of Cleaning Up the Chesapeake Bay: A Valuation of the Natural Benefits Gained by Implementing the Chesapeake Clean Water Blueprint'. Chesapeake Bay Foundation, Annapolis, MD. http://www.cbf.org/econo micbenefits.
CBP. 2014. “Chesapeake Bay Watershed Agreement.” https://www.chesapeakebay.net/ channel_files/24334/2014_chesapeake_watershed_agreement.pdf.

CBP. 2020a. https://cast.chesapeakebay.net/Documentation/ModelDocumentation.

CBP. 2020b. "Indicator Analysis and Methods Document: Bay Watershed Population, Updated 07/21/20." https://www.chesapeakebay.net/state/population.

CBP. 2020c. “Submerged Aquatic Vegetation”, https://www.chesapeakeprogress.co $\mathrm{m} /$ abundant-life/sav.

Cerco, C., Kim, S...C., Noel, M., 2010. The 2010 Chesapeake Bay Eutrophication Model. Chesapeake Bay Program Office, US Environmental Protection Agency, Annapolis, MD.

Cerco, C.F., Cole, T., 1993. Three-dimensional eutrophication model of Chesapeake Bay. J. Environ. Eng. 119, 1006-1025.

Cerco, C.F., Moore, K., 2001. System-wide submerged aquatic vegetation model for Chesapeake Bay. Estuaries 24, 522-534.

Cerco, C.F., Noel, M.R., 2013. Twentyone year simulation of Chesapeake Bay water quality using CE-QUAL-ICM eutrophication model. J. Am. Water Resour. Assoc. 49, 1119-1133.

Cerco, C.F., 2000. Phytoplankton kinetics in the Chesapeake Bay eutrophication model. Water Qual. Ecosyst. Model. 1, 5-49.

Cerco, C.F., Noel, M.R., 2004. Process-based primary production modeling in Chesapeake Bay. Mar. Ecol. Prog. Ser. 282, 45-58.

Christensen, V., Beattie, A., Buchanan, C., Ma, H., Martell, S.D.J., Latour, R.J., Preikshot, D., Sigrist, B., Uphoff, J.H., Walters, C.J., Wood, R.J., Townsend, H., 2009. Fisheries Ecosystem Model of the Chesapeake Bay: methodology, parameterization, and Model Explanation'. U.S. Department of Commerce, NOAA Technical Memorandum, p. 146. NMFS-F/SPO-106.

Christensen, V., Coll, M., Piroddi, C., Steenbeek, J., Buszowski, J., Pauly, D., 2014. A century of fish biomass decline in the ocean. Mar. Ecol. Prog. Ser. 512, 155-166.

Clark, J.B., Long, W., Hood, R.R., 2017. Estuarine sediment dissolved organic matter dynamics in an enhanced sediment flux model. J. Geophys. Res.: Biogeosciences 122, 2669-2682.

Cleaves, E.T., 2003. Conceptual model for transferring information between small watersheds. Environ. Geol. 45, 190-197.

Collick, A.S., Fuka, D.R., Kleinman, P.J.A., Buda, A.R., Weld, J.L., White, M.J., Veith, T. L., Bryant, R.B., Bolster, C.H., Easton, Z.M., 2015. Prediting phosphorus dynamics in complex terrains using a variable source area hydrology model. Hyrdol. Process. 29, 588-601.

Craig, L.S., Palmer, M.A., Richardson, D.C., Filoso, S., Bernhardt, E.S., Bledsoe, B.P., Doyle, M.W., Groffman, P.M., Hassett, B.A., Kaushal, S.S., 2008. Stream restoration strategies for reducing river nitrogen loads. Front Ecol Environ 6, 529-538.

Craine, J.M., Elmore, A.J., Wang, L., Aranibar, J., Bauters, M., Boeckx, P., Crowley, B.E., Dawes, M.A., Delzon, S., Fajardo, A., 2018. Isotopic evidence for oligotrophication of terrestrial ecosystems. Nat. Ecol. Evol. 2, 1735-1744.

Crear, D.P., Latour, R.J., Friedrichs, M.A.M., St-Laurent, P., Weng, K.C., 2020a. Sensitivity of a shark nursery habitat to a changing climate. Mar. Ecol. Prog. Ser. 652, 123-136.

Crear, D.P, Watkins, B.E, Friedrichs, M.A.M., St-Laurent, P., Weng, K.C., 2020 b. Estimating Shifts in Phenology and Habitat Use of Cobia in Chesapeake Bay Under Climate Change. Front Mar Sci 7, 943.

Dalyander, P.S., Cerco, C.F., 2010. Integration of a fish bioenergetics model into a spatially explicit water quality model: application to menhaden in Chesapeake Bay. Ecol. Model. 221, 1922-1933.

Dance, S., 2016. Scientists Give Chesapeake Bay Its Highest Environmental Grade Since 1992, 6. Baltimore Sun, p. 38. May 17,pm.

Dari, B., Nair, V.D., Sharpley, A., Kleinman, P.J., Franklin, D., Harris, W.G., 2018 Consistency of the threshold phosphorus saturation ratio across a wide geographic range of acid soils. Agrosyst., Geosci. Environ. 1, 1-8.

Dewar, H., Landers, T., Ridlington, E., 2009. Watermen blues: economic, Cultural and Community Impacts of Poor Water Quality in the Chesapeake Bay. Environment Maryland Research and Policy Center, Baltimore, MD, p. 41.

Dietrich, W.E., Bellugi, D.G., Sklar, L.S., Stock, J.D., Heimsath, A.M., Roering, J.J., 2003. Geomorphic transport laws for predicting landscape form and dynamics. Geophys. Monograph-Am. Geophys. Union 135, 103-132.

DiToro, D., 2001. Sediment Flux Modeling. John Wiley and Sons, New York.

Dortch, M.S., Chapman, R.S., Abt, S.R., 1992. Application of three-dimensional Lagrangian residual transport. J. Hydraul. Eng. 118, 831-848.

Easton, Z.M., D. Scavia, D. Alexander, K. Boomer, P. Kleinman, A. Miller, J. Pizzuto, D. Smith, and C. Welty. 2017. “Scientific and Technical Advisory Committee Review of the Chesapeake Bay Program Phase 6 Watershed Model.' STAC Publication Number 17-007, 47 pp. Edgewater, MD. https://www.chesapeake.org/stac/publications/.

Easton, Z.M., K. Stephenson, A. Collick, P.M. Feleming, E. Kellner, J. Martin, M. Ribaudo, and G. Shenk. 2020. “Increasing Effectiveness and Reducing the Cost of Non-Point Source Best Management Practice Implementation: is Targeting the Answer?' Edgewater, MD: STAC Publication Number 20-002. https://www.chesapeake.org/ stac/publications/.

Easton, Z.M., Walter, M.T., Steenhuis, T.S., 2008. Combined monitoring and modeling indicate the most effective agricultural best management practices. J. Environ. Qual. 37, 1798-1809.

Edinger, J., Brady, D., Geyer, J., 1974. Heat Exchange and Transport in the Environment. Departement of Geography and Environmental Engineering, Johns Hopkins University, Baltimore, MD.

Ehrlén, J., Morris, W.F., 2015. Predicting changes in the distribution and abundance of species under environmental change. Ecol. Lett. 18, 303-314.

Fang, K., Ji, X., Shen, C., Ludwig, N., Godfrey, P., Mahjabin, T., Doughty, C., 2019. Combining a land surface model with groundwater model calibration to assess the 
impacts of groundwater pumping in a mountainous desert basin. Adv. Water Resour. 130, 12-28.

Feng, Y., Friedrichs, M.A.M., Wilkin, J., Tian, H., Yang, Q., Hofmann, E.E., Wiggert, J.D., Hood, R.R., 2015. Chesapeake Bay nitrogen fluxes derived from a land-estuarine ocean biogeochemical modeling system: model description, evaluation, and nitrogen budgets. J. Geophys. Res.: Biogeosciences 120, 1666-1695.

Filoso, S., Palmer, M.A., 2011. Assessing stream restoration effectiveness at reducing nitrogen export to downstream waters. Ecol. Appl. 21, 1989-2006.

Filoso, S., Smith, S.M.C., Williams, M.R., Palmer, M.A., 2015. The efficacy of constructed stream-wetland complexes at reducing the flux of suspended solids to Chesapeake Bay'. Environ. Sci. Technol. 49, 8986-8994.

Foley, K.M., et al., 2010. Incremental testing of the Community Multiscale Air Quality (CMAQ) modeling system version 4.7. Geosci. Model Dev. 3, 205-226.

Gallegos, C.L., Bergstrom, P.W., 2005. Effects of a Prorocentrum minimum bloom on light availability for and potential impacts on submersed aquatic vegetation in upper Chesapeake Bay. Harmful Algae 4, 553-574.

Ganju, N.K., Brush, M.J., Rashleigh, B., Aretxabaleta, A., Barrio, P.D., Grear, J.S. Harris, L.A., Lake, S.J., McCardell, G., O’Donnell, J., 2016. Progress and challenges in coupled hydrodynamic-ecological estuarine modeling. Estuaries Coasts 39, 311-332.

Glibert, P.M., Anderson, D.A., Gentien, P., Granéli, E. and Sellner, K.G. 2005. `The global complex phenomena of harmful algal blooms'. Oceanography 18(2), 136-147.

Glibert, P.M., Burford, M.A., 2017. Globally changing nutrient loads and harmful algal blooms: recent advances, new paradigms, and continuing challenges. Oceanography $30,58-69$.

Guisan, A., Thuiller, W., 2005. Predicting species distribution: offering more than simple habitat models. Ecol. Lett. 8, 993-1009.

Hagy, J.D., Boynton, W.R., Keefe, C.W., Wood, K.V., 2004. 'Hypoxia in Chesapeake Bay, 1950-2001: long-term change in relation to nutrient loading and river flow Estuaries 27, 634-658.

Harman, C.J., Ward, A.S., Ball, A., 2016. How does reach-scale stream-hyporheic transport vary with discharge? Insights from rSAS analysis of sequential tracer injections in a headwater mountain stream, Water Resources Research, Vol. 52(9), 7130-7150.

Harding, J.M., Mann, R., 2001. Oyster reefs as fish habitat: opportunistic use of restored reefs by transient fishes. J. Shellfish Res. 20, 1208-1220.

Harris, C.K., Paul, R.J., Sung-Chan, K., Paul Rinehimer, J., Sung-Chan, Kim, 2013. Estimates of bed stresses within a model of Chesapeake Bay. Estuarine Coast. Model. 2011.

Homer, C., Dewitz, J., Yang, L., Jin, S., Danielson, P., Xian, G., Coulston, J., Herold, N., Wickham, J., Megown, K., 2015. 'Completion of the 2011 National Land Cover Database for the conterminous United States-representing a decade of land cover change information'. Photogrammetr. Eng. Remote Sens. 81, 345-354.

Hood, R.R., Shenk, G., Dixon, R., Ball, W., Bash,J., Cerco, C.F., Claggett, P., Harris, L., Ihde, T.F., Linker, L., Sherwood, C., and Wainger, L., 2019. 'Chesapeake Bay Program Modeling in 2025 and Beyond: A Proactive Visioning Workshop', STAC Publication Number 19-002: 61 pp. https://www.chesapeake.org/stac/publications

Hudson, K., and Murray, J.T., 2016. 'Virginia Shellfish Aquaculture Situation and Outlook Report', In VSG-15-01, VIMS Marine Resources Report No. 2016-4.

Ihde, T.F., Kaplan, I.C., Fulton, E.A., Gray, I.A., Hasan, M., Bruce, D., Slacum, W. Townsend, H.M., 2016. 'Design and Parameterization of the Chesapeake Bay Atlantis Model: A spatially Explicit End-To-End Ecosystem Model. U.S. Department of Commerce, NOAA Technical Memorandum, p. 145. NMFS-F/SPO-166.

Ihde, T.F., Townsend, H.M., 2017. Accounting for multiple stressors influencing living marine resources in a complex estuarine ecosystem using an Atlantis model. Ecological Model. 365, 1-9.

Irby, I.D., Friedrichs, M.A.M., 2019. Evaluating confidence in the impact of regulatory nutrient reduction on Chesapeake Bay water quality. Estuaries Coasts 42, 16-32.

Irby, I.D., Friedrichs, M.A.M., Da, F., Hinson, K.E., 2018. The competing impacts of climate change and nutrient reductions on dissolved oxygen in Chesapeake Bay. Biogeosciences 15, 2649-2668.

Irby, I.D., Friedrichs, M.A.M., Friedrichs, C.T., Bever, A., Hood, R.R., Lanerolle, L.W.J., Li, M., Linker, L., Scully, M., Sellner, K., 2016. Challenges associated with modeling low-oxygen waters in Chesapeake Bay: a multiple model comparison. Biogeosciences 13, 2011.

Jassby, A.D., Platt, T., 1976. Mathematical formulation of the relationship between photosynthesis and light for phytoplankton. Limnol. Oceanogr. 21, 540-547.

Johnson, B.H., Kim, K.W., Heath, R.H., Butler, H.L., Hsieh, B.B., 1991. Development and Verification of a Three-Dimensional Numerical hydrodynamic, salinity, and Temperature Model of the Chesapeake Bay. U.S. Army Corp of Engineers Waterways Experiment Station, Vicksburg, MS. Report HL-91-7.

Kall, N.D., Porter, C.D., Fincher, S.W., 2014. MOVES model sensitivity analysis to assist in prioritizing input data efforts. In: 107th Annual Air \& Waste Management Association Conference. Long Beach, California. June 24-27.

Karpatne, A., Atluri, G., Faghmous, J.H., Steinbach, M., Banerjee, A., Ganguly, A., Shekhar, S., Samatova, N., Kumar, V., 2017. Theory-guided data science: a new paradigm for scientific discovery from data. IEEE Trans. Knowl. Data Eng. 29, 2318-2331.

Kelly, J.T., Koplitz, S.N., Baker, K.R., Holder, A.L., Pye, H.O.T., Murphy, B.N., Bash, J.O., Henderson, B.H., Possiel, N.C., Simon, H., 2019. Assessing PM2. 5 model performance for the conterminous US with comparison to model performance statistics from 2007 to 2015'. Atmos. Environ. 214, 116872.

Kemp, W.M., Boynton, W.R., Adolf, J.E., Boesch, D.F., Boicourt, W.C., Brush, G., Cornwell, J.C., Fisher, T.R., Glibert, P.M., Hagy, J.D., 2005. Eutrophication of
Chesapeake Bay: historical trends and ecological interactions. Mar. Ecol. Prog. Ser. $303,1-29$.

Kim, C., Kang, H.Y., Lee, Y.-J., Yun, S.-G., Kang, C.-K., 2020. Isotopic variation of macroinvertebrates and their sources of organic matter along an estuarine gradient. Estuaries Coasts 43, 496-511.

Kim, S.-.C., 2013. Evaluation of a three-dimensional hydrodynamic model applied to Chesapeake Bay through long-term simulation of transport processes. J. Am. Water Resour. Assoc. 49 (5), 1078-1090. https://doi.org/10.1111/jawr.12113.

Klemick, H., Griffiths, C., Guignet, D., Walsh, P., 2018. Improving water quality in an iconic estuary: an internal meta-analysis of property value impacts around the Chesapeake Bay. Environ. Resour. Econ. 69, 265-292.

Koralewski, T.E., Westbrook, J.K., Grant, W.E., Wang, H.-H., 2019. Coupling general physical environmental process models with specific question-driven ecological simulation models. Ecol. Modell. 405, 102-105.

Koupal, J., DeFries, T.H., Palacios, C.F. and Fincher, S.W.. 2013. Study of MOVES Information for the National Emission Inventory: CRC Project A-84.

Landsberg, J.H., Hall, S., Johannessen, J.N., White, K.D., Conrad, S.M., Abbott, J.P., Flewelling, L.J., William Richardson, R., Dickey, R.W., Jester, E.L.E., 2006. Saxitoxin Puffer Fish Poisoning in the United States, With the First Report of Pyrodinium bahamense As the Putative Toxin Source, 114. Environmental Health Perspectives, pp. 1502-1507.

Leavesley, G.H., Markstrom, S.L., Restrepo, P.J., Viger, R.J., 2002. A modular approach to addressing model design, scale, and parameter estimation issues in distributed hydrological modelling. Hydrol. Process. 16, 173-187.

Lefcheck, J.S., et al., 2018. Long-term nutrient reductions lead to the unprecedented recovery of a temperate coastal region. Proc. Natl. Acad. Sci. U.S.A. 115 (14), 3658-3662. https://doi.org/10.1073/pnas.1715798115.

Lefcheck, J.S., Wilcox, D.J., Murphy, R.R., Marion, S.R., Orth, R.J., 2017. Multiple stressors threaten the imperiled coastal foundation species eelgrass (Zostera marina. Glob. Chang. Biol. 23, 3474-3483.

Lewis, K.A., Rose, K.A., Mutsert, K.D., Sable, S., Ainsworth, C., Brady, D.C., Townsend, H., 2021. Using Multiple Ecological Models to Inform Environmental Decision-Making'. Front. Mar. Sci. 8, 283.

Li, L. . 2019. Watershed reactive transport. Reviews in Mineralogy and Geochemistry, 85 (1), 381-418.

Linker, Lewis C, Batiuk, Richard A, Shenk, Gary W, Cerco, Carl F, 2013a. Development of the Chesapeake Bay watershed total maximum daily load allocation. JAWRA J. Am. Water Resour. Assoc. 49, 986-1006.

Linker, L.C., Dennis, R., Shenk, G.W., Batiuk, R.A., Grimm, J., Wang, P., 2013 b. Computing atmospheric nutrient loads to the Chesapeake Bay watershed and tidal waters. JAWRA J. Am. Water Resour. Assoc. 49, 1025-1041.

Linker, L.C., Shenk, G.W., Wang, P., Hopkins, K.J., Pokharel, S., 2002. A short history of Chesapeake Bay modeling and the next generation of watershed and estuarine models. Proc. Water Environ. Federation 14, 569-582.

Liu, J., Spargo, J.T., Kleinman, P.J.A., Meinen, R., Moore, P.A., Beegle, D.B., 2018. Water-extractable phosphorus in animal manure and manure compost: quantities, characteristics, and temporal changes. J. Environ. Qual. 47, 471-479.

Liu, J., Veith, T.L., Collick, A.S., Kleinman, P.J.A., Beegle, D.B., Bryant, R.B., 2017. Seasonal manure application timing and storage effects on field- and watershed-level phosphorus losses. J. Environ. Qual. 46, 1403-1412.

Liu, X., 2015. A more accurate method using MOVES (Motor Vehicle Emission Simulator) to estimate emission burden for regional-level analysis. J Air Waste Manage. Assoc. $65,837-843$.

Ma, H., Townsend, H., Zhang, X., Sigrist, M., Christensen, V., 2010. Using a fisheries ecosystem model with a water quality model to explore trophic and habitat impacts on a fisheries stock: a case study of the blue crab population in the Chesapeake Bay. Ecol. Modell. 221, 997-1004.

Macdonald, P., Laurenson, C.H., Johnson, A., Tait, L., 2009. A comparison of catch rates of artificial lures from an automated handline fishery at Shetland, UK'. Fish. Res. 95, 379-385.

Marshall, H.G., Burchardt, L., Egerton, T.A., Stefaniak, K., Lane, M., 2008. Potentially toxic cyanobacteria in Chesapeake Bay estuaries and a Virginia lake. Adv. Exp. Med. Biol. 619, 172-173.

Miller, A., Baker, M., Boomer, K., Merritts, D., Prestegaard, K., Smith, S., 2019a. Legacy Sediment, Riparian Corridors, and Total Maximum Daily Loads. STAC Publication.

Miller, M.D., Gall, H.E., Buda, A.R., Saporito, L.S., Veith, T.L., White, C.M., Williams, C. F., Brasier, K.J., Kleinman, P.J.A., Watson, J.E., 2019b. Load-discharge relationships reveal the efficacy of manure application practices on phosphorus and total solids losses from agricultural fields. Agric. Ecosyst. Environ. 272, 19-28.

Moeckel, R., 2017. Constraints in household relocation: modeling land-use/transport interactions that respect time and monetary budgets. J. Transp. Land Use 10, 211-228.

Murray, A.G., Parslow, J.S., 1999. Modelling of Nutrient Impacts in Port Phillip Bay — a semi-Enclosed Marine Australian ecosystem, 50. Marine and Freshwater Research, pp. 597-612.

Newell, R.I.E., Cornwell, J.C., Owens, M.S., 2002. Influence of simulated bivalve biodeposition and micro-phytobenthos on sediment nitrogen dynamics: a laboratory study. Limnol. Oceanogr. 47, 1367-1379.

Ni, W., Li, M., Testa, J.M., 2020. Discerning effects of warming, sea level rise and nutrient management on long-term hypoxia trends in Chesapeake Bay. Sci. Total Environ. 737, 139717.

Nichols, J.D., Williams, B.K., 2006. Monitoring for conservation. Trends Ecol. Evol. (Amst.) 21, 668-673.

Nixon, S.W., 1995. Coastal marine eutrophication: a definition, social causes, and future concerns. Ophelia 41, 199-219. 
Noe, G.B., Cashman, M.J., Skalak, K., Gellis, A., Hopkins, K.G., Moyer, D., Webber, J., Benthem, A., Maloney, K., Brakebill, J., 2020. Sediment dynamics and implications for management: state of the science from long-term research in the Chesapeake Bay watershed. USA' Wiley Interdiscip. Rev.: Water 7, e1454.

North, E.W., King, D.M., Xu, J., Hood, R.R., Newell, R.I.E., Paynter, K., Kellogg, M.L., Liddell, M.K., Boesch, D.F., 2010. Linking optimization and ecological models in a decision support tool for oyster restoration and management. Ecological Applications 20, 851-866.

Phillips, S.W., Lindsey, B.D., 2003. The Influence of Ground Water On Nitrogen Delivery to the Chesapeake Bay. US Department of the Interior, US Geological Survey.

Pianosi, F., Beven, K., Freer, J., Hall, J.W., Rougier, J., Stephenson, D.B., Wagener, T., 2016. Sensitivity analysis of environmental models: a systematic review with practical workflow. Environ. Model. Softw. 79, 214-232.

Pizzuto, J.E., 2014. Long-term storage and transport length scale of fine sediment: analysis of a mercury release into a river. Geophys. Res. Lett. 41, 5875-5882.

Pyke, C.R., Gottschalk, K., Theobald, D., Lister, A., Spano, T.T., and Johnson, T. 2010. "Review of land-use and land cover dataset and methodology."' Edgewater, MD: Chesapeake Bay Program Scientific and Technical Advisory Committee, 21 pp. https://www.chesapeake.org/stac/publications/.

Pyke, C.R., Parker, D., Pontius, G., Pijanowiski, B.C., and Kittle, J. 2008. “Chesapeake Bay land change modeling technical review." 26 pp. Edgewater, MD: Chesapeake Bay Program Scientific and Technical Advisory Committee. https://www. chesapeake.org/stac/publications/.

Rahmani, F., Lawson, K., Ouyang, W., Appling, A., Oliver, S., Shen, C., 2021. Exploring the exceptional performance of a deep learning stream temperature model and the value of streamflow data. Environ. Res. Lett. 16, 024025.

Razavi, S., Gupta, H.V., 2015. What do we mean by sensitivity analysis? The need for comprehensive characterization of "global" sensitivity in E arth and E nvironmenta systems models'. Water Resour. Res. 51, 3070-3092.

Reger, J., and Cleaves, E.T. 2008. `Physiographic Map of Maryland’, Maryland Geological Survey: Annapolis, MD.

Reichstein, M., Camps-Valls, G., Stevens, B., Jung, M., Denzler, J., Carvalhais, N., 2019 Deep learning and process understanding for data-driven Earth system science. Nature 566, 195-204.

Roehl, J.E., 1962. Sediment source areas, and delivery ratios influencing morphological factors. Int. Assoc. Hydro. Sci. 59, 202-213.

Sanford, W.E., Pope J.P., Selnick, D.L., and Stumvoll, R.F., 2012, Simulation of groundwater flow in the shallow aquifer system of the Delmarva Peninsula, Maryland and Delaware: USGS Open-File Report 2012-1140, 58 pp.

Sanford, W.E., Pope, J.P., 2013. Ouantifying groundwater's role in delaying improvements to Chesapeake Bay water quality. Environ. Sci. Technol. 47 13330-13338.

Secor, D.H., Kerr, L.A., Cadrin, S.X., 2009. Connectivity effects on productivity, stability, and persistence in a herring metapopulation model. ICES J. Mar. Sci. 66, 1726-1732

Shen, C., 2018. A transdisciplinary review of deep learning research and its relevance for water resources scientists. Water Resour. Res. 54, 8558-8593.

Sheng, Y.P., 1986. A Three-Dimensional Mathematical Model of coastal, Estuarine and Lake Currents Using a Boundary Fitted grid', Report No. 585. ARAR Group of Titan Systems, Princeton, N.J.

Shenk, G.W., Linker, L.C., 2013. Development and application of the 2010 Chesapeake Bay watershed total maximum daily load model. J. Am. Water Resour. Assoc. EPA903-R-13-004, CBP/TRS-310-13-3.

Shenk, G., Wainger, L., Wu, C., Capel, P., Friedrichs, M., Hubbart, J., Iho, A., Kleinman, P., Sellner, K., Stephenson, K., 2020. 'Assessing the Environment in Outcome Units. STAC Publication Number 20-003, Edgewater, MD, p. 34.

Skamarock, W.C., Klemp, J.B., 2008. A time-split nonhydrostatic atmospheric model for weather research and forecasting application. J. Comput. Phys. 227, 3465-3485. https://doi.org/10.1016/j.jcp.2007.01.037.

Smith, S., Belmont, P., Wilcock, P.R., 2011. Closing the gap between watershed modeling, sediment budgeting, and stream restoration. Geophys. Monogr. Ser. 194 293.

Smith, S.M.C., Wilcock, P.R., 2015. Upland sediment supply and its relation to watershed sediment delivery in the contemporary mid-Atlantic Piedmont (USA)' Geomorphology 232, 33-46.

St-Laurent, P., Friedrichs, M.A.M., Li, M., Ni, W., 2019. Impacts of Sea Level Rise On Hypoxia in the Chesapeake Bay: A model Intercomparison. Virginia Institute of Marine Science, William \& Mary. https://doi.org/10.25773/42XY-JT30.

St-Laurent, P., Friedrichs, M.A.M., Najjar, R.G., Shadwick, E.H., Tian, H., Yao, Y., 2020 Relative impacts of global changes and regional watershed changes on the inorganic carbon balance of the Chesapeake Bay. Biogeosciences 17, 3779-3796.

Steefel, C.I., Beckingham, L.E., Landrot, G., 2015. Micro-continuum approaches for modeling pore-scale geochemical processes. Rev. Minerol. Geochem. 80, 217-246.

Tango, P.j., Batiuk, R.A., 2013. Deriving Chesapeake Bay water quality standards. JAWRA J. Am. Water Resour. Assoc. 49, 1007-1024.

Tango, P.J., Magnien, R., Butler, W., Luckett, C., Luckenbach, M., Lacouture, R., Poukish, C., 2005. Impacts and potential effects due to Prorocentrum minimum blooms in Chesapeake Bay. Harmful Algae 4, 525-531.

Testa, J.M., Li, Y., Lee, Y.J., Li, M., Brady, D.C., DiToro, D.M., Kemp, M.W., 2017. Modeling Physical and Biogeochemical Controls On Dissolved Oxygen in Chesapeake Bay: Lessons Learned from Simple and Complex Approaches. Modeling Coastal Hypoxia (Springer).

Testa, J.M., Murphy, R.R., Brady, D.C., Kemp, W.M., 2018. Nutrient-and climate-induced shifts in the phenology of linked biogeochemical cycles in a temperate estuary Front. Mar. Sci. 5, 114.

Tomer, M.D., 2018. A twice-paired watershed experimental design to assess stacked practices through field-edge monitoring. J. Soil Water Conserv. 73, 58-61.
Townsend, H., 2014. Comparing and coupling a water quality and a fisheries ecosystem model of the Chesapeake Bay for the exploratory assessment of resource management strategies. ICES J. Mar. Sci. 71, 703-712.

Tyler, R.M., Brady, D.C., Targett, T.E., 2009. Temporal and spatial dynamics of dielcycling hypoxia in estuarine tributaries. Estuaries Coasts 32, 123-145.

USDA. 2013. “US Dept of Agriculture - Agricultural Research Service 2013. Science Documentation Revised Universal Soil Loss Equation Version 2.", 355 pp. https: //www.ars.usda.gov/ARSUserFiles/60600505/RUSLE/RUSLE2 Science Doc.pdf.

USDA-NRCS 2011. Assessment of the Effects of Conservation Practices on Cultivated Cropland in the Chesapeake Bay Region. 158 pp. http://www.nrcs.usda.gov/Int ernet/FSE_DOCUMENTS/stelprdb1042076.pdf.

USDA-NRCS 2007. Revised Universal Soil Loss Equation 2 (RUSLE2). Natural Resources Conservation Services. Accessed September 20, 2007.

USEPA, 2010. Chesapeake Bay Total Maximum Daily Load for Nitrogen, Phosphorus and Sediment. U.S. Environmental Protection Agency Chesapeake Bay Program Office, Annapolis MD. https://www.epa.gov/chesapeake-bay-tmdl/chesapeake-bay-tmdl -document.

USEPA, 2018. Midpoint Assessment of the Chesapeake Bay Total Maximum Daily Load. U.S. Environmental Protection Agency Chesapeake Bay Program Office, Annapolis MD. https://www.epa.gov/sites/production/files/2018-07/documents/factsheet-ep a-midpoint-assessment-chesapeake-bay-tmdl.pdf.

Vadas, P. 2014. Annual Phosphorus Loss Estimator - Theoretical Documentation (Version 2.4). Available online at http://ars.usda.gov/Services/docs.htm?docid=21763.

Van Dolah, E.R., Paolisso, M., Sellner, K., Place, A., 2016. Employing a socio-ecological systems approach to engage harmful algal bloom stakeholders. Aquatic Ecol. 50, 577-594.

Veith, T.L., Gall, H.E., Elkin, K.R., 2019. Seasonal manure application timing and storage effects on field- and watershed-level phosphorus losses. J. Soil Water Conserv. in press.

Veith, T.L., Wolfe, M.L., Heatwole, C.D., 2004. Cost-effective BMP placement: optimization versus targeting. Trans. Am. Soc. Agric. Biol. Eng. 47, 1585-1594.

Veith, T.L., Wolfe, M.L., Heatwole, C.D., 2003. Optimization procedure for cost effective bmp placement at a watershed scale 1. JAWRA J. Am. Water Resour. Assoc. 39, 1331-1343.

Wainger, L., Van Houtven, G., Loomis, R., Messer, J., Beach, R., Deerhake, M., 2013. Tradeoffs among ecosystem services, performance certainty, and cost-efficiency in implementation of the Chesapeake Bay Total Maximum Daily Load. Agric. Resour. Econ. Rev. 42, 196-224.

Wallace, C.W., McCarty, G., Lee, S., Brooks, R.P., Veith, T.L., Kleinman, P.J.A., Sadeghi, A.M., 2018. Evaluating concentrated flowpaths in riparian forest buffer contributing areas using LiDAR imagery and topographic metrics'. Remote Sens. (Basel) 10, 614.

Wang, R., Guo, X., Pan, D., Kelly, J.T., Bash, J.O., Sun, K., Paulot, F., Clarisse, L., Damme, M.V. and Whitburn, S. 2021. 'Monthly Patterns of Ammonia Over the Contiguous United States At 2Km Resolution', Geophysical Research Letters, 48(5), e2020GL090579.

Warner, J.C., Perlin, N., Skyllingstad, E.D., 2008a. Using the Model Coupling Toolkit to couple earth system models. Environ. Model. Software 23, 1240-1249.

Warner, J.C., Sherwood, C.R., Signell, R.P., Harris, C.K., Arango, H.G., 2008b. Development of a three-dimensional, regional, coupled wave, current, and sedimenttransport model. Comput. Geosci. 34, 1284-1306.

Weller, D.E., Baker, M.E., 2014. Cropland riparian buffers throughout Chesapeake Bay watershed: spatial patterns and effects on nitrate loads delivered to streams. J. Am. Water Resour. Assoc. 50, 696-712.

Wen, H., Perdrial, J., Abbott, B.W., Bernal, S., Dupas, R., Godsey, S.E., Harpold, A. Rizzo, D., Underwood, K., Adler, T., 2020. Temperature controls production but hydrology regulates export of dissolved organic carbon at the catchment scale. Hydrol. Earth Syst. Sci. 24, 945-966.

Wiggert, J.D., Hood, R.R., Brown, C.W., 2017. Chapter 6: modeling Hypoxia and Its Ecological Consequences in Chesapeake Bay. In: Dubravko, J., Rose, K.A., Hetland, R.D., Fennel, K. (Eds.), Modeling Coastal Hypoxia: Numerical Simulations of Patterns, Controls and Effects of Dissolved Oxygen Dynamics. Springer, Gewerbestrasse, Switzerland.

Williams, M.R., Buda, A.R., Elliot, H.A., Collick, A.S., Dell, C., Kleinman, P.J.A., 2015 Linking nitrogen management, seep chemistry and stream water quality in two agricultural headwater watersheds. J. Environ. Qual. 44, 910-920.

Williams, M.R., Bhatt, G., Filoso, S., Yactayo, G., 2017. Stream restoration performance and its contribution to the Chesapeake Bay TMDL: challenges posed by climate change in urban areas. Estuaries Coasts 40, 1227-1246.

Williams, M.R., Filoso, S., Longstaff, B.J., Dennison, W.C., 2010. Long-term trends of water quality and biotic metrics in Chesapeake Bay: 1986 to 2008'. Estuaries Coasts 33, 1279-1299.

WIP. 2019a. 'https://mde.maryland.gov/programs/Water/TMDL/TMDLImplementat ion/Documents/Phase \%20III\%20WIP\%20Report/Final\%20Phase\%20III\%20WIP\% 20Package/Phase\%20III\%20WIP\%20Document/Phase\%20III\%20WIP-Final_Mar yland_8.23.2019.pdf'.

WIP. 2019b. 'https://www.deq.virginia.gov/Portals/0/DEQ/Water/Ch esapeakeBay/Final\%20Phase\%20III\%20WIP/Virginia_Ch esapeake Bay TMDL Final Phase\%20III WIP\%20(2).pdf'.

WIP. 2019c. 'http://www.wvca.us/bay/files/bay_documents/1298_WV_WIP3_fina 1_082319.pdf'.

WIP. 2019d 'https://www.dep.pa.gov/Business/Water/Pennsylvania\%E2\%80\%99s\% 20Chesapeake\%20Bay\%20Program\%200ffice/WIP3/Pages/PAs-Plan.aspx'.

Xu, J., Hood, R.R., 2006. Modeling biogeochemical cycles in Chesapeake Bay with a coupled physical-biological model. Estuarine and Coastal Shelf Science 69, 19-46. 
Xu, J., Long, W., Wiggert, J., Lanerolle, L.W.J., Brown, C.W., Murtugudde, R., Hood, R. R., 2011. Climate Forcing and Salinity Variability in Chespeake Bay, USA', Estuaries and Coasts, 35, 237-261. https://doi.org/10.1007/s12237-011-9423-5.

Ye, F., Zhang, Y., Wang, H., Friedrichs, M.A.M., Irby, I.D., Alteljevich, E., ValleLevinson, A., Wang, Z., Huang, H., Shen, J., Du, J., 2018. A 3D Unstructured-Grid Model For Chesapeake Bay: Importance of Bathymetry, 127. Ocean Modelling, pp. 16-39.

Zhang, H., Li, J., Ying, Q., Yu, J.Z., Wu, D., Cheng, Y., He, K., Jiang, J., 2012. Source apportionment of PM2, 5 nitrate and sulfate in China using a source-oriented chemical transport model. Atmos. Environ. 62, 228-242.

Zhang, Q., Zheng, Y., Tong, D., Shao, M., Wang, S., Zhang, Y., Xu, X., Wang, J., He, H., Liu, W., 2019a. Drivers of improved PM2. 5 air quality in China from 2013 to $2017^{\prime}$. Proc. Natl. Acad. Sci. 116, 24463-24469.

Zhang, Y., Ateljevich, E., Yu, H.C., Wu, C.H., Yu, J.C.S., 2015. A New Vertical Coordinate System For a 3D Unstructured-Grid Model, 85. Ocean Modelling, pp. 16-31.
Zhang, Y., Ye, F., Staney, E.V., Grashorn, S., 2016. 'Seamless cross-scale modeling with SCHISM'. Ocean Model. 102, 64-81.

Zhang, Y., Foley, K.M., Schwede, D.B., Bash, J.O., Pinto, J.P., Dennis, R.L., 2019a. A measurement-model fusion approach for improved wet deposition maps and trends. J. Geophys. Res.: Atmospheres 124, 4237-4251.

Zhi, W., Feng, D., Tsai, W.-P., Sterle, G., Harpold, A., Shen, C., Li, L., 2021. From Hydrometeorology to River Water Quality: can a Deep Learning Model Predict Dissolved Oxygen at the Continental Scale?'. Environ. Sci. Technol. 55, 2357-2368.

Zhi, W., Li, L., 2020. The shallow and deep hypothesis: subsurface vertical chemical contrasts shape nitrate export patterns from different land uses. Environ. Sci. Technol. 54, 11915-11928.

Zhi, W., Li, L., Dong, W., Brown, W., Kaye, J., Steefel, C., Williams, K.H., 2019. Distinct source water chemistry shapes contrasting concentration-discharge patterns. Water Resour. Res. 55, 4233-4251. 